Sönke Kreft

Factors determining success and failure of development projects in Lesotho

Bachelorarbeit im wissenschaftlichen Studiengang Agrarwissenschaften an der GeorgAugust Universität Göttingen, Fakultät für Agrarwissenschaften

Studienrichtung: Umwelt- und Ressourcenmanagement

1. Prüfer: Dr. Stefan Schwarze

2. Prüfer: Prof. Dr. Hans Meliczek

Abgabetermin: $\quad$ 10.04.2007

Angefertigt im: Department für Agrarökonomie und Rurale Entwicklung 


\begin{abstract}
Natural deterioration is visible everywhere throughout Lesotho. This study aims to provide insights into factors favouring the outcomes of development projects in the natural resource sector. Case studies based on qualitative research methods were undertaken. The study calls for multidimensional approach of development projects, which also take Lesotho's mountain specificities into account. Furthermore, this study offers an explanation of how project ideas in Lesotho are determined and which recommendations are decided upon.

Die Zerstörung der natürlichen Ressourcen ist in gesamt Lesotho sichtbar. Diese Untersuchung versucht Einblicke zu geben, welche Einflussfaktoren den Erfolg von Projekten im Bereich der natürlichen Ressourcen ermöglichen. Fallstudien, basierend auf Methoden der qualitativen Sozialforschung, wurden unternommen. Der Autor fordert einen multidimensionalen Ansatz bei der Entwicklung von Projekten, der zusätzlich auch die naturräumlichen Gegebenheiten Lesothos beachtet. Darüber hinaus erklärt diese Arbeit, wovon der Verbreitungsprozess von Projektansätzen in Lesotho beeinflusst wird, und gibt entsprechende Empfehlungen.
\end{abstract}

Diese Arbeit basiert auf Daten gewonnen im Rahmen eines Projektpraktikums vom 01.08.31.10.2006 bei der Deutschen Gesellschaft für Technische Zusammenarbeit (GTZ), GmbH in Maseru, Lesotho. 


\section{Map of Lesotho}

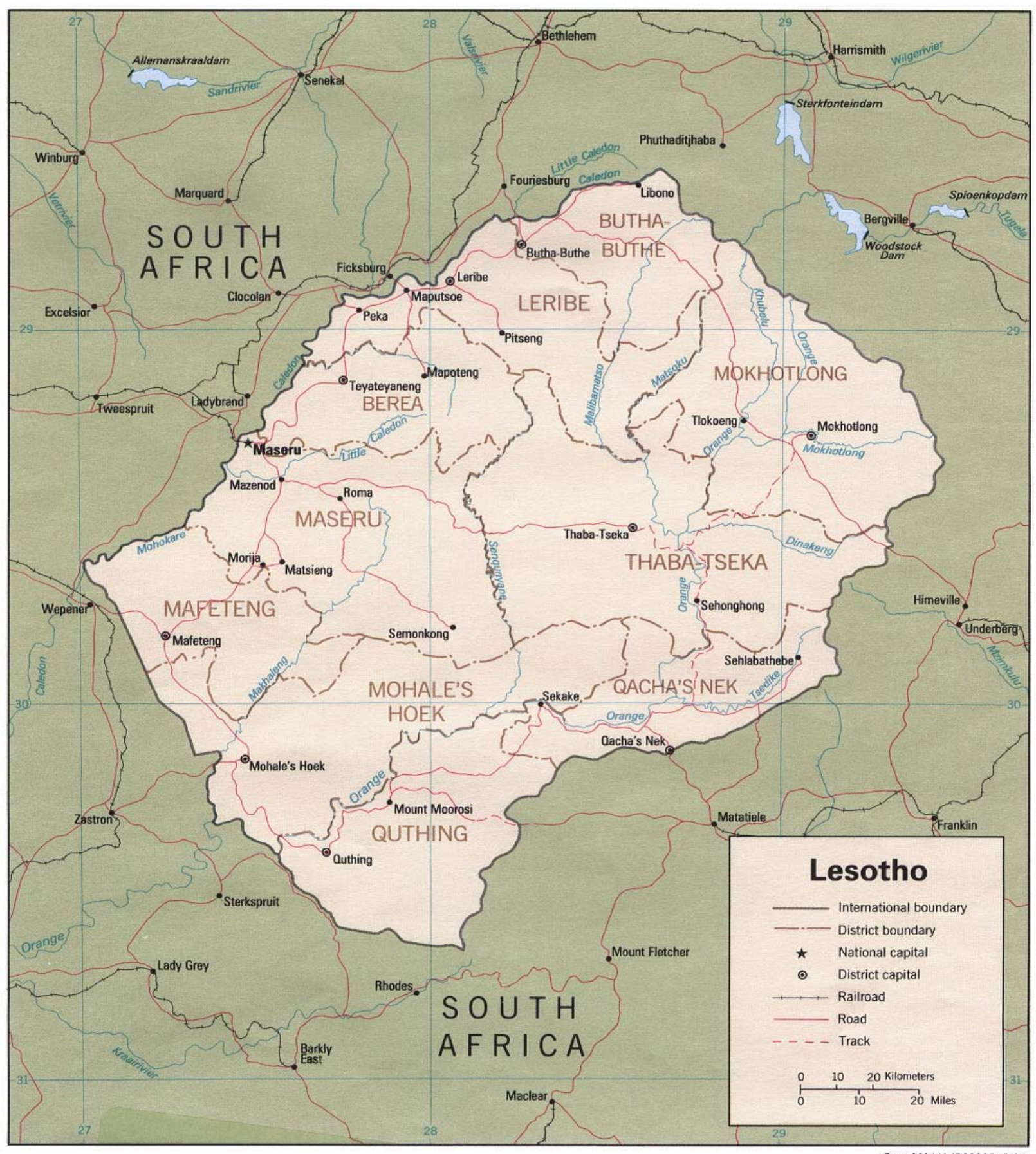




\section{Acknowledgements}

I would like to express my deep gratitude to those who have helped me in completing my research.

I must firstly thank my supervisor, Dr. Stefan Schwarze as well as Prof. Dr. Hans Meliczek, for providing me with support and guidance throughout the writing process of this study.

I also wish to thank Dr. Silvio Decurtins as well as Rajeev Ahal and Kirsten Röttcher for giving me strong guidance, valuable influences and for always being available for any kind of request. I also wish to thank them for giving me the opportunity to gain the truly amazing and unique experiences of my internship.

Furthermore, my thanks are due to Nicola Stevenson and Hannah Williams for revising my work.

Last but not least, I want to thank Nane not just for being a great support but also providing me with worthy inputs regarding my thesis. 


\section{Table of contents}

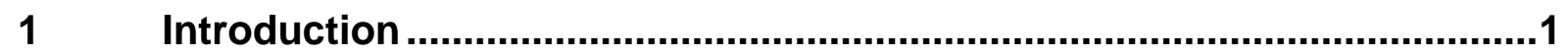

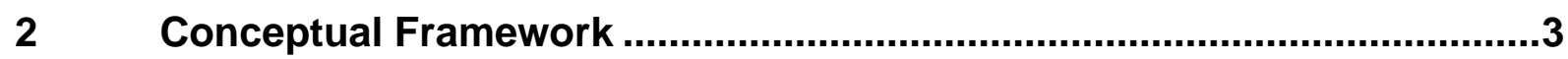

2.1 The Regional Rural Development (RRD) Tool .........................................

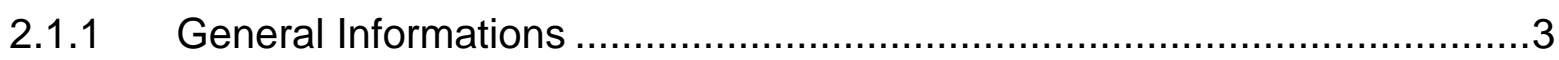

2.1.2 The Four Dimension of Rural Development......................................

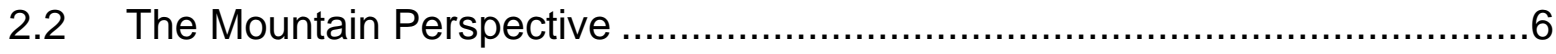

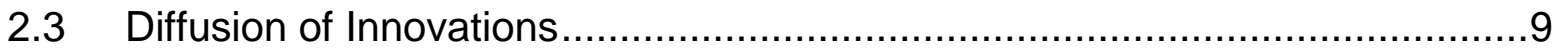

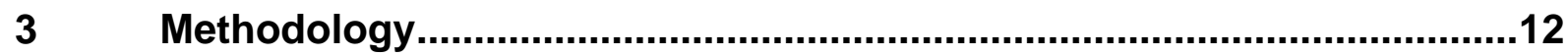

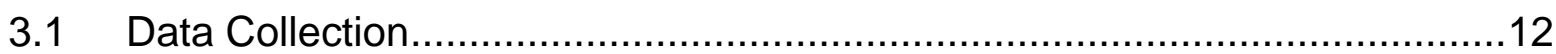

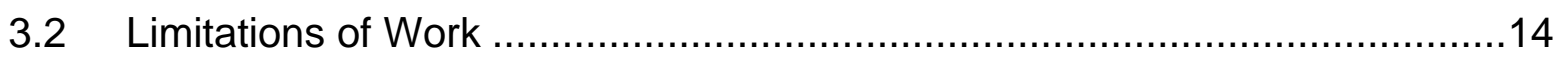

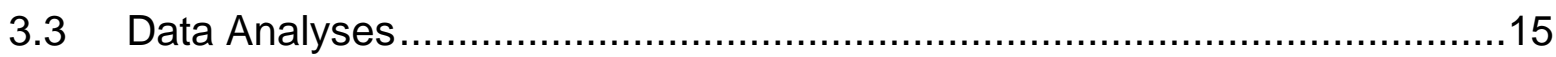

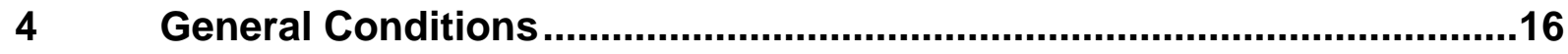

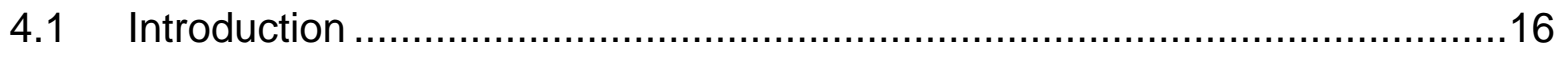

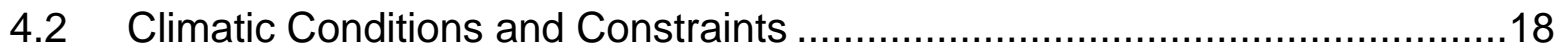

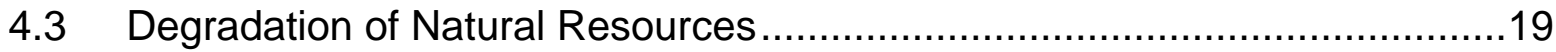

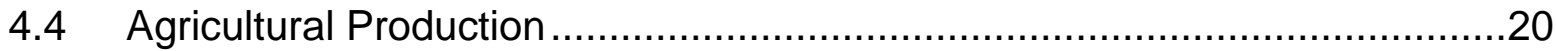

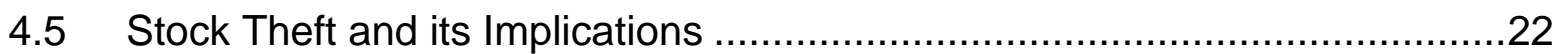

4.6 Chieftainship and the Empowerment of Elected Structures ......................22

4.7 Reasons for Natural Degradation and the "Tragedy of the Commons" ........24

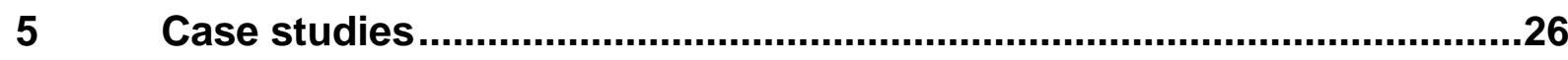

5.1 The Promotion of Machobane Farming System .....................................26

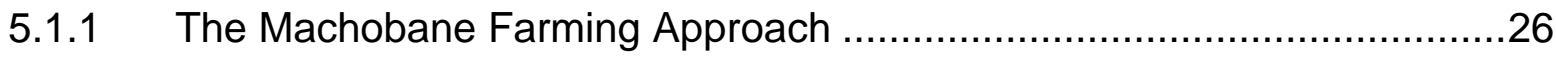

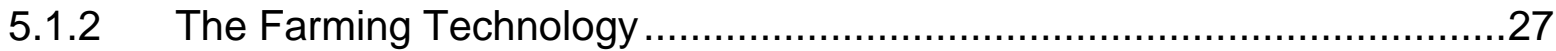

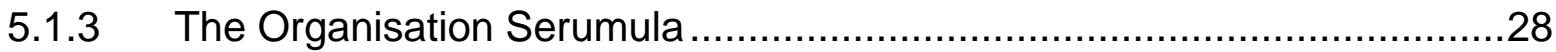

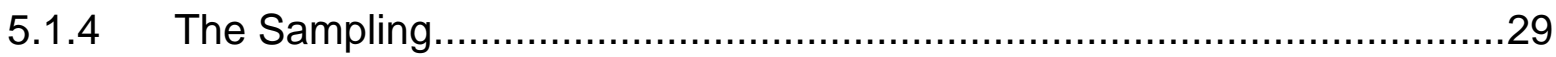

5.1.5 Reasons to start Machobane Farming System …..................................30

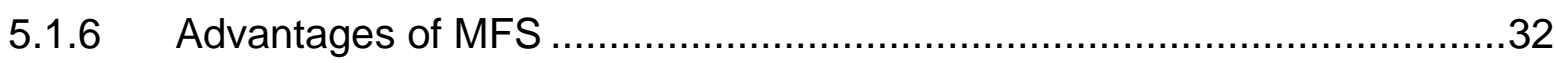

5.1.7 Reported Disadvantages and Resentments .........................................33

5.2 The Promotion of Conservation Agriculture by Reverent Basson .................35 
5.2.1 Conservation Agriculture: The Technique involved.............................35

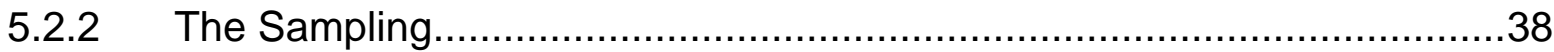

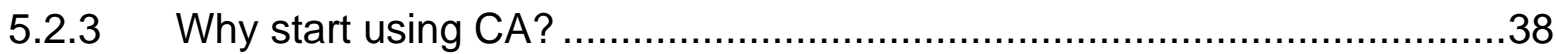

5.2.4 Advantages compared to Conventional Farming Design ......................39

5.2.5 Encountered Problems and Resentments by Non-Users .....................40

5.3 The Sustainable Agriculture and Natural Resource Management ..............44

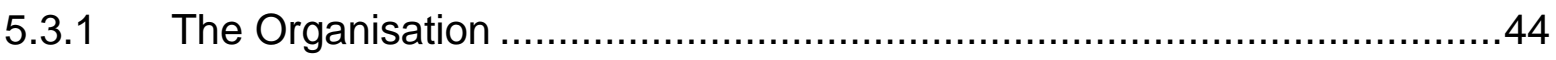

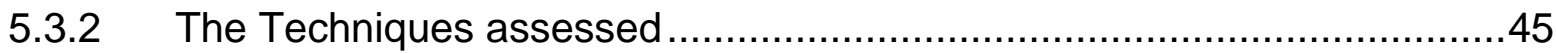

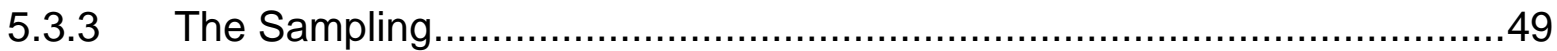

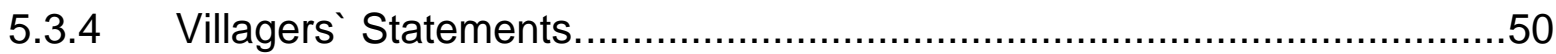

5.3.5 Excursus: Agricultural Extension ............................................... 53

5.4 The Maluti Drakensberg Transfrontier Project (MDTF) ............................55

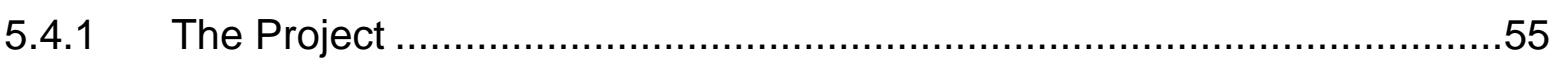

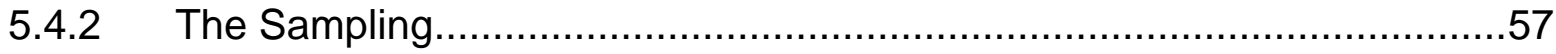

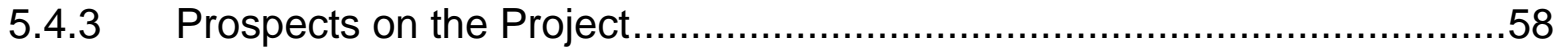

5.5 Food for Work promoted by World Food Programme and C-Safe ...............60

5.5.1 The Organisations involved: WFP and C-Safe ................................60

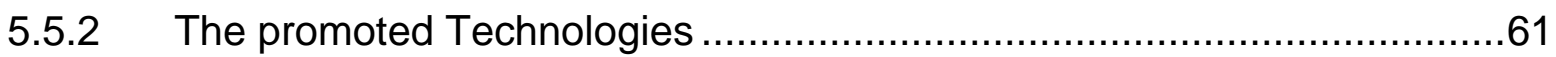

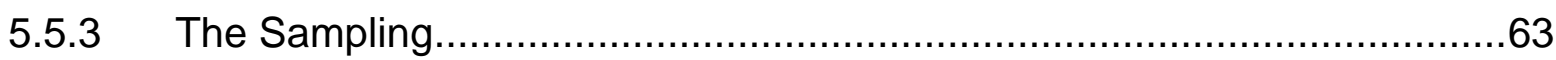

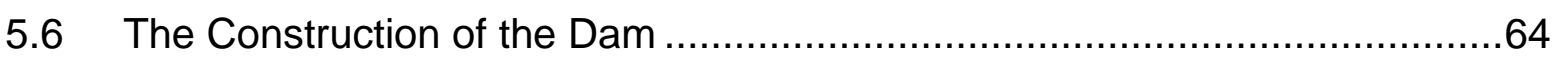

5.6.1 Discussion: the Impact of Food Aid on Projects................................66

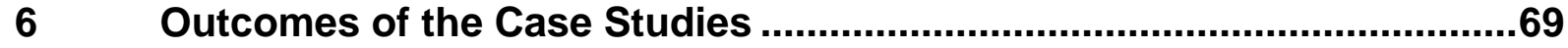

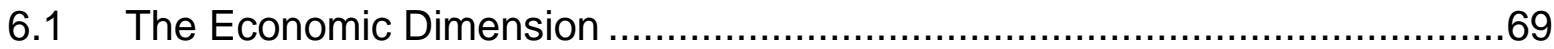

6.2 The Socio-cultural Dimension .......................................................

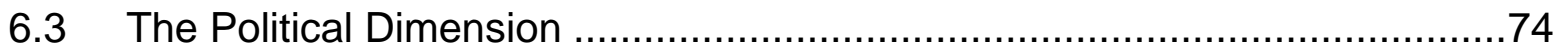

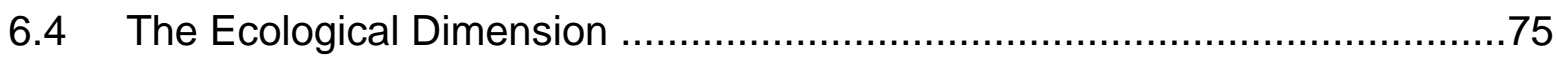

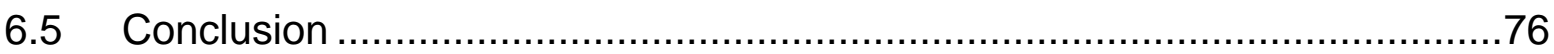

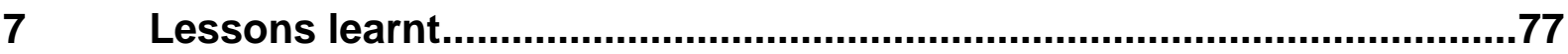

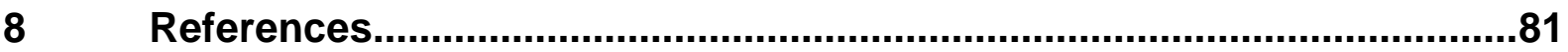

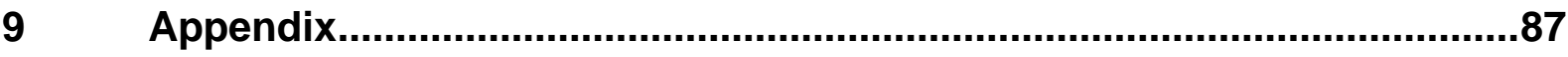




\section{List of Figures}

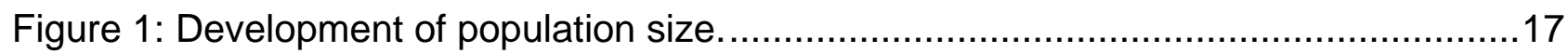

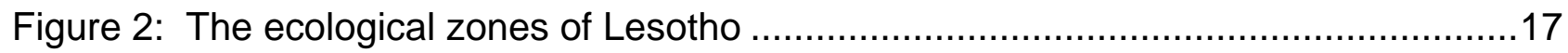

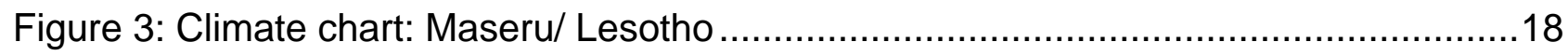

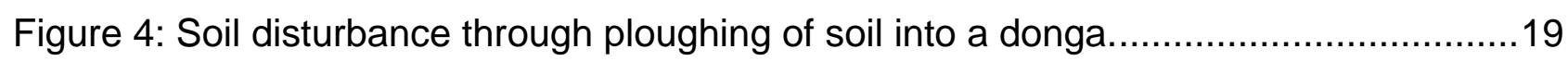

Figure 5: Cereal Production Trends for the Period 1964/65 to 1995/95...........................20

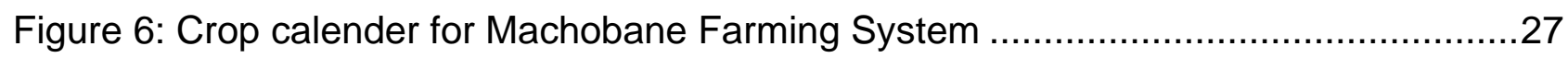

Figure 7: The only field under MFS-regime, field is greener through ............................28

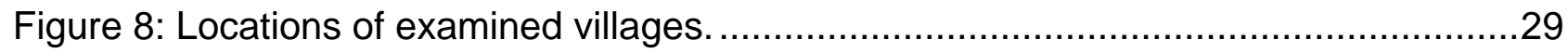

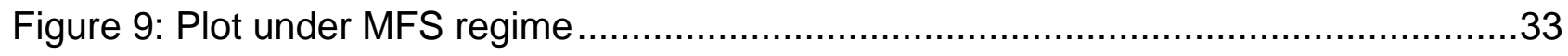

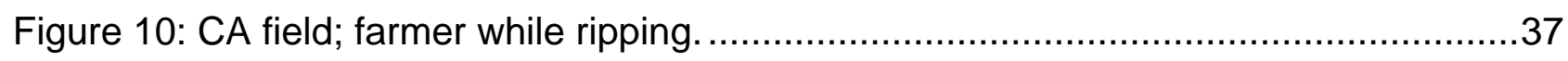

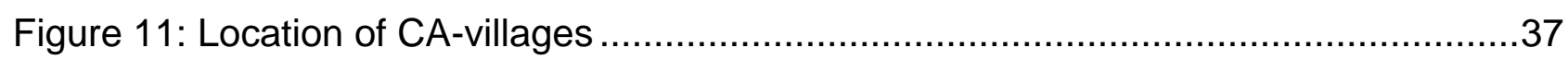

Figure 12: The site of the Community Garden ............................................................

Figure 13: Left picture: Stone contours; right picture planting of grass. ..........................4 47

Figure 14: Afforestation and donga reclamation. ......................................................... 49

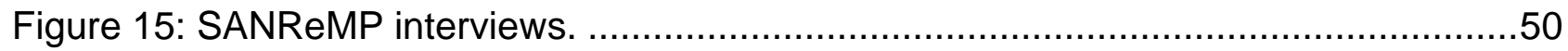

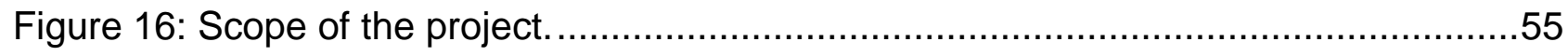

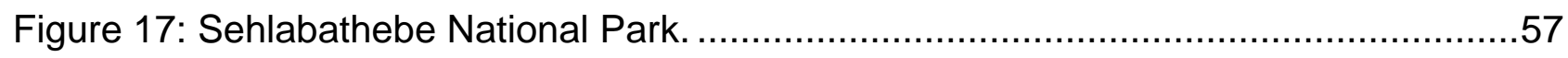

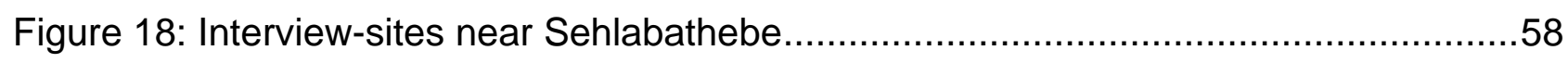

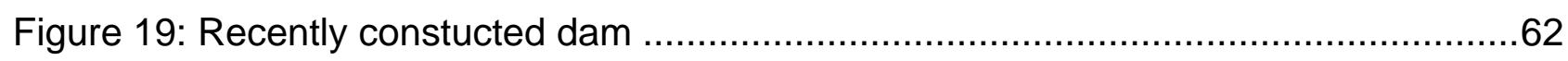

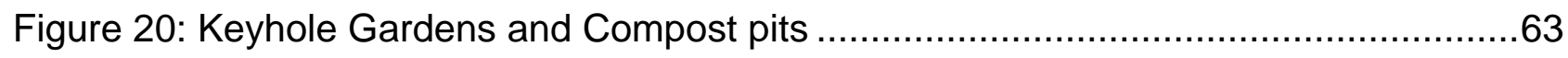

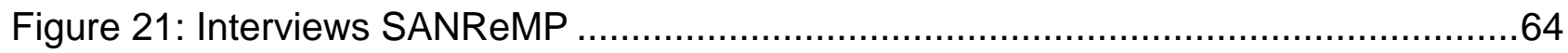

\section{List of Tables}

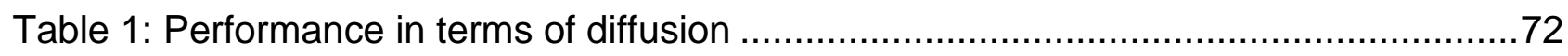

Table 2: Performance of projects regarding the mountain perspective............................76 


\section{Abbreviations}

$\begin{array}{ll}\text { AA } & \text { Agricultural Assistant } \\ \text { APCBP } & \text { Agricultural Policy and Capacity Building Project } \\ \text { CA } & \text { Conservation Agriculture } \\ \text { CAP } & \text { Community Action Plan } \\ \text { CC } & \text { Community Council } \\ \text { DFID } & \text { Department for International Development } \\ \text { FAO } & \text { Food and Agriculture Organisation } \\ \text { GDP } & \text { Gross Domestic Product } \\ \text { GTZ } & \text { Gesellschaft für technische Zusammenarbeit } \\ \text { IFAD } & \text { International Fund for Agricultural Development } \\ \text { LAB } & \text { Land Utilisation Board } \\ \text { MADF } & \text { Machobane Agriculture Development Foundation } \\ \text { MDTP } & \text { Maluti Drakensberg Transfrontier Project } \\ \text { MFS } & \text { Machobane Farming System } \\ \text { NGO } & \text { Non Governmental Organisation } \\ \text { NRM } & \text { Natural Resource Management } \\ \text { NUL } & \text { National University of Lesotho } \\ \text { R\&D } & \text { Research \& Development } \\ \text { RRD } & \text { Regional Rural Development } \\ \text { RSA } & \text { Republic of South Africa } \\ \text { SANReMP } & \text { Sustainable Agriculture Natural Resource Programme } \\ \text { WFP } & \text { World Food Programme }\end{array}$




\section{Introduction}

Lesotho's environmental problems have reached unprecedented proportions today because attempts to solve them have always focused on the 'green issues' or physical environment, totally ignoring the 'brown issues' of the social, cultural and political aspects of the environment. Simanda, 2003

Lesotho's ongoing deterioration of natural resources is visible across the entire country. A grid of dongas $^{1}$ erodes the countryside, fields do not bear good crops and grasses grow sparsely on the rangelands. Across the border in South Africa the fields are green and the dams are filled with water. But why, within a stone's throw, does the state of the environment change so drastically?

Despite appropriate technologies being available, none of them seem to work in Lesotho. Lesotho has witnessed a wide range of natural resource based projects and programmes throughout the years, - agriculture, forestry, rangeland management, soil and water conservation measures, agroforestry, large- and small-scale irrigation, livestock improvement, dairy farming and silage -this list could be continued until eternity without seeing major benefits. DECURTINS (2006) wonders what underlying parameters determine this failure seen in Lesotho. Why are the ideas not spreading by themselves, even if overwhelming evidence of the advantages for the Basotho ${ }^{2}$ is obvious?

Therefore, this study intends to provide answers to the following questions.

Which factors determine the successes and the respective failures of projects in the natural resource sector in Lesotho?

Which factors foster or hamper the spreading of technologies among the Basotho?

Are there any promising technologies in place, which legitimise a joint effort and should be scaledup throughout Lesotho?

Due to the exploitive character of this study a very comprehensive but general approach of how

South-African word for gullies.

Basotho refers to the people from Lesotho. 
development should be designed and conducted is applied. The Regional Rural Development (RRD) is grounded in a multidimensional approach and can be communicated easily to personnel working in Lesotho. However, the RRD is designed for rural areas, Lesotho, known as "the Roof of Africa", features very mountainous areas. Thus, for this study the RRD is extended with the Mountain Perspective, -an approach developed by the International Centre for Integrated Mountain Development (Icimod) in Kathmandu, Nepal. However, both of them fail to give explanation of how the diffusion process within the communities works. The required theory of Diffusion of Innovation was developed by Rogers.

After describing the methodology the author wants to provide an insight about general conditions affecting all projects in Lesotho. The aim is not to just provide the reader with an overview of Lesotho's current situation, but also to allow the author to state his impressions and experiences gained in Lesotho.

As the backbone of the study five case studies are introduced. The case studies were chosen according to the following aspects. They should comprise a wide range of different organisations, being national NGOs, international NGOs or private missionaries as well as big governmental schemes. They should also cover a wide range of natural resource based activities, for instance agriculture, rangeland management and rehabilitation, water storage capacity or biodiversity protection and eco-tourism.

These are then compared with the earlier introduced approaches and theories and eventually used to draw conclusions reflecting the above mentioned questions.

Then, the given results as well as personal views and experiences of the author developed while conducting this study, are loosely stated in the chapter of lessons learnt. 


\section{Conceptual Framework}

\subsection{The Regional Rural Development (RRD) Tool}

\subsubsection{General Informations}

RRD is the technical approach of GTZ of how to explain and how to tackle problems in rural areas.

RRD is a concept for rural development interventions in a given region primarily in poor or transition countries. It focuses on people to reduce poverty by supporting the development in various sectors of the economy (RAUCH et al., 2001).

Rural development is still very relevant in the face of market globalisation, because rural areas provide livelihoods for people without regular employment in the formal economy and supply not only local habitants but national and global urban populations as well. Due to increasing population density, migration and changes of the ecosystems, rural areas will need to change if they are to continue to provide a living for a growing number of people. Since poverty and extreme vulnerability are predominant in rural areas, RRD helps to enhance the opportunities of the poorest of the poor (RAUCH et al., 2001).

Rural development calls for a regional approach. Macro-level reforms can provide a favourable policy framework and effective incentives. But real benefit is just possible through interventions on the regional level, enabling most people in rural areas to seize opportunities and cope with challenges. Only on this level solutions can be found, which take the natural and socio-cultural environment into account. For maximum impact RRD should complement national and local interventions (RAUCH et al., 2001).

In contrast to the mountain perspective described in the next chapter RRD is a people-orientated development approach rather than a resource-, sector-, technology- or growth-oriented one. As usually the case in rural areas, people earn a living directly through trades or small farms, what they decide and plan determines the direction of development. This people-orientated approach differs significantly from classical programmes for agro-based, export-led or development by rural growth centres. Instead RRD aims for interventions that correspond to specific rural people in a given rural region giving everybody a chance to participate (RAUCH et al., 2001). 
In the typical problem situation, deficient economic, social and institutional systems do not enable the rural poor to access the services, resources, markets and information they require. Thus poorer, rural people cannot take advantage of the new economic and democratic opportunities theoretically available for them. RRD intends to open these opportunities for them focusing on four strategic components: the economic dimension, the socio-cultural dimension, the political and institutional dimension and the ecological dimension (RAUCH et al., 2001).

\subsubsection{The Four Dimension of Rural Development}

\section{economic dimension}

RRD puts the focus on food and cash rather than a profit and export orientated growth-centred approach, because rural people live from what they produce and what they can sell. Deregulation and privatisation in economy have brought not just opportunities but challenges, risks and problems like global competition, reduced demand for rural products and extreme price fluctuation. People in central locations possessing good infrastructure can take advantage of the new liberalised markets more easily than people in remote areas and producers with less resources who have suffered income losses and been exposed to greater risk. RRD ensures that the poor and vulnerable majority in remote areas, too, can harness new opportunities and cope with risks and challenges (RAUCH et al., 2001).

The four elements of the RRD-strategy preparing rural people for market economy are:

- Capacity-building among rural people enabling them to exploit market opportunities;

- identification and creation of new economic opportunities;

- ensuring fair access to available opportunities;

- providing systems to cover emergencies, disasters and diseases people cannot cope with.

\section{socio-cultural dimension}

This component deals with how ideas, technologies and policies are advocated to the people. 
RRD in contrast to national policies has two main advantages: regional programmes are better adapted to local social and cultural conditions and can therefore negotiated easier to local players. In the decision-making process knowing and interacting with stakeholders is crucial for good regional and local governance. RRD aims to close the gap between the rural dwellers and the service system. Supporting the access to services, RRD follows four core principles (RAUCH et al., 2001):

- Democratisation, which results in empowerment of the peasant population and meeting their needs.

- Partnership between service providers and service users that respects community or user ownership. This also includes how people are approached, how people are taken into consideration in planning processes and how people are equipped with ownership as a result of their involvement in decision making.

- Joint knowledge generation, which implies target-group-orientated and site-specific solutions.

- Reaching all of the poor and providing services on a gender equity basis. RRD provides inclusive support for all societal groups as well as exclusive support for specific groups who particularly need them

As the HIVIAids epidemic affects a growing number of people it impacts society as a whole and is more than „just a health problem“. In RRD it is acknowledged as a multi-dimensional development challenge with consequences for poverty and vulnerability, gender relations, education, production systems etc. Consequently, it requires a multi-sectoral response (RAUCH et al., 2001).

\section{political-institutional dimension}

Whereas the socio-cultural dimension focuses on better access to services, the politicalinstitutional dimension concentrates on the building up of service institutions. Since in rural areas entrepreneurship is too new, the civil society too unstructured, the community not sufficiently organised, RRD emphasises on decentralisation. Decentralisation of public administration is the most effective way to provide rural people with more appropriate, effective and coordinated services, and to ensure that such services meet requirements in terms of participatory, transparent and accountable procedures. Decentralisation should, of course, be part of a broader process of 
institutional reform and of orientating service systems to poverty reduction (RAUCH et al., 2001).

\section{ecological dimension}

To promote sustainable livelihoods in rural areas, RRD must mainstream sustainable natural resource management. This depends upon (RAUCH et al., 2001):

- The identification of appropriate techniques;

- the establishment of community based frameworks;

- a service system responsible for natural resource management;

- incentives for sustainable practices ;

- alternative income opportunities to ease pressure on natural resources.

\subsection{The Mountain Perspective}

[Present day] development interventions are based on approaches and models which were not conceived and designed for mountain areas. Consequently, they have generally proved to be less relevant and quite ineffective to handle the problems of mountain areas

JODHA, 1992

Since the RRD approach was developed for rural areas in general, not for mountains, the author decided to include the "mountain perspective" in this study. The mountain perspective extends both the socio-cultural and the economical and mainly the ecological dimension with a consideration of mountain specificities. The most obvious difference between both approaches is that RRD is people-centred, whereas the mountain perspective is resource based.

The 'mountain perspective' described simply, means [of] explicit or implicit consideration of specific mountain conditions or characteristics and their implications while designing and implementing activities in mountain habitats.

JODHA, 1992

JODHA (1992; 1997) defines different specificities: First order specificities, namely inaccessibility, fragility, marginality diversity/heterogeneity and second order specificities, which compose of 
natural suitability or 'niche' activities. Niche itself is defined as products in which mountains have comparative advantages over the plains. Often, these niches are gained through 'human adaption mechanism'. All first and second order specificities are explained below as well as the resulting actions needed to be taken. The responds of conventional development approaches to the challenges caused by mountains are also mentioned. However, one should consider that Jodha developed his approach more than 15 years ago and thus the stated conventional development design does not necessarily correspond with recent ones.

Inaccessibility: Due to overall terrain conditions mountain people suffer from inaccessibility: isolation, distance, poor communication and limited mobility. Traditional systems adaptations manifest amongst others in local, renewable and circular flow economy and institutional arrangements for collective subsistence farming as well as improving of infrastructure such as bridal paths, donkey tracks etc. Conventional development interventions to inaccessibility include transport subsidy, local processing of products and promotion of external linkages to outsiders. The activities, usually, result in high overhead costs and hence reduced efficiency of projects. Interventions also comprise of industrial infrastructure development, such as roads (JODHA, 1992).

Fragility: mountains can withstand disturbances to a lesser degree than plains. When mountain resources start to deteriorate it happens at a fast rate, with irreversible or long term reversible consequences. Traditional systems often adapt to suit the natural restrictions of mountains for instance, terracing, community irrigation system, agro-forestry etc. Conventional development interventions in the past, however, often comprised of modern agriculture, intensified, mechanised inputs and general disregard of traditional systems. They also, frequently, consist of onedimensional resource development (e.g. agriculture, livestock, forestry etc.) with output, maximising R\&D support (JODHA, 1992).

Marginality: Marginalised people are hindered in participating in mainstream activities, due to remoteness, limited resources and man-made constraints. Traditional approaches to overcome such obstacles include adapted social systems and strong social capital for mountain inhabitants. Conventional development activities to tackle the marginality of mountain people are usually based on provision of welfare. This often generates a high dependency on patronage (e.g. monthly payment, wages or in the humble opinion of the author: food aid) (JODHA, 1992).

Diversity and Heterogeneity: mountains feature immense variation amongst ecozones. Adoption of new techniques needs to be varied. This conflicts with old-school sector based development approaches of the past. The traditional pattern of activities by mountain people was determined by 
the diversity of the natural conditions. To harness the potential of diversity, mountain people need to be supported, so that diversified, interlinked and resource rather than demand driven management practices are strengthened (JODHA, 1992).

Niche and Comparative Advantages: Some productions of goods in mountainous areas provide comparative advantages over the plains (e.g. medicinal plants, unique fruits). Jodha calls this a potential 'niche'. Unfortunately, these are in practice often dormant and not harnessed. This can be explained by the historical fact, that mountain people were often cut off and hence not well practiced in trading goods. Further, JODHA (1992) warns "proper harnessing of niche can support sustainability, while their reckless exploitation can result in [the] elimination of niche". Such overexploitation happened frequently throughout conventional development projects, where projects forced the production of high-value products beyond natural limits.

Human Adaption Mechanism: Mountain communities have evolved techniques to cope with the constraints and opportunities of mountainous land. Either mountain characteristics are modified to suit the needs (terracing, irrigation) or activities are designed as needed to fulfil requirements by natural conditions. In the past adoption mechanism helped to use mountain resources sustainably. Due to changes related to population, markets and the state of the environment, many adaption mechanisms are losing their feasibility and efficacy (JODHA, 1992).

Multidimensionality of Development Goals: Objectives of development need to be broadened by emphasising equity issues, environmental stability and economical improvement. Long-term health of natural resources need to be highlighted more than in development projects of plains (JODHA, 1992).

Resource-centred Strategies: Development strategies for mountains have to be resource centred rather than demand driven. Resource use is determined by resource characteristics (fragility etc.). Again, Jodha highlights sustainability as the first goal of such a strategy, to put them in contrast to exploiting resource-centred activities, such as mining (JODHA, 1992).

Compelling Basis for Integrated Approach: Mountain characteristics, either constraints or as stated above resource based potentials, are interlinked and may have common origins but cannot be treated separately. Hence, development strategies for mountainous areas need to consist of an integrated approach. Furthermore, backward and forward as well as site effects need full consideration and incorporation in the project-design (JODHA, 1992). 
Planning from Below and Participatory Development: People's experience and wisdom in coping with the harsh conditions of mountains must be included in planning and conducting development projects. Thus, it is essential, particularly in the mountain context, to establish planning from below and a high level of participation by the stakeholders (JODHA, 1992).

\subsection{Diffusion of Innovations}

Since DECURTINS (2006) asks, why already proven successful technologies are not spreading, the author decided to put a third emphasis on the diffusion process itself. It helps to understand the process of adoption, if a few conceptional models are introduced beforehand. Later in the discussion this will enrich the socio-cultural dimension-

Many technologists believe that advantageous innovations will sell themselves: The obvious benefits of the new idea will be widely realized by potential adopters, and the innovation will therefore diffuse rapidly. This is seldom the case. Most innovations, in fact, diffuse at a disappointingly slow rate.

ROGERS, 1995

ROGERS (1995) characterises diffusion as the process by which an innovation is communicated through certain channels over time among the members of a social system. Thus the four main elements of diffusion are the type of innovation, the set-up of communication channels, time and the interrelation with the social system:

\section{Innovation}

An innovation is an idea, practice, project or object perceived as new by individuals, communities or societies. It is not necessarily objectively new, but new in terms of knowledge, persuasion or decision to adopt. Rogers uses technology as a synonym to innovation. Technology is defined as a design for instrumental action that reduces the uncertainty in the cause-effect relationships involved in achieving a desired outcome. Usually, a new technology brings at least some advantages for its potential users. On the other hand the technology implicates in the perspective of a potential user different kinds of uncertainty, - if the technology will perform as the previous one and if there are any further consequences. However, it also gives implications for new opportunities to motivate adoption of it.

Technology always consists of two parts: a hardware component, which includes the material or physical features of technologies, and a software component, which describes the information 
aspect of a technology. The relation of hardware to software differs from technology to technology.

According to ROGERS (1995), the rate of adoption of an innovation or technology depends on five characteristics:

1. Relative Advantage

Relative advantage shows the degree of superiority of an innovation to the old idea. This includes not just objective advantage, but social prestige, convenience and satisfaction of the users. The individual just needs to perceive the innovation as beneficial.

2. Compatibility

Compatibility is the term whether the innovation is compatible to traditions, norms and values of the society. An innovation, which is diametrically opposed to views and norms of a social system will spread at a much slower rate.

3. Complexity

Complexity is the degree to which a technology is perceived as hard to understand. Simple solutions will be adopted faster than difficult ones.

4. Trialability

Trialability describes the degree to which experiments with the innovation, on limited basis can be conducted. Many users may first try a small sample and later on apply it on a bigger scale. Therefore, the method needs to be trialable to reduce users' uncertainty.

5. Observability

The easier and more obvious it is to see the new technology itself and its results, the faster the adoption will happen. Rogers (1995) uses solar panels as an example. The more exposed panels (and thus more visible) are faster adopted than for instance home computers, in developing countries. 


\section{Communication channels}

Another important variable of diffusion are the channels of communication. The crucial part of diffusion is the exchange of information. ROGERS (1995) highlights, that interpersonal channels rather than mass media channels are the major transmitter for most people. He also emphasises, that more effective communication occurs amongst similar people (similar views, social standing etc.) Thus, because most societies are heterogeneous, all different groups within a community need to be addressed, targeted and approached differently.

\section{Time}

The adopter usually traverses five different steps in his innovation-decision process: 1 . knowledge about an innovation, 2. persuasion, 3. decision, 4. implementation and 5. confirmation. An individual seeks information at every step in the innovation-decision process. The time needed for the diffusion of an innovation depends on the type of adopter. Roger distinguishes between innovators, which adopt rapidly, early adopters, early majority, late majority and laggards, which represent the slowest group of adopters. Generally, if organisations and networks are involved, the decision process is much more difficult and thus takes longer.

\section{Social systems}

According to ROGERS (1995) the most crucial element of diffusion is the structure and the disposition of the social systems. Norms, as already mentioned, have an eminent influence in the uptake of ideas but can also be a barrier. ROGERS (1995) identifies opinion leaders, which are described as 1. more exposed to external communication and hence more cosmopolitan, 2 . usually of a higher social status, 3. more innovative and last but not least have a key position in the communication network of the community. Therefore, it can be concluded, that efforts of implementing new technologies should be directed at such people predominantly. 


\section{Methodology}

\subsection{Data Collection}

Due to the explorative character of this study, qualitative methods were chosen. Qualitative research has its strength in exploring new hypothesis and theories, whereas quantitative research aims for proving theories. Qualitative is subjective, whereas quantitative research is an objective technique. Qualitative research is often biased in its interpretation; quantitative research is often biased in its research design. Qualitative research is often accused of not being scientific and some people limit its usefulness to initial states of research. It is argued that since qualitative research is working with small sample size, results are not universally valid. Qualitative researchers, counter that without qualitative methods the scientific community could not extend its knowledge, due to the narrowness of quantitative methodologies (GIRTLER, 2001; FLYVBJERG, 2006).

Qualitative research utilises various techniques to gain insight into human interrelations, such as fieldwork, participant observation, structured, semi-structured and unstructured interviews. All of them are characterised by open questions.

Due to time constraints the author decided to use semi-structured interviews. BERNARD (2002) prefers semi-structured interviews for situations, where its' not possible to interview someone more than once. He also adds that semi-structured interviews combine advantages of both, unstructured and structured interviews. They have the freewheeling quality of unstructured interviewing but the interview guide is set of clear instructions. A preliminary worked out list of questions helps to cover all topics, which might be of interest.

This list was pre-tested in the area of Malealea from $17^{\text {th }}$ to the $19^{\text {th }}$ of August 2006. It was assessed, determining how questions worked and if they inconvenienced anybody.

BERNARD (2000) highlights the importance of probing. One way to probe is by leading with a question. Many researchers caution against such an approach. This of course is correct, but every question leads a respondent. BERNARD (2000) explains that it might be necessary to show a respondent that the interviewer is on the same level of cultural competence. Otherwise, he would abbreviate too much because he thinks, that you do not know enough. GIRTLER (2001) urges that probing by leading should be used where one wants to investigate delicate matters. BERNARD 
(2000) calls the process "phased-assertion": As one learns one piece of the puzzle from one informant, it is used with another one to gain more information.

Qualitative social research represents a circular evolving process of new questions and new issues. This results in a consistent reflecting and adapting of questions.

Sampling was usually done in the following way:

Key informants ${ }^{3}$, namely project coordinators, extensions staff, project employees etc. were consulted in their offices in Maseru and respectively in the branches in the districts. Then areas of suitable villages for the interviews were identified. Once the author appeared in the village, the chief was approached to ask for project participators (farmers). The chief usually knows very well who forms part of the project. A visit was usually used to conduct an interview with the chief, since he is an important actor at village level. Depending on the farmers' answers, further respondents ${ }^{4}$ and informants either within or outside of the project were identified and questioned.

Due to language barriers all interviews were conducted in Sesotho. This was done with the help of a local interpreter. The author himself approached respondents with appropriate greeting customs as these were easy to learn. The interviews were recorded on a voice recorder and transcribed on the same day to complement parts of poor quality from memory.

Usually people were interviewed in their own housing. ZICHE (1992) adds: "Respondents will give more valid information if they are allowed to talk to the interviewer in an informal conversational way. They will do so if they feel in control. They feel in control if they are interviewed at home instead of being summoned to the venue". In some cases, where for instance the understanding of techniques by the users were doubted, the author accompanied the respondents to their fields. Usually, the project site was nearby and hence a visit was no problem. Interviewing in people's homes ensured better quality of voice records, since site noises such as wind were eliminated.

The author tried to conduct interviews with individuals. Often this was a problem, particularly for communities not used to development workers since the author was racially different and arrived in a car not usually found in such areas. ZICHE (1992) describes the situation and its implementation as followed: sooner or later interviewing becomes a public affair which results in either social

3 Definition according to BERNARD (2000): People who knew knowledgeably about things.

4 When people describe their culture, they are informants. When they talk about their own beliefs (opinion, preferences, values, ideas), and their own experiences and behaviour, they are respondents (LEVY AND HOLLAN, 1998) 
pressure (therefore lower validity) or correction of interviewers by listeners (higher validity).

Due to the large number of funerals (perhaps HIVIAIDS related) taking place on Saturdays, the author noted that interviews on the weekend were not feasible.

A total of 75 participants were interviewed in this study: chiefs, agricultural assistants, councillors, and participators and non-participators of the project.

\subsection{Limitations of Work}

It is impossible to eliminate reactivity and subjectivity in interviewing, but like any other craft, you will get better and better at interviewing the more you practice.

BERNARD, 2000

The author wants to highlight, that he was not experienced in interviewing prior to this study. Interviewing is definitely an art and needs to be practiced. Although, a pre-test was conducted, there is no doubt that over time the accuracy of questions and answers increased.

BERNARD (2000) states other factors which might lead to false responses, must be considered, while judging the accuracy of the outcomes:

- Inaccuracy of responses: people try to answer all questions, once they agreed to be interviewed, even if they do not know the correct answer.

- People want to mislead one to create a good impression, over reporting of socially desirable behaviour.

The latter was often noticed by the author. One had the impression that people over reported problems and constraints, because they equated such research with future development activities. Particularly past interventions were glorified. ZICHE (1992) summarises "surveys are assigned with the role of donor. People often expect benefits."

The scope and the time of the study were very limited. BERNARD (2000) advises: "The amount of time you spend in the fields really makes the difference in what you are likely to find. If you are starting out fresh and not as a member of the culture, count on taking three months or more, under best conditions, to be accepted."

Due to the appearance of the researcher some statement might be false. ZICHE (1992) prioritises 
that young people in non-Western culture are rarely respected by elders. The author never got such impression while interviewing villagers but it was a problem speaking to officials, especially from the governmental sector. Often these people covered their lack of respect badly.

Since most of the project beneficiaries were not able to speak English, all questions as well as responses had to be translated from English to Sesotho and visa versa. This again might reduce validity.

\subsection{Data Analyses}

The data was firstly refined in terms of correct English. Afterwards, the statements were arranged according to the relevant chapter of the study (comp. annex). Generally the responses were distinguished between motivation to start, stated advantages and disadvantages. Where necessary responses were analysed together (for example with the perception of local authorities). Subsequently, each statement taken from the responses was interpreted in the chapters of the case studies. 


\section{General Conditions}

\subsection{Introduction}

Lesotho is an entirely land-locked country situated in southern Africa. It is wholly surrounded by South Africa (RSA). Its size is 30,355 square kilometres, which is approximately the size of Belgium. Lesotho is located in the Drakensberg Range, the highest mountains in southern Africa, and hence termed as the Roof of Africa. It is described as the only country which lays completely above $1000 \mathrm{~m}$ and which features the highest lowest point $(1400 \mathrm{~m})$ in the world (WORLD BANK, 2005).

Lesotho is a developing country. It ranks $149^{\text {th }}$ in the Human Development Index out of $177^{\text {th }}$ (UN, 2006). The gross domestic product (GDP) is similary bleak with a 620 US\$ per capita, giving a rank of 143 in the world. The highly inequitable income distribution results in a Gini-coefficient of 0.66. Approximately, $58 \%$ of the population lives below the poverty line ${ }^{5}$. Despite representing just $17.5 \%$ of overall GDP, the agricultural sector is still the major economical backbone, giving employment to $55 \%$ of the entire population (WORLD BANK, 2006; SANREMP, 2004). Historical, remittances from mine-workers in RSA used to be a common income-source for Lesotho households. However, since end of apartheid and restructuring of RSA-mines this has lost ground, manifesting in a contribution in 1999 of just 18\% of the GDP (compared to $62 \%$ in 1990) (HASSAN \& OJO, 2002).

The average population size has dramatically increased since the San, the ancient inhabitants, settled in Lesotho. It is estimated that at the peak not more than 10000 of these bushmen populated Lesotho. Since the 1950s the population has doubled to nearly 1.8 million inhabitants in 2005 (NATIONAL ENVIRONMENT SECRETARY, 1999).

Comparing the figure below one recognises a reduction of growth in recent years. This is due to the dramatic aids-pandemic with an estimated prevalence-rate of $31 \%$ of the Basotho. The average life expectancy for males has dropped to an appalling 36 years in past years (WORLD BANK, 2006). The dramatic observations made by the author range from frequently occurring orphans and widows to child headed households. The drastic impact on daily life, social structures and safety nets are evident everywhere in Lesotho. Ironically, Lesotho's richest man is the owner

$5 \quad$ Defined as amount of money needed to meet the requirement of $2200 \mathrm{kcal}$. 
of a funeral parlour.

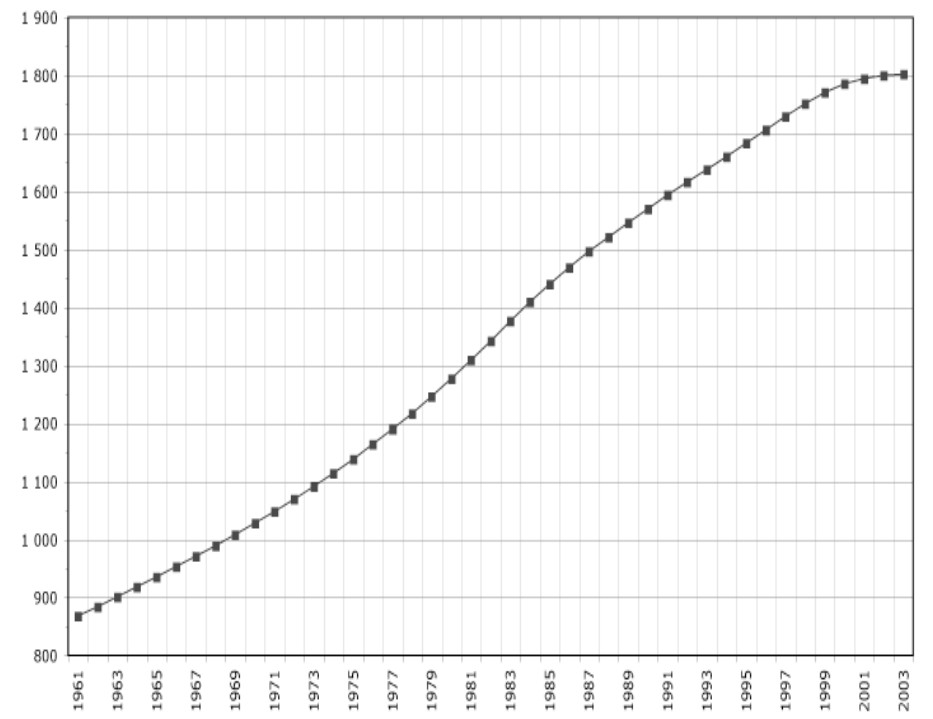

Figure 1: Development of population size. Source: FAOSTAT (2005)

Lesotho is characterised by four physiographic regions: the lowlands, the foothills, the Senqu valley and the highlands (see figure below).

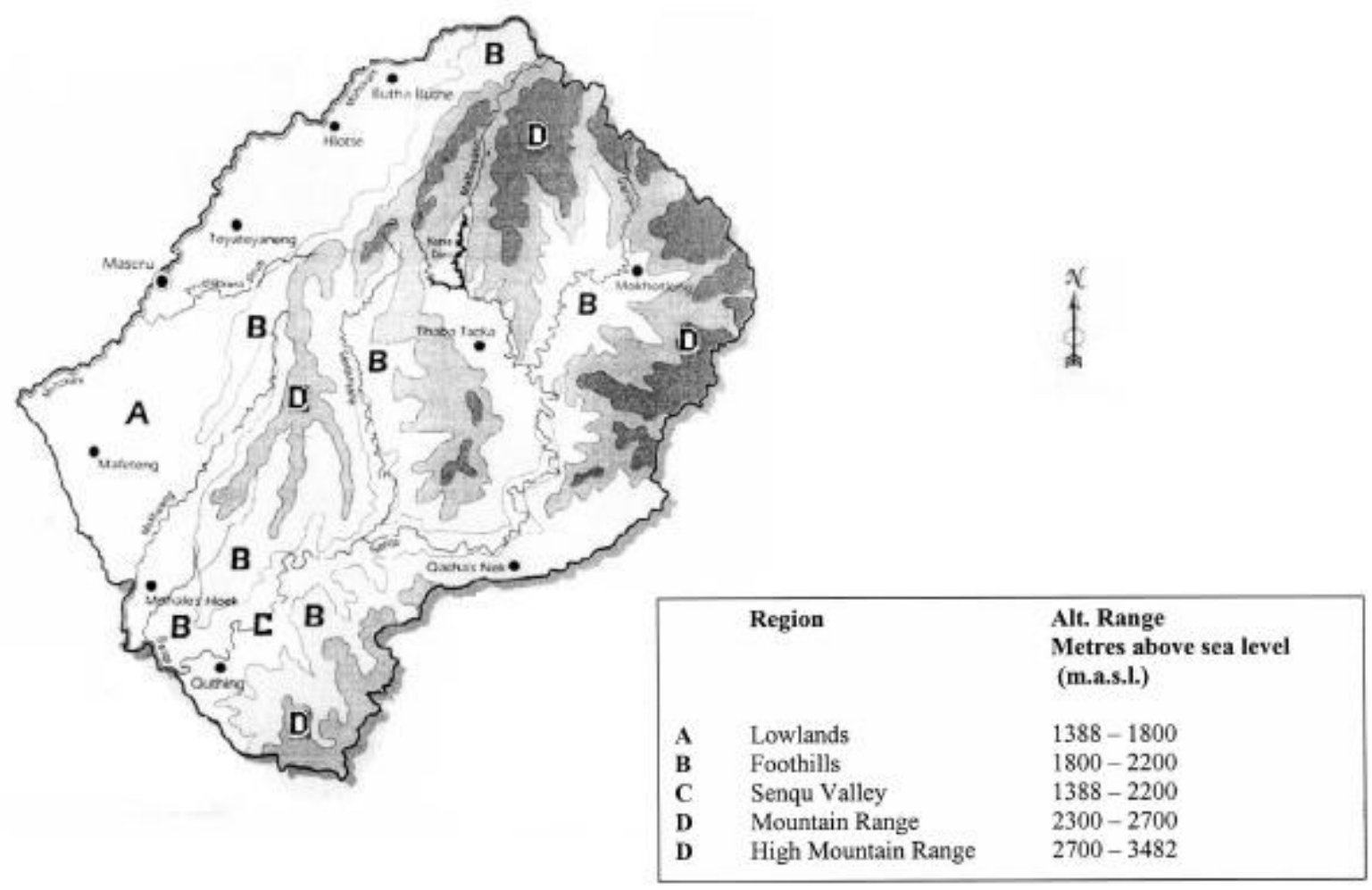

Figure 2: The ecological zones of Lesotho. Adapted from KATONGE, J (2001)

The lowlands feature over 80 percent of Lesotho`s productive arable land and have consequently 
the highest density of population. Their average height ranges from 1500 to $1800 \mathrm{~m}$ above sea level. The lowlands are situated along the western border of the country.

The foothills have a height of 1800 to $2000 \mathrm{~m}$ and form a small belt from north to south between the lowlands and the mountains.

The highlands rise up to $3482 \mathrm{~m}$ in the east. Mountains are predominantly used for summer grazing. They host the most valuable but also vulnerable alpine habitats with their inherent value for biodiversity. The Senqu Valley has similar altitudes as the lowlands and meanders from east to the south west. This area is mostly used for livestock rearing (NATIONAL ENVIRONMENT SECRETARY, 1999).

\subsection{Climatic Conditions and Constraints}

One aspect needed to be taken into account as a condition affecting all projects is the effect of weather and climate on farming and natural resources. Generally, Lesotho is defined as temperate. Although, the mountains face harsh winters and up to 200 days ground frost per year. The distribution of rain is uneven among the different regions and ranges from $450 \mathrm{~mm}$ in the south west up to $1000 \mathrm{~mm}$ in the eastern lowlands and in the highlands per year. Figure 3 shows the annual rainfalls and the distribution throughout the year: During the winter months Lesotho has its dry season, while the rainy season in the summer months should restock the water storage of the soil. Depending on the strength of summer rains, the average precipitation is strongly fluctuating, making Lesotho prone to droughts (NATIONAL ENVIRONMENT SECRETARY, 1999).

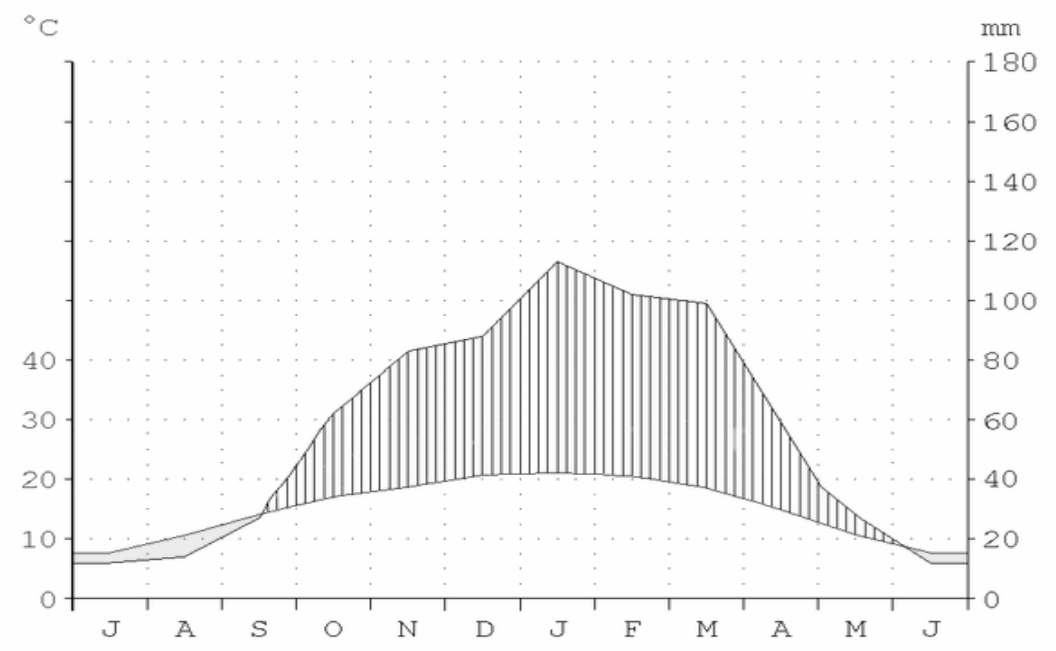

Figure 3: Climate chart: Maseru/ Lesotho (1631m) 
The weather conditions implicate several risks for farmers:

- The precipitation is unevenly distributed and generally unreliable;

- crops are often damaged through hail storms;

- unpredictably late or early frost occurs.

The grade of the problems may be different from area to area and in general they are bigger in the highlands than in the lowlands (VAILLANT, 2003). The author noticed that farmers are not seeding all possible fields, because they were discouraged by previous poor harvests.

\subsection{Degradation of Natural Resources}

Lesotho is covered with a grid of dongas. Although this is the most noticeable form of erosion, it accounts for just $2 \%$ of the overall soil losses. Soil losses are caused by inappropriate farming practice (comp. fig. 4), consistent depletion of organic matter through either removal of cow-dung or shrubs and trees as a source of energy respectively fodder, loss of protective soil cover due to overgrazing around village settlements, intense thunderstorms in the summer months and highly erodible soils. This results in an overall loss of 38.8 mill. tons per annum, representing the second highest rate in the world (SANREMP, 2004; SIMANDA, 2003).

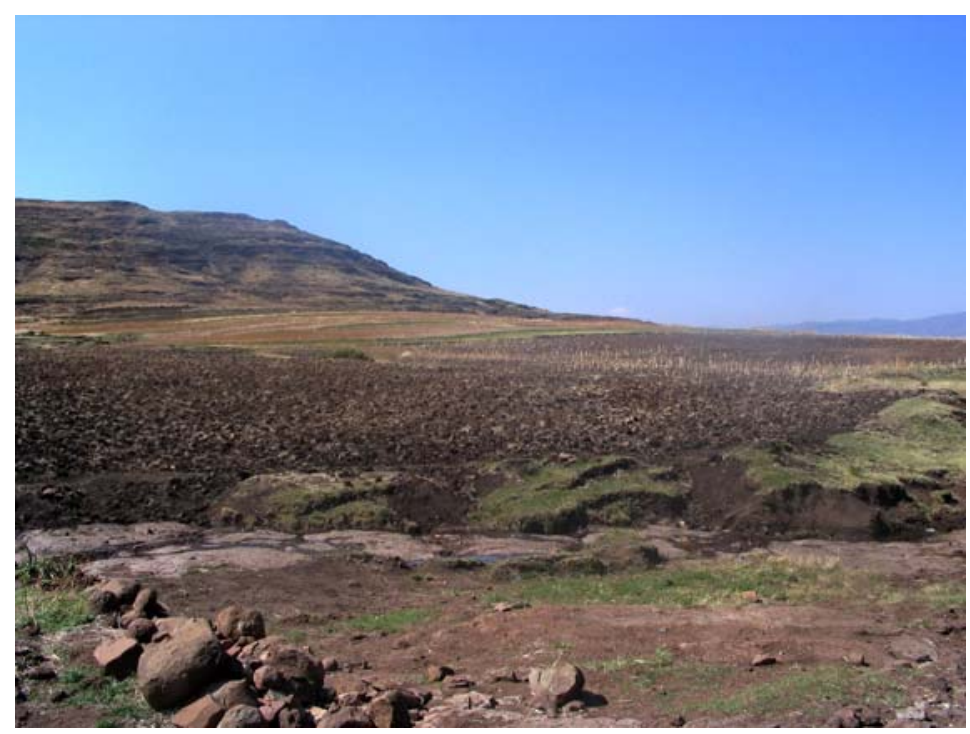

Figure 4: Soil disturbance through ploughing of soil into a donga. Example for poor farming knowledge.

One aspect easily to be observed is the appalling state of the rangelands. Although most of the so 
called cattle post areas, being remotely located, are under-grazed, the majority of grazing lands around settlements, particularly in the lowlands, are severely damaged due to overstocking (SANREMP, 2004). Stocking rates of cattle and ruminants in general exceed 1 million animal units, contrary to a calculated carrying capacity for the whole of Lesotho of less than 300000 . Despite the Basotho-diet being very rich in meat, cattle are often kept for social prestige and social position and not for nutrition purposes (KATONGE, 2001). This is underpinned by personal observation of the author, where many farmers although cattle showed characteristics of having a bad genetic background, refused to remove them.

In spite of the daily visible evidence of natural degradation, the author observed inadequate understanding of erosion amongst the rural population. Most people are aware of the problems correlated with dongas and prioritise the fight against them as highly desired. However, nearly none of the interviewees know about further interrelations, for instance, that erosion results in nutrition depletion or the fact that rangelands without shrub cover result in higher runoff downwards.

Therefore, it is not surprising that soil conservation methods are almost non-existent. Actually, bufferstrips are widely spread but albeit the fact that they are less effective on steep slopes (SCHWERTMANN et al., 1996) and hence not the ideal solution for Lesotho's mountains, they are an entirely alien method, brought by colonials in 1930 (NATIONAL ENVIRONMENT SECRETARY, 1999). Due to heavy grazing in the winter months, most of the grass buffers have collapsed.

\subsection{Agricultural Production}

As revealed earlier on, the steady decline of natural resources in Lesotho leads to a stagnation or even a decrease in agricultural production. Besides annual fluctuation explainable through the unpredictable climate, fig. 5 shows the not significant but apparent decline since the 1970s.

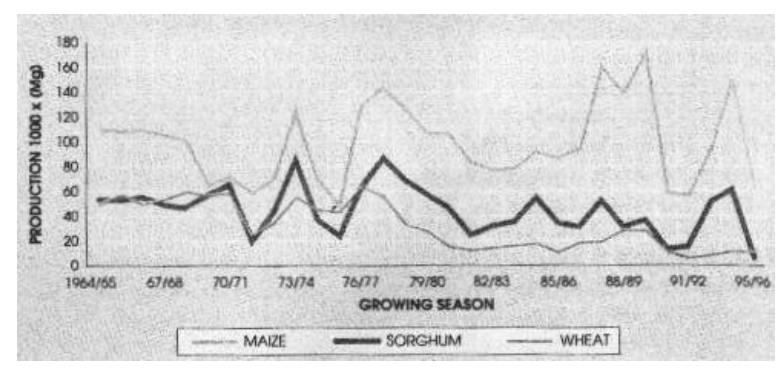

Figure 5: Cereal Production Trends for the Period 1964/65 to 1995/95 Growing Seasons.

Source: NATIONAL ENVIRONMENT SECRETARY, 1999 
Historically, three fields, for one of the three staple grains each, were allocated to every farmer. Because maize (used as pap, a porridge-like dish and essential part of southern African diet) is highly preferred by the households, the relation between the three grains, maize, sorghum and wheat has shifted toward maize. This causes new problems like the hampering NRM-efforts in soil stabilisation $^{6}$ or the requiring of more fertiliser. VAILLANT (2003) shows that, because maize has an irreplaceable importance for the diet of the poor, an increase in maize-prices results in an increase on the demand-site as well (so called Giffen-good ${ }^{7}$ ). Therefore, in case of subsistence farming, the increase of fields under maize regime is not so much despite the unfavourable environment, but because of them, a vicious circle, since the extension of maize growing is a major contributor to the environmental problems.

The livestock production, albeit the enormous absolute number, is fairy low. Besides the fact that improved breed is refused by farmers and herders, vaccination supply is almost non existent. Thus, the overall output and quality of meat and fibre is very poor (SANREMP, 2004).

As a matter of fact the above mentioned low agriculture production is not able to serve Lesotho's demand, which results in Lesotho's food aid dependency persisting since the 1930 (MAKENETE et al., 1998).

MATABO et al. (2006) pioneers, that the devastating HIVIAIDS-pandemic negatively effects Lesotho's agriculture and food-security. Affected households lost active labour force as well as burdened with the care of ill patients. This results also in a reduced food security for these households. People of non-farming households are adversely affected, since they have no safetynets with other farmers or share-cropping partners. They also warn that due to cultural customs more livestock will be used for burial rites, which contributes to food insecurity.

Generally the author observed, in spite of the huge relevance for rural living, a negative reputation of agriculture. Similar to western societies, Basotho perceive agriculture as being backwards. If possible, they try to get a job with a monthly income and use agriculture as an act of necessity. One will not find the spirit of innovation and renovation against such a background, but which would be necessary to tackle the problems related to the decline of natural resources. Therefore, a major challenge is to find new leaders and innovators, who identify themselves with agriculture.

6 Maize has different disadvantages for Natural Resource Management: For instances: In the Universal Soil Loss Equation, the Crop factor (C) maize accounts for 0.50, the Crop-factor for other summer grains is just 0.35 (MINISTRY FOR AGICULTURE, FOOd AND RuRAL AFFAIRS, 2000)

7 Giffen-Good: If prices of staple food increase, poor people cannot longer afford to supplement their diet with better foods and must consume more of the staple food 


\subsection{Stock Theft and its Implications}

Stock theft is one of the biggest problems in Lesotho, particularly in the areas neighbouring RSA (SANREMP, 2004). For a poor family such an assault results in an entire loss of one's livelihood, particularly if it happens during the ploughing season. The robbers are usually heavily armed with superior firearms such as AK-47. There is some reported evidence that policemen collaborate with them (KINGDOM OF LESOTHO, 2000). It is estimated, that more stock is stolen than brought to the abattoirs (SANREMP, 2004). The author himself witnessed farmers desperately seeking for their stolen cattle.

\subsection{Chieftainship and the Empowerment of Elected Structures}

The administration of land and people is the responsibility of traditional authorities. The hierarchy ranks from the headman on village level, to the ward chief, to the principal chief and to the king on national level. Apart from minor adjustments by the British colonials, who reduced the total of officially recognised chiefs, the land allocation was a responsibility of these traditional village leaders. To be allocated with land the applicant must be adult ${ }^{8}$ and possessing residence, then he would get three different plots, usually situated in different locations. However, due to the result of population pressure, the average number of allocated fields is decreasing (MOKITIMI, 1998). Nowadays, it is common to meet landless people. In some areas chiefs and community councillors reported to the researcher that land allocation no longer exist anymore.

Shortly after independence a 'Land Utilisation Board' was established. This served the chiefs to work out proper standards for the land allocation. Because it was felt that land allocation solely based on the chiefs decision was open to abuse of bribing, so called 'Land Advisory Boards' (LAB), consisting of elected members of the community, were launched, which needed to be consulted in the decision making process. As suggested by the name, these LABs just had advisory power. In many cases chiefs ignored the LABs respectively manipulated the election of LABS (MOKITIMI, 1998).

As a result of disputes between the ruling governmental party and the traditional structures, so called Development Committees were induced to create a counter balance to the power of the chiefs on land allocation. Development Committees comprise of elected members and appointed ones. Eventually, power was shifted towards newly created Village Development Councils. As an effect of ongoing struggles between the traditional structures and the opposing political leaders, all

8 i.e. married 
established solutions were ineffective and not working well (MOKITIMI, 1998). Personal observations made by the author still underpin this relation of scepticism and distrust between local councillors and chiefs. Since chiefs have seen all intervention as an eroding of their sinecures and powers, one can just overcome it with including them in the new local government structures (DECURTINS, 2006).

The latter represents a major stipulation of recent GTZ activities in Lesotho. GTZ, being in the country since the 1980 , has shifted its emphasis towards decentralised rural development in recent years. GTZ offers under its "Technical Cooperation - Support to Decentralized Rural Development Programme" help to recent efforts in policy towards decentralisation by the government. This is an urgent problem, since the existing way of governing in a centralised manner results in a poor outcome on grass-roots level. Therefore, the GTZ programme consists of 5 pillars, 1. establishing the legal and institutional framework conditions for decentralisation; 2 . help in development planning processes (on district level, community level); 3. increase the service capacities of local government structures and other service providers; 4. institute a transparent human resource management for the governmental body and 5. achieve a good focal area coordination of German development agents.

After the local government election of 2005, which were widely acknowledged as being fair, Community councils (CC), consisting of elected members and chiefs, are in place. On district level so called district councils are established, too. Agriculture extension services are made available to each community council. Other governmental bodies, such as the Ministry of Agriculture, the Ministry of Forestry and Land reclamation are now under the umbrella of the district councils in order to bring the services closer to the communities. The GTZ (on a trial base first for the district of Qacha's Nek) has developed a tool, the so called Quick and Smart-approach (simple, measurable, achievable, relevant and time bound), to gather villagers' needs and then channel donor help through the community councils according to it. Community councils also act as a "gateway" (hence the so called "gateway-approach") to offer help and tackle HIVIAIDS (AHAL, 2006). Community councils also fulfill the duty of land-allocation (although traditional agreements are still common) and according to the authors own observations, work hand in hand with the chiefs (since some of the chiefs are members of CCs). Personal observations also suggest, that on village level, albeit community council are not in place for a very long time and achievements are negligible, the responsibilities between community councils and chiefs are shared as follows: Community councils are widely seen as the ones being in duty for enabling "development" and channeling help, whereas chiefs represent the judiciary and administer law on village level. Since chiefs often have traditional ideas and opinions, this has to be included as a frame condition for 
projects, because punishment for instance might not be followed as strictly as necessary. As already stated, the share of responsibilities in terms of land allocation is quite blurry, working usually in the way that people firstly ask the chief, the chief decides, and hereafter goes to the community council to get the stamp.

\subsection{Reasons for Natural Degradation and the "Tragedy of the Commons"}

SIMANDA (2003) prioritises the need to look for underlying causes of natural resource deterioration. $\mathrm{He}$ argued, that one has to look for cultural reasons, which results in natural degradation rather than natural degradation on its own, although being the most obvious thing to start with. Following his rationale, Basotho people became so nature abusing as they are now because of historical reasons. Being a tribe settling the fertile plains of the area now called "Free State" the Basotho were pushed by the Voortrekkers into the mountains of the Drakan-range with less choice than using their old techniques in this unsuitable environment. Formally, the Basotho were a folk of livestock keepers and under the pressure of the Boer-threat they strengthened this identity. Simultaneously, they had to plough the slopes of the fragile mountains, instead of the fertile plains of the Free State. Since later approaches like interventions of the British, who wanted to reduce the number of livestock of each household, were diametrically opposing the identity of Basotho, they were seen as a repression of the government and failed.

Furthermore, SIMANDA (2003) argues, that due to increased population pressure, natural resources became scarce and disputes between and within communities arose. Since agricultural land used to be shared equally and everybody was getting access to the rangelands, many studies were undertaken, exploring whether this traditional land tenure system exacerbates the deterioration. The rationale underlying this problem was published by HARDIN (1968), suggesting that common land is depleted because each individual tries to extract as much as possible in order to maximise the personal benefit.

Obwohl offiziell Privatgut des Königs, ist die Produktionsfunktion des Bodens in Lesotho zu einer open-access Ressource geworden, einem Allmendegut, für das keine klaren Zugangsregelungen bestehen. Durch illegale Landnahme wird Boden quasi wieder in ein Privatgut im - allerdings sehr unsicheren - Besitz Einzelner umgewandelt: Mangelnde staatliche Kontrolle wirkt als Anreiz, sich Land anzueignen und andere von der Nutzung dieses Gutes auszuschließen. Gleichzeitig werden die knappen vorhandenen Flächen mit unangepassten Techniken ausgebeutet, da wegen der Unsicherheit der Besitzverhältnisse sich ein nachhaltiger Umgang, der Erosion und Degradierung vermeidet, für den Einzelnen nicht lohnt.

FISCHER et al. (2004) 
Later publication (MOKITIMI, 2006) as well as personal observation have proved that this is a common disbelief, despite being very rational from a western (economists') point of view. Since agricultural plots are used lifelong and can be inherited ${ }^{9}$, the author argues that there is some general land security for the farmers; hence it is profitable for the individual to invest in order to ensure sustainability. Thus, it can be concluded, that there must be other reasons for the ongoing depletion, namely social ones. Since the customary law comprises of efficient strategies not just to split natural risks (sharecropping etc.) but to cope with natural deterioration, such as the right to take away land, that has been inappropriately cultivated or the right to take rangelands out of usage to allow a recovering as well, one can certainly suggest that an eroding of these traditional measures is one of them. However, since customary law is still part of the culture, this needs to be considered as a frame condition of all project activities in Lesotho.

9 According to customary law, the chief revokes the land, but preferences in the allocation process is given to members of the family. 


\section{Case studies}

\subsection{The Promotion of Machobane Farming System}

\subsubsection{The Machobane Farming Approach}

Formally, the ploughing of the fields was predominantly done by men. With the increased demand of workers in South Africa's mines and the following migrating of miners to RSA, the amount of defacto-women-headed households increased dramatically, which resulted in stronger occurrence of fallow land. In the 1950s, James Machobane, a local agronomist, started to develop a farming technique, whereby women were able to care for the fields through reducing the ploughing to once within five years (RALITSOELE, 2006). Initially, he conducted experiments on his own fields for 13 years to design the agronomic framework and techniques for his approach (PRETTY, 2004). Unlike other agronomic extension methods, he then combined his methods with behavioural requirements necessary to adopt his messages. According to PANTANALI (1996) these are:

(a) Self reliance: farmers must be convinced, that they can achieve food security without external assistance: it is their will that makes the difference;

(b) appreciation of the resource base: farmers must believe that they can improve crop production by fully exploiting their global resource base (land, labour, livestock, waste and by-products), turning all its potential to their advantage;

(c) readiness to do hard work: those who want to achieve independence of basic needs must be prepared to sweat for it;

(d) learning and teaching by doing: farmers must be trained in their own fields, and farmer trainers must be ready to work along with them;

(e) spontaneous technology spreading: farmers learn from other farmers: Machobane farmers have a duty to help their neighbours.

Because his system was diametrically opposed to the governmental contempory approaches of the 1970s, which advocated a rise in agricultural output through intensive large scale agriculture, Machobane had to suffer harassment finally resulting in a prohibition of his approach and imprisonment (RALITSOELE, 2006).

After the first trials in the 1980s by IFAD and GTZ, Machobane Farming System (MFS) gained attention amongst donors and implementing agents, so that up to now several NGOs (e.g. MADF, 
Serumula, RSDA, WorldVision, NUL) are involved in MFS (PANTANALI, 1996; FAO, unpubl.).

\subsubsection{The Farming Technology}

The Machobane Farming System is based upon a few paradigms (Pantanali, 1996):

(a) - Intensive inter-cropping by growing several crops simultaneously or in rows in the same field;

(b) - soil fertility and moisture retention capacity is increased through placement of ash and manure; ash and manure replace expensive mineral fertilisers;

(c) - planting of crops is distributed equally across the year, this ensures a continuous harvest throughout the year and a spreading of risks of fluctuations in yields. Furthermore, since techniques of food preservation are absent, MFS ensures a minimum of variety in people's diet;

(d) - pest control is carried out by sustainable practices such as insect repellent herbs, winter ploughing and a deeper understanding of pest biologies (remove litter etc.).

Fig. 6 shows a possible crop calendar for the Machobane Farming System. Cash crops such as wheat, peas, and possibly potatoes, are planted as intercrops in April-May for harvesting the following January-March, and summer crops like maize, beans, sorghum, possibly pumpkins and water melons, are planted in August-October for harvesting in November-December (GRAVES et al., 2003)

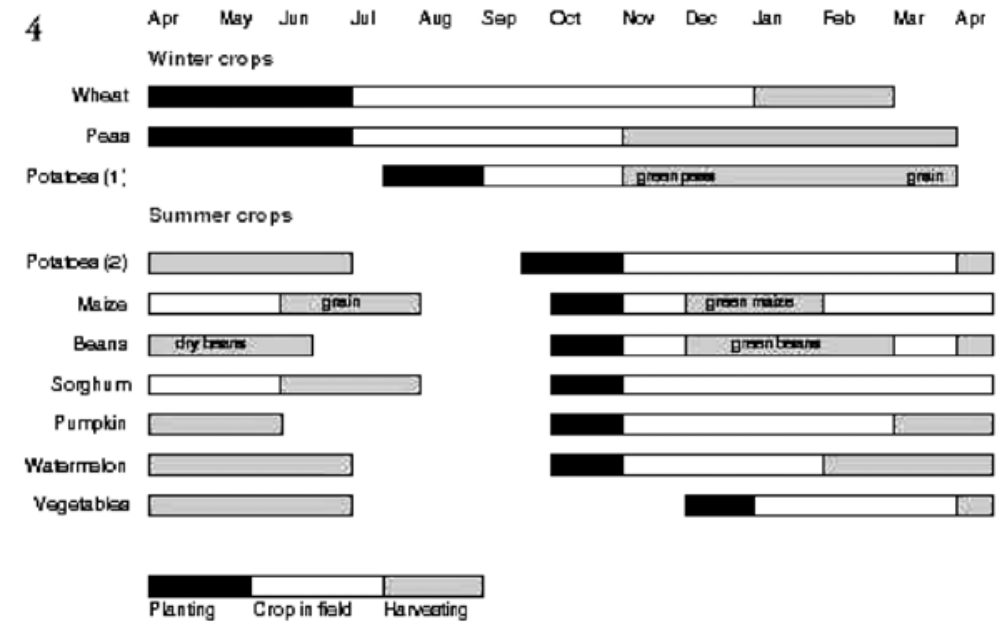

Figure 6: Crop calender for Machobane Farming System (from GRAVES et al., 2003) 
Overall manual labour input is high; peaks rising up to 14 days a month (Pantanali, 1996). This fact, therefore, is reflected in a three times higher productivity, compared to the conventional system, allowing an average five headed household to be self-sufficient on 1 acre of land $(0,4 \mathrm{ha})$ (PRETTY, 1999).

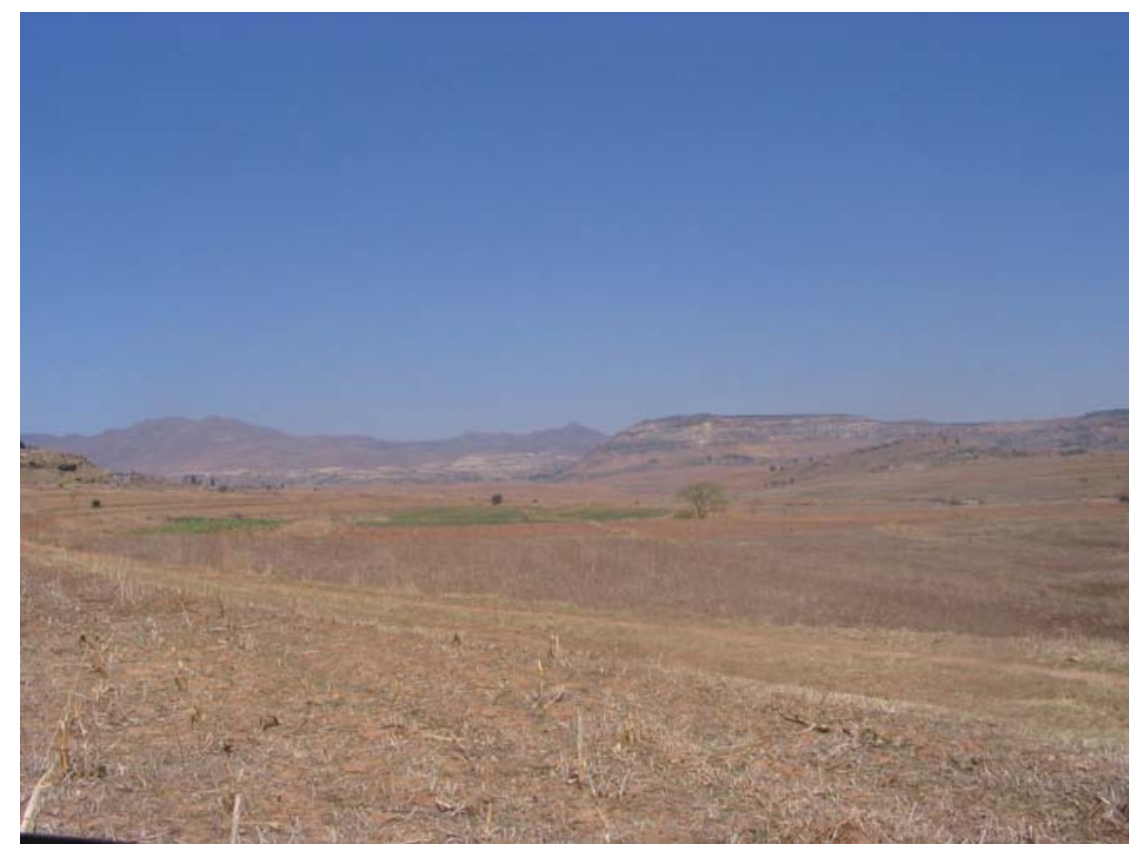

Figure 7: The only field under MFS-regime, field is greener through higher moisture retention.

The fact that humus builds up by the plant residues, combined with reduced soil disturbance (through reduced ploughing) and a continuous crop cover, helps also to minimise the impact of soil erosions. Furthermore, it is claimed that fields under MFS-regime have a higher retention of moisture (GRAEVES et al., 2003); a fact that is underpinned by personal observation of the author (compare Fig. 7)

\subsubsection{The Organisation Serumula}

Serumula is a national NGO focussing amongst others on facilitation of rural development in the natural resource sector (SERUMULA, 2006a; 2006b). Serumula emerged from the Swiss Helvetas, an international NGO, which was active in Lesotho with its Natural Resource Management Programme until 2005. The employees were recruited from the pool of former Helvetas-workers. (HELVETAS, 2004) Since the establishment in 2003, Serumula took over Helvetas natural resource management programme on a mandate base, allowing Helvetas to withdraw first technical then financial support in 2005 (HELVETAS LESOTHO, 2003).

Today, Serumula is an independent NGO, mainly funded by Kellogg Foundation and FAO. They 
manage approximately 60 beneficiaries in the district of Butha-Buthe and 126 in the region of Phamong. In order to equip farmers with ownership and hence to raise the success of the approaches, Serumula has established embedded structures through a process of civil engagement, namely, Moteng Small Farmers Association in Butha-Buthe and Ho Ipusa Moiphepi Development Association in Phamong (LEKHOLOANE, 2006; MOSIUOA, 2006). Although Serumula is not particularly targeting women, $95 \%$ of the beneficiaries are female. As a second feature, beneficiaries comprise $70 \%$ of people older than 40 (SERUMULA, 2006b).

\subsubsection{The Sampling}

Interviews were conducted in the area of St. Peters in Butha-Buthe district from $31^{\text {st }}$ of August until the $2^{\text {nd }}$ of September 2006 and in the area of Phamong on the Mohale's Hook riverside of the Senqu on the $16^{\text {th }}$ of September. The locations of the interview-sites are marked in Figure 8.

Firstly, assumed key informants, represented by the area chief, recent elected local councillor, the Serumula-coordinator for the Phamong-area and Bolai Ramonot'si, a lodge owner and Serumula facilitator of St. Peters, were approached and interviewed. Secondly, 13 farmers, consisting of users and non-users of MFS, were identified and interviewed as described in the chapter of methods. In order to compare Serumula's way of implementing, targeting and facilitating MFS, seven farmers, who started under the support of MADF and thus represent original fellows of the way Machobane proposed his approach, were questioned as well. These farmers have no support whatsoever and at present are completely on their own.

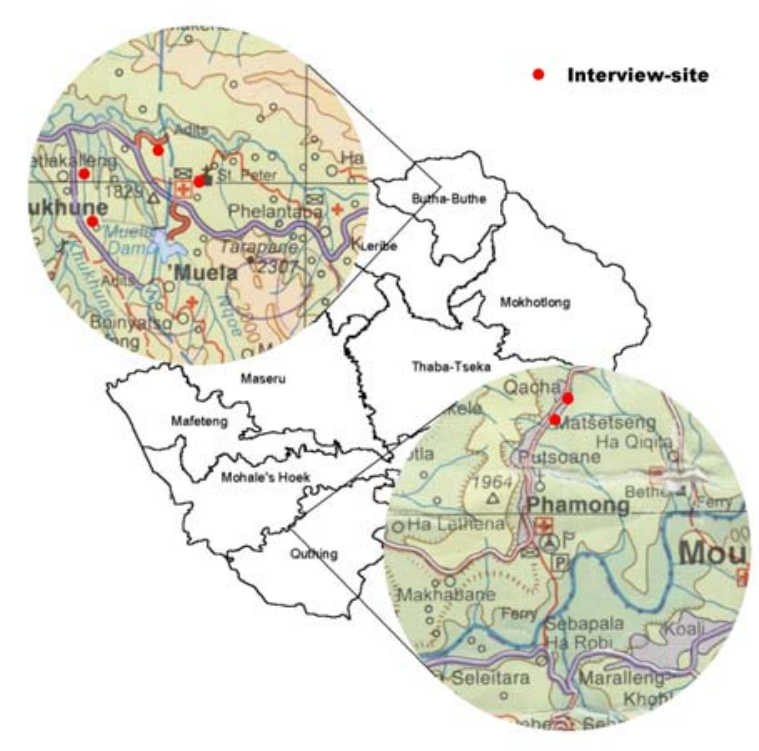

Figure 8: Locations of examined villages. 


\subsubsection{Reasons to start Machobane Farming System}

Generally, the respondents showed two types of different initial motivation to start the Machobane farming system. The first by far the biggest group got involved with MFS, because he or she was in a bad financial situation and could not afford the means, which need to be brought up for conventional farming (i.e. fertilisers, seeds, pesticides).

- It was possible with the new system to meet my needs given the fact that all my family members are deceased.

- The use of manure not fertilizer is cheaper.

This type of adopters, however, was also very often motivated by the fact, that Serumula distributed seeds for free, respectively at half of the costs in the beginning

- Serumula people told me, if I had the land they would supply me with the seed.

- The large family and the extra load makes it harder for me to get the seeds, with the school fees and day- to-day needs of the household there is not enough money to buy the seeds.

Those people often show characteristics of being poor and marginalised (i.e. traditional Basothohut, ragged clothing, poor appearance in general and also often report, that they have to care for HIVIAIDS-orphans in their families. Usually, they gain all their income through agriculture. As an obvious similarity, these farmers were attracted by the financial benefits. Interestingly, from retrospect the farmers first saw the financial merit and afterwards the advantages listed in the next chapter.

The second type of adopters was convinced through the better quality of crop and other positive side-effects achieved by MFS.

- I wanted to improve the quality of the soil.

- It has a better taste and it has more minerals and vitamins.

This group shows characteristics of being better off, manifesting in western styled housing, crafted furniture and TV-DVD equipment. In most cases the money originates from remittances of mineworkers or the partner in general. In essence, they gained their income not entirely through agriculture.

Nonetheless, there are more factors, which enhance the motivation to adopt:

- I saw other people how successful they were. 
Many farmers referred to Bolai Ramonot'si, who in their opinion, has used MFS very successfully. This corresponds with the theory of ROGERS (1995) described in the chapter of diffusions of innovations. Mr Ranonot'si is a very cosmopolitan gentleman with a degree in electrical engineering from South Africa. He is very open minded about new techniques; besides his involvement with Serumula, he and his brother are also involved with the MDTP-Project, which will be the content of a chapter later on. This corresponds with the definition of an opinion leader, made by Rogers (1995). However, it is important, that traditional village leaders such as chiefs promote the same opinion and do not discourage reluctant farmers from adopting the new technique. According to RAMONIT'SI (2006) and MOKOKO (2006) the chief is pushing MFS and hence stimulating the uptake. The influence of local authorities (including chiefs and community councils) on the success will be dealt with in later chapters.

- They [other farmers applying MFS] approached me in my garden to physically show me what to do.

This statement was done by an MFS farmer not under Serumula support, but recruited through the Machobane approach of MADF. Evidently, it shows the effectiveness of embedding the concept of project spreading in the initial approach.

RAMONIT'SI (2006) highlights, that in his opinion, the project of Serumula was very successful in terms of attendance, because local people were involved rather than foreigners or people from town. This coincides with personal studies of the author, where the agricultural assistants, who originates from urban areas and other districts causes more resentment and have less access to communities (comp. Chapter SANReMP). LEKHOLOANE (2006) adds that for a fruitful approach of beneficiaries, one needs to behave according to traditional Basotho customs, which includes traditional clothing.

MATLALENG (2006) prioritises that the seeds were given not for free but on loan basis. In the past this has worked very well, but in recent times there are increased problems with the payment behaviour. Loan management seems to be a common problem amongst Basotho people; even respectful personalities such as chiefs delay the payback of credits deliberately.

Mr Machobane himself developed a very interesting way of how to supply farmers with seeds. Every farmer gets supplied with seeds, but must return the double amount at the end of the harvest season. Since Serumula is using high yield varieties, it is not applied by them. However, this would ensure a spreading after the project ends. 


\subsubsection{Advantages of MFS}

The most stated benefits are the consistent supply with fresh food by MFS and the eradication of hunger. In some cases this even enables farmers to sell small surpluses to markets in the village.

- Continuous harvesting of the crops and vegetables, plots doesn't need to be big to gain a good harvest.

- I have been able to take some of my produce [potatoes] to the market and sell.

- Life is easier; I don't have to go around looking for food. All I have to do is to take care of my garden.

- Even during times of hunger (spring, when last years harvest is depleted), there is still something in my garden.

As already described in the literature, MFS seems to enable farmers to be self sufficient in terms of food. During periods of high prices (e.g. spring), MFS farmers benefit still from their own harvest. It was also reported, that although they have been burdened with orphans, farmers still are able to feed all members of the family. Hence, one can expect, that MFS increases the ability to cope with the extra stress through HIVIAIDS.

Poor people are exposed to several risks. The responses of the interviewees lead to the conclusion, that one main advantage of MFS is the reducing of risks. It was confirmed:

- Pest affecting one crop does not result in loss of the whole harvest.

In case of infestation with pests MFS-farmers have 'several eggs in their basket', in other words they hedge against contingencies of plant production and spread their risks. One farmer reported small black beetles, which affect the maize in stock. Again, MFS-farmers can substitute in such cases maize with beans and do not have to suffer hunger. By the way, the beetle would be a challenging topic for a research project on biological control measures.

- Because people plant the same crop, I am able to sell my produce as alternatives.

Furthermore, MFS-farmers gain a pioneer advantage, which means that because of product variation, they have a higher market potential for their goods. Obviously, these can just be utilised until all suppliers change their production. 


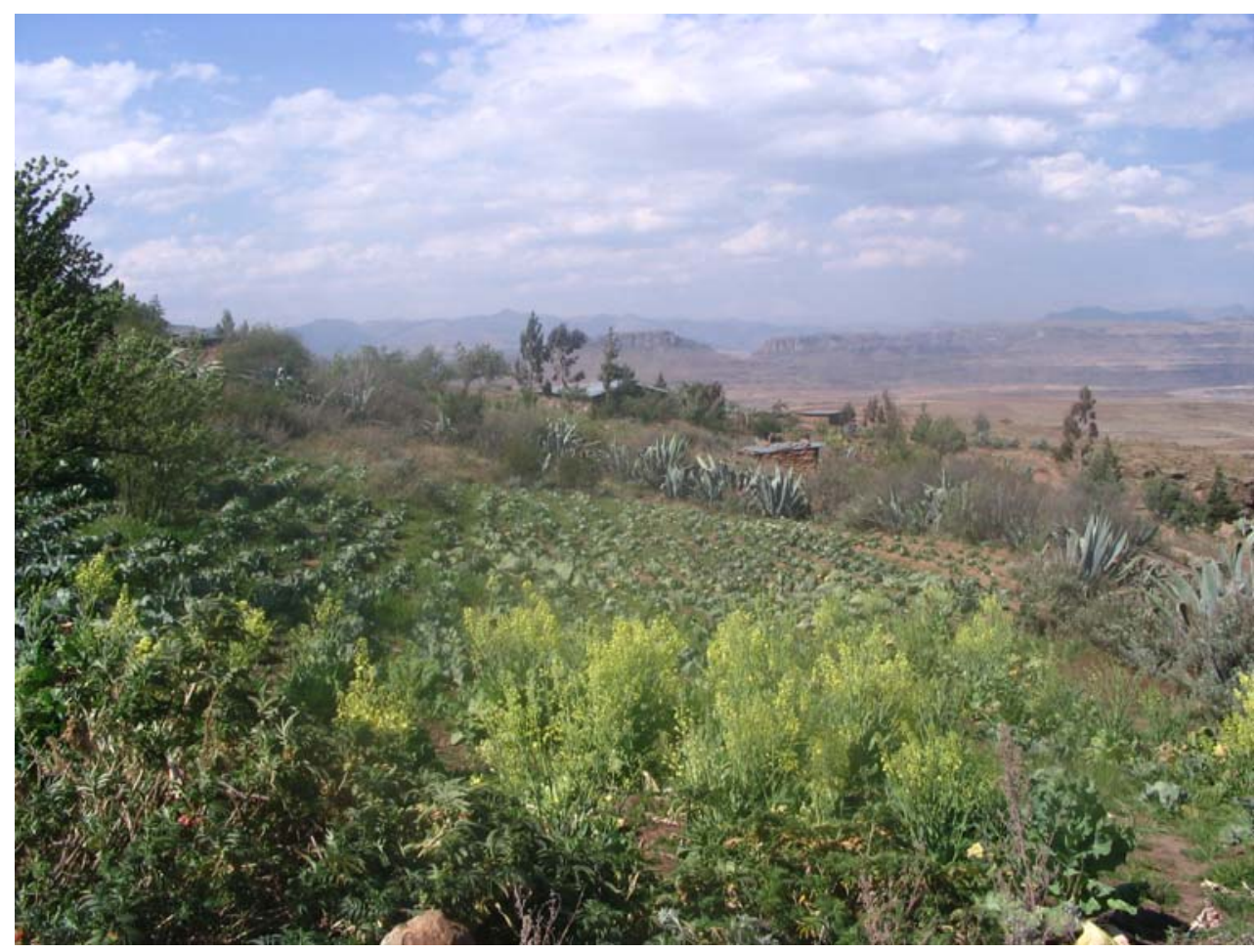

Figure 9: Plot under MFS regime

\subsubsection{Reported Disadvantages and Resentments}

Most of the problems stated by the users referred to issues valid for agriculture in general:

- Shortage of water causes our plants not to be as successful as they could have been.

- We have problems with small black beetles, it is difficult to store the maize.

One can even assume, hence MFS has a higher moisture retention, the reported problems affect MFS adopter to a lesser extent. However, there are drawbacks:

- Some people don't have manure. That is why they have stopped using this farming system.

- We don't have cattle so we ask for cow-dung from the community.

- The fault was with us, the use of not decomposed manure resulted in a small harvest.

The latter, although claimed to be a failure, gives a measure of how good the adoption of the technique is. The farmer (in this case she) did not stop though she faced problems; she questioned the origin of the difficulties and found a solution. WUEST et al. (1999) shows the fruitful effect of such 'on-farm research'. Even without support of the project, it can be expected, that the farmer is capable of coping with unexpected challenges.

The first quotation underlines an inherent problem of the MFS-system - the requiring of cow-dung 
as a substitute for fertilisers. Usually, the possessing of cattle can be used as a measure of wealth. Many people cannot afford cows. There are other opportunities to organise the manure such as gathering of cow droppings on nearby rangelands or buying them from other villagers. Generally, cow-dung is an underused resource; however, a countrywide application of MFS would assumedly raise the prices and worse, foster the depletion of organic matter from the rangelands and hence accelerate erosion. Up to now, the impact is surely not evident but the author wants to draw this future trade-off. For present days, it can be concluded, that MFS suits better people owning cows, in other words not to the poorest of the poor. If non-owners are targeted, an approach for manure supply needs to be embedded in the project-design.

Non-users frequently believe, that there is too much work involved with MFS:

- I don't have the energy to do the hard work that is involved.

- I think it is too hard work.

- The work was too laborious

were the main reasons not to start MFS or stopping it. Given data in literature (comp. PANTANALI, 1996) suggests that farmers need to invest 14 days a month during peak times (harvest, weeding etc.) of workload. Since there is no measure for 'too much work' and this is still depending on personal views, the author does not want to judge about the amount of work which needs to be brought up. Actually, some users were responding, that they prefer MFS because of 'the little work needed'. However, since the opportunity costs in rural Lesotho for farmers should be pretty low, a labour intensive cropping system should be worthwhile for the peasant population. This matches with personal observation, where farmers who stopped MFS were showing signs of wealth. They simply do not need to invest the work, it is more remunerative for them to buy the food.

Other problems are related to market constraints. Even if MFS farmers have a comparative advantage on conventional ones, the consumer potential on village level is pretty low. Lesotho supermarkets, which are mostly owned by Chinese people, are known for their ruthless financial behaviour. Despite this, in Phamong-area, farmers sell their vegetables to a supermarket in Mohale's Hoek with Serumula's support. The problem is that retail sellers claim minimum requirements in terms of quantity and quality. Thus, the challenge is to provide channels for marketing produce in a sustainable manner, i.e. sustaining after the project's end. A second option would be the production of seed potatoes. The author reckons, that concerning this matter Lesotho would have a comparative advantage over RSA, since the mountainous area favours the production.

- They don't give us food for the work or money. 
LEKHOLANE (2006) says that a lack of voluntarism stands for the biggest problem Serumula faces. This is magnificently underpinned by the answer above. Farmers were complaining about the fact, that they are not rewarded for activities for their own good. The impact of aid on villagers behaviour, especially food aid distributed, will be discussed later. Serumula's response is the forming of Farmers' association to equip them with the feeling of ownership.

\subsection{The Promotion of Conservation Agriculture by Reverent Basson}

\subsubsection{Conservation Agriculture: The Technique involved}

Conservation Agriculture (CA) has an increasing impact on farming practice throughout Africa. As a main advantage it offers universal solutions for the whole range of farmers. With little adaptation, it can be used from small-scale farms to big mechanised large screen fields (IIRR \& ACT, 2005).

Conservation Agriculture comprises three main principles:

Disturb the soil as little as possible.

Keep the soil covered as much as possible.

Mix and rotate crops.

Ideally, Conservation Agriculture does not disturb the soil at all. However, usually the tillage is reduced to a ripping (important to break a plough-pan) or planting with a hoe. The absence of big soil breaking and turning tools like ploughs is essential (IIRR \& ACT, 2005).

In order to avoid bare earth, Conservation Agriculture aims for consistent soil cover through crop residues, cover crops and mulching. This helps to hinder water to wash the soil away. It also helps to suppress weeds and heightens the water retention (IIRR \& ACT, 2005).

The third pillar is the application of crop rotation in order to inhibit soil borne diseases, certain pests and weeds from multiplying. It also helps to maintain fertility through rotation with nitrogen fixing plants (IIRR \& ACT, 2005).

Although, a comprehensive baseline study of CA activities in Lesotho is conducted but yet not published, first results suggest a significant positive impact on yields (SILICI \& PEDERSEN, 2006). In some cases, increases in production multiplied up to 1000\% (MAKETE et al., 2005). Generally, the 
major benefit such as reduced erosion rates, better soil fertility as well as reduced work requirements and site effects like carbondioxid sequestration through increased organic matter functioned on a medium to long term base (GARCÍA- TORRES ET AL., 2002; FAO, 2007).

Therefore, the major challenge of promoting CA is to persuade farmers about the merits of abandoning conventional farming approaches. Because of the higher work-load (in order to remove dormant weed-seeds), or higher input of pesticides in the beginning, subsidies in the first year need to be considered. Secondly, required fertiliser rates might be higher, due to immobilisation of nitrogen ${ }^{10}$, although CA allows preciser fertiliser application (FAO, 2007; IIRR \& ACT, 2005).

In case of Tebellong, Conservation Agriculture is embedded in a whole range of social activities, such as teaching orphans, a focussing on the youth (e.g. football league) or a general stimulating of social involvement. The work is done by Rev. Basson, who is a missionary of the Dutch Reformed Church. He answered the question of why he had started in Tebellong with "I don't think that you will put it in your report, but God called me to be here" (BASSON, 2006). First activities such as fruit production were set off after 1993, but soon he realized that the impact of his actions on the community were marginal, affecting not more than five families, which were employed to do the work. In his contribution to the World Congress of Conservation Agriculture he conceded:

"After all of this I had very little to show for all this money. We could never get to the break even point or making a profit. If we are honest about development in Africa we would realize this is what we see most of the time. I heard a figure of \$US 96 billion pumped into Sub Sahara Africa since 1992 to 2004. Africa is worst off after all this money. I am sorry to say, but I contributed to that figure" (in MAKETE et al., 2005).

He shifted towards the promotion of CA 2002. After incentives were necessary during the initial phase, his approach is now more based on local trainees, responsible for spreading the idea (BASSON, 2006). Up to now (including branched activities in Lesobeng, which is situated in the mountains of Thaba Tseka) 500 households of small scale farms are part of the CA activities (FAO, unpubl).

10 Higher organic matter content widens the $\mathrm{C} / \mathrm{N}$ ratio, which results in immoblisation of $\mathrm{N}$. 


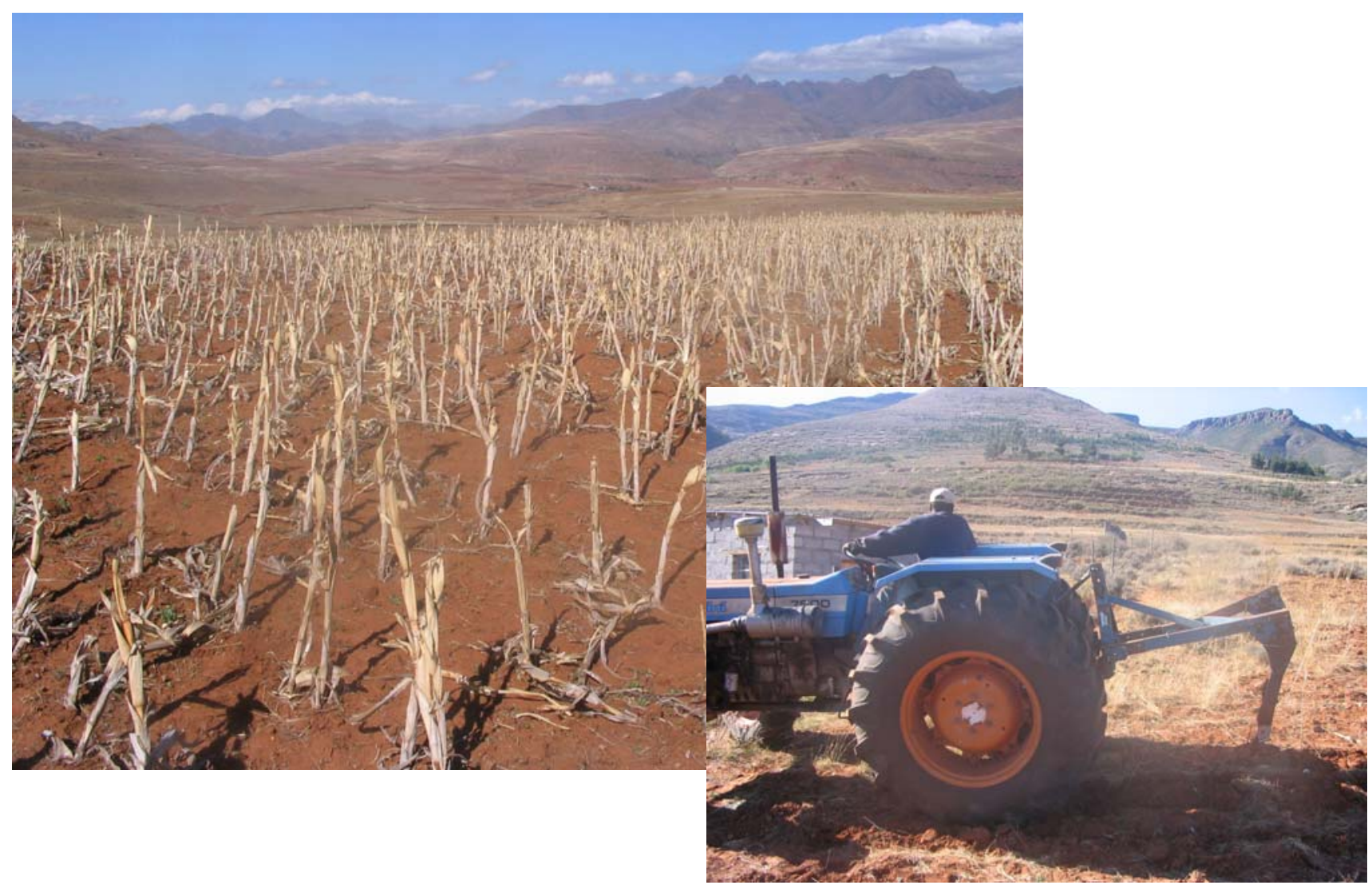

Figure 10: CA field; farmer while ripping.

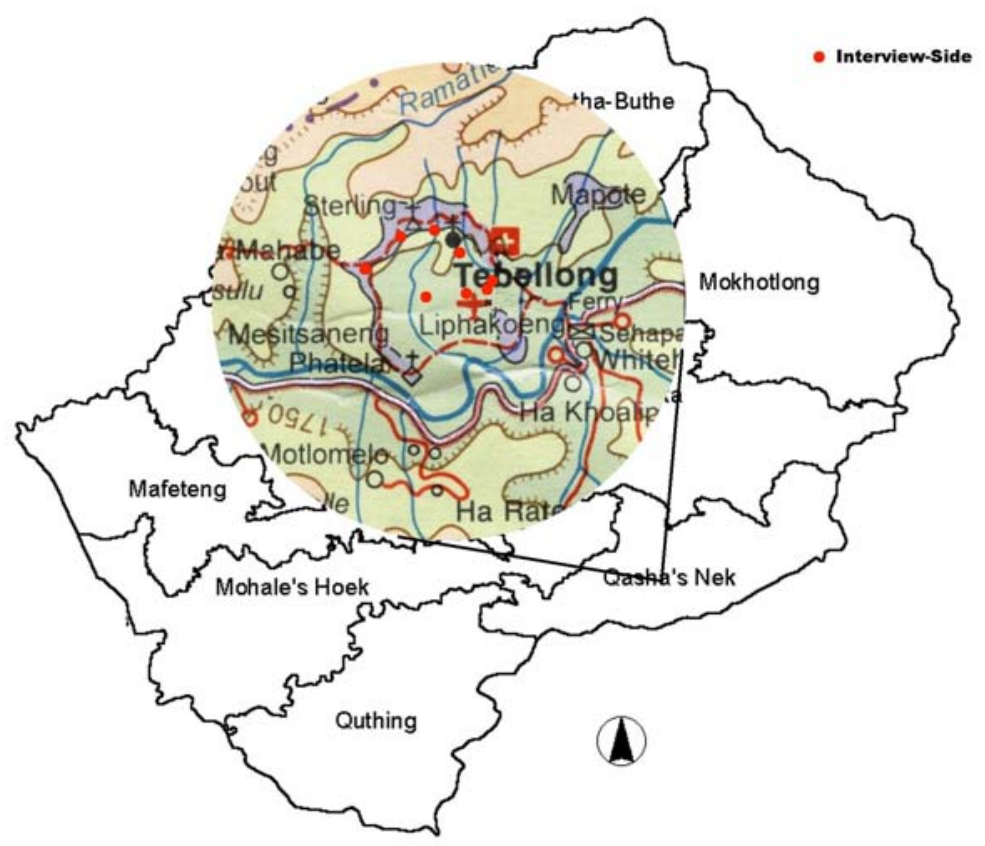

Figure 11: Location of CA-villages 


\subsubsection{The Sampling}

Interviews were conducted from $20^{\text {th }}$ to $23^{\text {rd }}$ of September, 2006 (see fig. 11). All in all 10 farmers (comprising users and non-users) have been approached. Concomitant interviews with Rev. August Basson, , with the chief and the councillor were undertaken. The local Agricultural Assistant for Nutrition was questioned as well as the responsible in the Ministry of Agriculture in Qacha's Nek.

\subsubsection{Why start using CA?}

Usually, farmers in Tebellong area heard about CA through gatherings by the Rev. On the first gathering most of them did not take him seriously. In the initial phase he had to pay farmers to conduct CA-trials on their fields (BASSON, 2006).

- I heard it from Rev. Basson and thought he was crazy. He called for a gathering for interested people. We were quite a few, but many abandoned the project again. Now, they are back on track because they see our success.

Even today he is still providing seeds as incentives, in some cases fertiliser as well. WFP again is involved, providing food for work in the first phase. According to the WFP representative in Q.N this will be reduced.

Analogous to the farmers working under MFS regime, the primary motivation to start CA are of a financial nature.

- I could not afford to hire a tractor.

- Even without cows or money for hiring the tractors, it is possible to feed your family.

- In the beginning the Rev. gave me fertiliser and seeds.

BASSON (2006) condensed this to the statement, that in order to get a good participation one needs immediate results. Since farmers do not have to pay for ploughing anymore, financial improvements are instantly seen. In some cases of hardships, animals were stolen. CA offered the only solution for this crises.

Corresponding to reasons why starting CA given in literature (IIRR \& ACT, 2005), some of the farmers, especially those starting CA not in the first place, were convinced by the prospect of gaining higher yields.

- The old way of agriculture gave me just $150 \mathrm{~kg}$ harvest. 
- We were quite a few, but many abandoned the project again. Now, they are back on track because they see our success.

Most of the people heard of CA through the Rev. Since the survey due to time constraints was limited to the surrounding areas of the church, other opinion leaders besides the Rev could not be found.

- Rev. Basson spoke about Conservation Agriculture. I saw the importance: the ploughing resulted in development of dongas.

Rev. Basson has noticed the importance of spreading the project beyond the group which follows his denomination. Therefore, schools and youth in general are a future focus of his activities. ODHIAMBO (2001) showed the potential of youth used as a vehicle to promote CA in Kenya. He argues, that youth has a key position, since parents and guardians are happy to learn from the sons and daughters, rather from strangers. Young people one the other hand are less biased and easier to indoctrinate (ODHIAMBO, 2001).

\subsubsection{Advantages compared to Conventional Farming Design}

As already explicated, farming prospects for Lesotho are unsatisfying. It seems, though that CA can curb this tendency. Practising CA-farmers are very satisfied, sometimes enthusiastic, about their outcomes.

- We are able to eat and support our families. Even though it is in the early stages we see that we are able to feed our families.

- I sell beans and maize and vegetable from my garden, I get the money from the people, which are working in RSA mines. I laugh at people, who need to go to the shops.

- From next year onwards I will do it completely on my own; this year I just got a bit fertiliser.

- Beforehand, I used my produce just for own consumption. Now, I can sell some of the harvest.

- When it rains, it becomes very successful.

- Reduced soil erosion, the fertiliser is used more efficient, I harvest more, the soil becomes less compact and it has a higher moisture retention.

However, one should consider, that this great leap forward may not only be linked to CA, but to a better farm management in general. The seed-bed is smaller (just basins are formed) and hence fertiliser can be applied more specifically for each crop. Similar to MFS, created surpluses often 
enable farmers to sell the produce and to make an income of it. Contrary to MFS no marketing problems were reported, though one can suggest, that due to the remoteness of the location, there are no more opportunities than the limited markets within the community.

- It is proven, that you have less soil erosion.

- It is cost effective, it protects the soil.

- It protects the soil; the wheat from my ploughing neighbours were growing everywhere in the donga.

- I harvest the soil of my neighbour's fields.

- I use just two bags of manure.

Tebellong's CA-farmers noticed similar improvements fostered by CA to the ones stated in the literature. Particularly, the observation of wheat growing in the dongas illustrates how harmful soil disturbance during intense rain events can be. Farmers showed the author a former donga, which was refilled by trapped silt, - with no other action undertaken then practising CA.

\subsubsection{Encountered Problems and Resentments by Non-Users}

As one can extract from the statements of CA-farmers, there is a major conflict between livestock owner and farmers:

- If you do not have cows, people let you pay for the cow dung (5 M/50kg). This might be a problem for some people.

- I caught some herders grazing in my fields during the night. They did it last year and the year before. I am on alert. They do it on purpose! They should send the cattle to the mountains, where the grass is green. They should buy some fodder in the winter.

- The cattle grazing is a big problem. We talk to the owners, but they do not listen to us. Some people come in the night to graze my fields. I can just observe the damage the next day. I suspect some people from my very own village, who do not like CA.

- Last year some cattle grazed on my fields during the night. It was a disaster. I could not identify the culprit.

Nearly all of the CA-farmers reported big problems with other people's cattle grazing in their fields. Of course one could argue that this is due to the amount of livestock in general and a general conflict between herders and farmers. However, this misses something out. According to MOKITIMI (2006) the farmers have exclusion rights for their plots during the growing season. Once the fields 
are harvested it reverts to communal land. Everybody is allowed to gather wild vegetables, cowdung, cutting grass for roof fetching and - there is the rub- graze his cattle on. Since one major principle of CA is the maintenance of a consistent soil cover, there are no periods besides the growing season, which results in less winter grazing areas for the remaining herders. This would explain, why people are so eager to damage the fields. It needs to be added that in most cases herders belong to a family, which is farming at the same time, means in many cases the conflict can be reduced to a conflict between villagers. However, the author wants to emphasise that this represents a major disadvantage of CA.

A second disadvantage is the resentment of the agricultural extension services. Several farmers reported, that they were discouraged by the agricultural assistant (AA).

- The AA and me are like oil and water. He wants to use ploughing. At vegetables fairs, he uses to stand close to me, because my harvest is the best and better than his.

- A lot of people are discouraged to start with CA. You need to know the importance of your work and the success to resist such.

- The AA told me to abandon CA. I did not listen to him, because I could not afford the plough.

To prove the fact of this case, the author approached the responsible extension worker, questioning him, about his perception on CA. Since his answers are not worth being citied (which might be explained with recent alcohol consumption) the author wants to make clear that resentment by governmental experts presents a major threat to projects outcomes. In the case of Tebellong, the agricultural assistant had a background of a degree in agriculture from the University of Bonn, which might explain his conceited behaviour towards the villagers. However, other agricultural workers, being quite young and recently graduated, supported CA-farmers and hence helped to encourage them. BASSON (2006) defined the persuading of political agents, namely the former Minster for Agriculture and Food Security, Dr. Rakoro Phororo, for the concept of CA as his major achievement. Nevertheless, one need to take into account that links between agriculture outposts and headquarters are weak and that supervision is very poor, so that it will take some time before directives by the minister trickle through all institutions.

- They [community councils] should stop with food aid. It is like cutting our hands, because we just wait for the aid and do not do anything. How long will food aid last?

- We do not need the food aid. How long will they stay?

The following statements were heard elsewhere in the country and will be discussed in the chapter on food aid. Farmers investing their own work force to are jealous of people, who are under 
support. They also stated, that they think it suppresses the outspread of the idea, since people are being allowed to be lazy.

The councillor on the other hand possesses the opinion, that WFP is a blessing. This might be conceivable, if one knows, that the channelling of food aid, in particularly food for work, is often done through the councillors, which then can claim it as their own success and use it to gain votes for the next election. The author, therefore asked him whether he thought if he would be elected again. He stated, it is dependent on future involvement of WFP.

- It is difficult; in order to gain a good harvest it requires a lot of weeding.

- It requires, that people come together to work on our fields.

- Regarding grazing in other people's fields. It depends on the action, that we want to take.

- We want them to forgive each other, rather than push charges.

- Poverty hinders the spread of CA. But with the help of WFP we might overcome it.

His statement of how to deal with grazing trespassers, exemplifies the need, why community councils should not be responsible for charging perpetrators, since they are depending on their future votes.

Furthermore, he prioritised that despite appreciating the existence of CA in general, he thinks a lot of work for weeding is involved. As stated earlier, this might be the case for the first years, but after decontaminating the field the workload decreases. Other responses by non-users show that people are put off by this fact.

- It requires a lot of work. We are lazy. The soil is very hard, I cannot do the work; I am old.

- It requires a lot of work. It is very hard for people, who are not in good health. The weeding is very difficult without ploughing.

- Without the cooperation of the Rev. it would be impossible to do it on one's own. He does this, because he is white and gets the help from donors.

Since the whole of Lesotho had to suffer serious droughts in consecutive years, some people blame CA for the losses. Obviously, this can hardly be the fault of CA. However, BASSON (2006) admitted, that there were problems, where cover crops (namely peas) dehumidified the soil too much and there was too little water for successful germination of the main crop:

- Using ploughing I yielded about 17 bags of 8kg each. From CA I only got three bags.

CA has brought hunger into the community. Those people practising it, are hired and paid 
with food aid. How should you do the job without any help?

The comment above, shows another negative effect of food aid: It serves as an excuse for not participating.

- Agriculture is God's thing, He said we should plough the land and get food.

- This is a technique for vegetables at home not for the field.

Some Basotho being very religious indeed, may align their lives with the bible. Hence project designers have to take this topic seriously and include them it into their design. Rev. Basson being a missionary and hence well versed in the Holy Scripture will certainly find a part in it to justify the non-existence of ploughs. But even so the common mindset of "agriculture needs ploughing" is according to the Rev. and the literature a major problem in promoting CA (BASSON 2006; MARAKE 2005). The latter response represents a big problem, the author has encountered. Other members of the community disregard CA as being "home gardening". Since agriculture in general is perceived as being backwards, how does one persuade people to practice techniques, which in essence seem not to differ from techniques used in ancient times. How to persuade about this newness, this innovativeness of approach, if tractors and ploughs are seen as the things to aim for? Answers can just be found in concentrated efforts by highly acknowledged institutions, by campaigning the value for Lesotho. As mentioned earlier, one needs to start with one's own staff.

- Last but not least, some farmer completely underrated the problem of natural resource deterioration.

- They say it prevents soil erosion, but there was soil, when we were born and there will be soil, when we will die.

- How could rain erode such dongas? They where here throughout.

- Nowadays it rains not half as much as it used to do and we still have the soil.

The statement shows that the general understanding of soil erosion and how it is linked to the management is very poor. This hypothesis is backed up by the work of MoKITIMI (2006), who figures out that awareness of erosion in Lesotho does not correspond with the actual extent. Furthermore, since decrease of production through soil erosion is a slow process, farmers may not notice it in the first moment (comp. CHISHOLM A \& DUMSDAY R, 1987). The author therefore recommends, that simple measures are undertaken, to show the interrelations of soil erosion to farmers. This can include tracer tests or the quoted seeds, which grow in the donga instead of the fields. 


\subsection{The Sustainable Agriculture and Natural Resource Management}

\subsubsection{The Organisation}

The Sustainable Agriculture and Natural Resource Management Programme (SANReMP) is part of the ongoing activities of IFAD (International Fund for Agricultural Development). In general IFAD aims to trigger the following developments in Lesotho (IFAD, undated):

- Diversifying and intensifying of agriculture;

- rehabilitating and reclaiming degraded lands;

- developing rural financial services to support improved agricultural production and create income-generating activities.

Therefore, IFAD emphasise following strategies for Lesotho:

- Improve food security and household nutrition and income, particularly among households headed by women;

- foster local people's participation in planning and implementing development activities;

- reverse land degradation and the decline in agricultural production by promoting sustainable natural resource use and management;

- build local capacities in support of the decentralization process;

- promote partnerships with NGOs;

- finance improvements in social infrastructure.

SANReMP was launched in 2005 and will continue until 2011. SANReMP has a financial strength of US\$12million partly funded by the Kingdom of Lesotho but mostly based on a long term IFAD Ioan (US\$ 10.1 million). The programme is implemented through two agents, the Ministry of Agriculture, being responsible for the first programme component and the Ministry of Forestry and Land Reclamation, being in charge of the second component. The first component is the promotion of agricultural diversification and intensification. This will be achieved by a whole range of activities, such as improved rainfed systems, MFS, micro-scale irrigation, community gardens, seed multiplication, harness making (collars instead of yokes) and the promotion of post harvesting processing techniques (SANREMP, 2004). 
The second component advocated by the Ministry of Forestry and Land Reclamation, comprises land and water management measures like soil- and water conservation, pasture rejuvenation, range management and afforestation (SANREMP, 2004).

The third component is entitled with local capacity building. On a communal level this will be achieved by the elaboration of Community Action Plans (CAPs), the strengthening of extension services and on district level this will be achieved by a general upgrading of facilities (vehicle etc. ) and the appointment of a programme accountant.

All in all a total of 177,177 households are targeted. However, during the time of this study most project activities faced severe constraints and were delayed (SANREMP, 2006)

\subsubsection{The Techniques assessed}

Due to the existing delay of activities, just a few project sites of SANReMP could be appraised. These included community gardens as a part of component one and the rejuvenation pastor land as well as generally soil conservation and afforestation activities from component two.

Community gardens: This technique describes the establishing of a homestead for the growing of vegetables. These then will be sold and provide income, particularly for the resource poor and the landless. The villagers founded a committee and managed the garden in a collaborative manner.

Fig. 12 shows the community garden of Ha-'Motsi. The first distinct feature is the remarkable fence. This was funded by the SANReMP in order to avoid trespassing by animals. In the author's view the fence looks extraordinary overdimensioned for a country, where fences are almost absent. However, even if the community garden fails, the fence will at least ensure a physical sustainability of the project. 


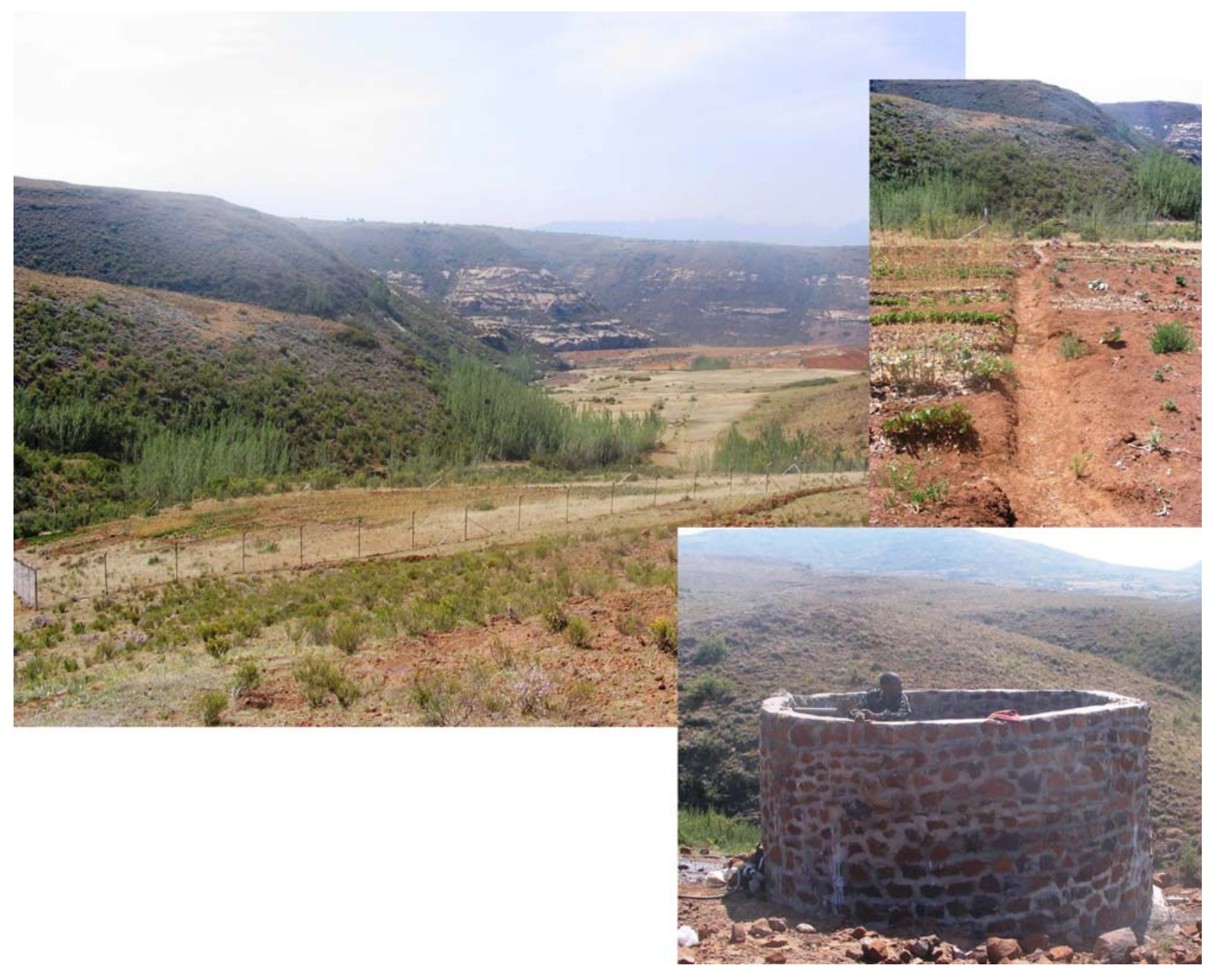

Figure 12: The site of the Community Garden

As one can see, the soil is very shallow and the placement across a slope is not an ideal location for a communal garden. The slope was covered with pebbles. In order to ensure the water supply for the irrigation, a tank was built, fed by a nearby spring under technical consultancy of the Ministry of Forestry and Land Reclamation. The tank however was much further away as a stream situated next to the garden (see. Fig. 12 , the stream lies next to the alignments of trees). This stream was bearing water during the time of the visit. Since this time is supposed to be the driest, one can assume that the stream would be an appropriate supply at all times. Even a gravity fed system would have been possible, needing less tubes than the tank would. To sum up, the whole site was not designed ideally and was showing signs of inefficiency.

The second project visited was a site near Ha-Ramosoeu where pasture rejuvenation and afforestation had been undertaken. The idea behind is to create a physical obstacle in the form of 
stone contours to slow down runoff and hence reduce erosion rates. Between the contours a very resistible grass species (Kikuyu grass Pennisetum clandestinum) is planted. Additionally some parts were afforested.

A crucial feature of stone contours is that the contour has to be on one level. Otherwise it leads to an increased erosion not a slow down (NILL et al., 1996). As one can easily observe (see. Fig. 13 ), this is not the case in the village. This is either due to an inadequate understanding of the supervisors (i.e. the field officer of the Ministry of Forestry and Land Reclamation) or an inadequate supervision in general. In addition some of the tree samplings had been grazed. Thus, it needs to be stated that grazing is in place, before sites for afforestation are chosen.

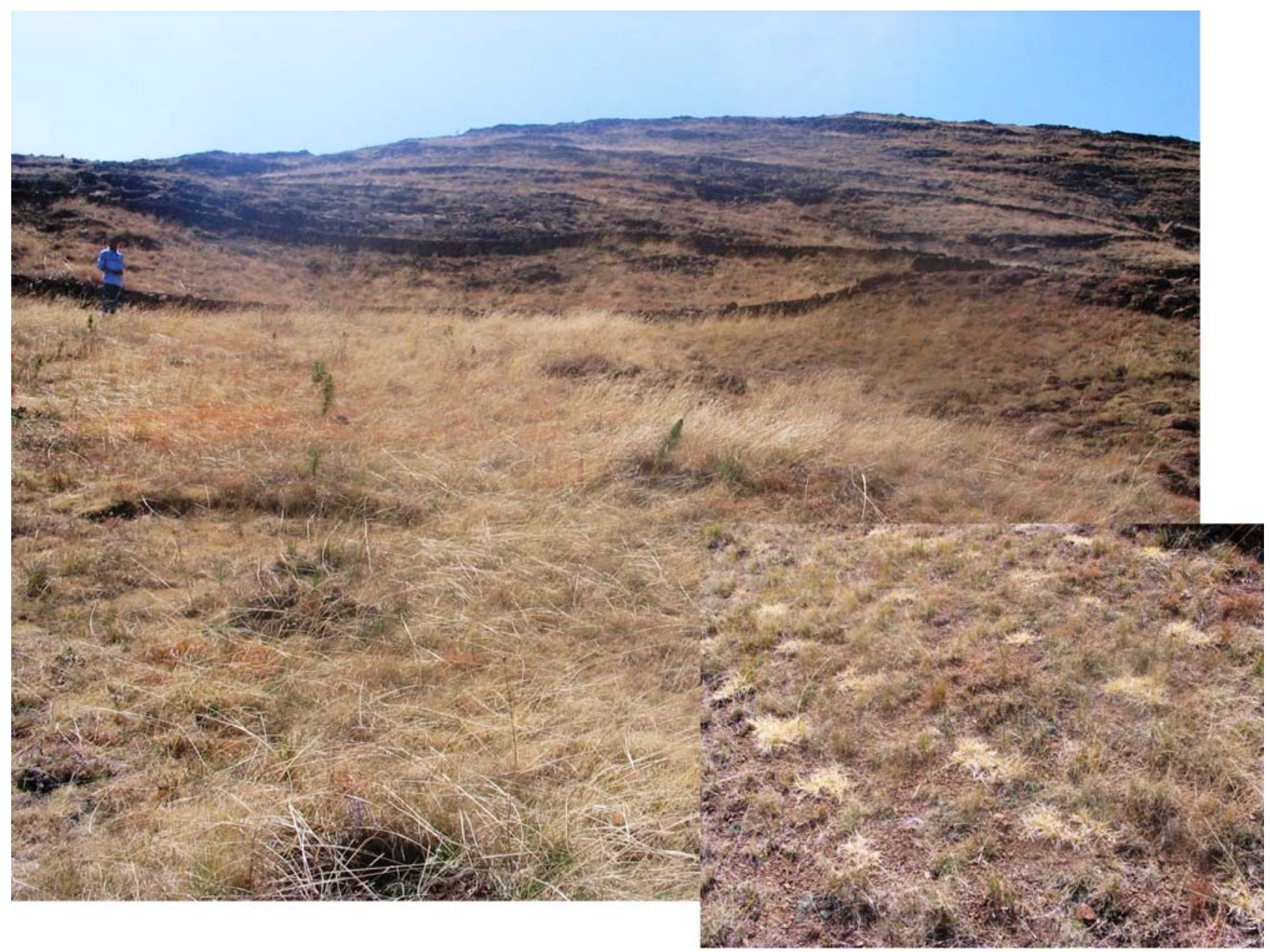

Figure 13: Left picture: Stone contours; right picture planting of grass.

In the village of Ha-Lepolesa the Ministry of Forestry and Land Reclamation conducted general soil conservation activities, based upon the construction of stone walls to tackle donga erosion and afforestation of rangelands. 
Stone walls help to reduce the current in dongas during intense rain incidents. They also trap silt so that in perfect conditions a donga disappears. The distance between the stone walls depends on the steepness of the slope. In general each pinnacle should be at the same height as the root of the next wall. Stone walls can either be constructed from big stone, like a dry stone wall, or with gabions, which are filled with smaller stones. Furthermore, in some cases fortification with concrete is advisable. Due to personal interest the author visited various sites in Lesotho, where donga reclamation has been undertaken. The construction with big stones characterising the simplest form has it main advantages in the local availability of material. In some very big dongas they can be washed away. Gabions in contrast need to be purchased, but allow the use of smaller stones; hence the work load is less. Additionally, they seem to be less prone to strong currents. Concrete offering a strong resistance to water is expensive to purchase and requires knowledge during the erection. Another disadvantage, is that they are not as expandable in the case that the donga bypassed the structure. If a donga bares water, dongas can be seeded with reed and Kikuyu grass. This can be used as fodder crop or for fetching roofs. If the donga-bed is dry, trees can be planted, allowing people to gain wood.

An important attribute of all construction is that they need to be maintained. If silt traps behind the construction, the wall needs to be heightened consistently. It also needs some general surveillance to prevent the water from bypassing.

In the case of Ha-Lepolesa the construction itself was conducted satisfyingly, but due to the amount of silt trapped, they already need to be expended. Since the construction is very young, the author viewed the overall prospect critically, because nobody seems to feel responsible for the maintenance. 


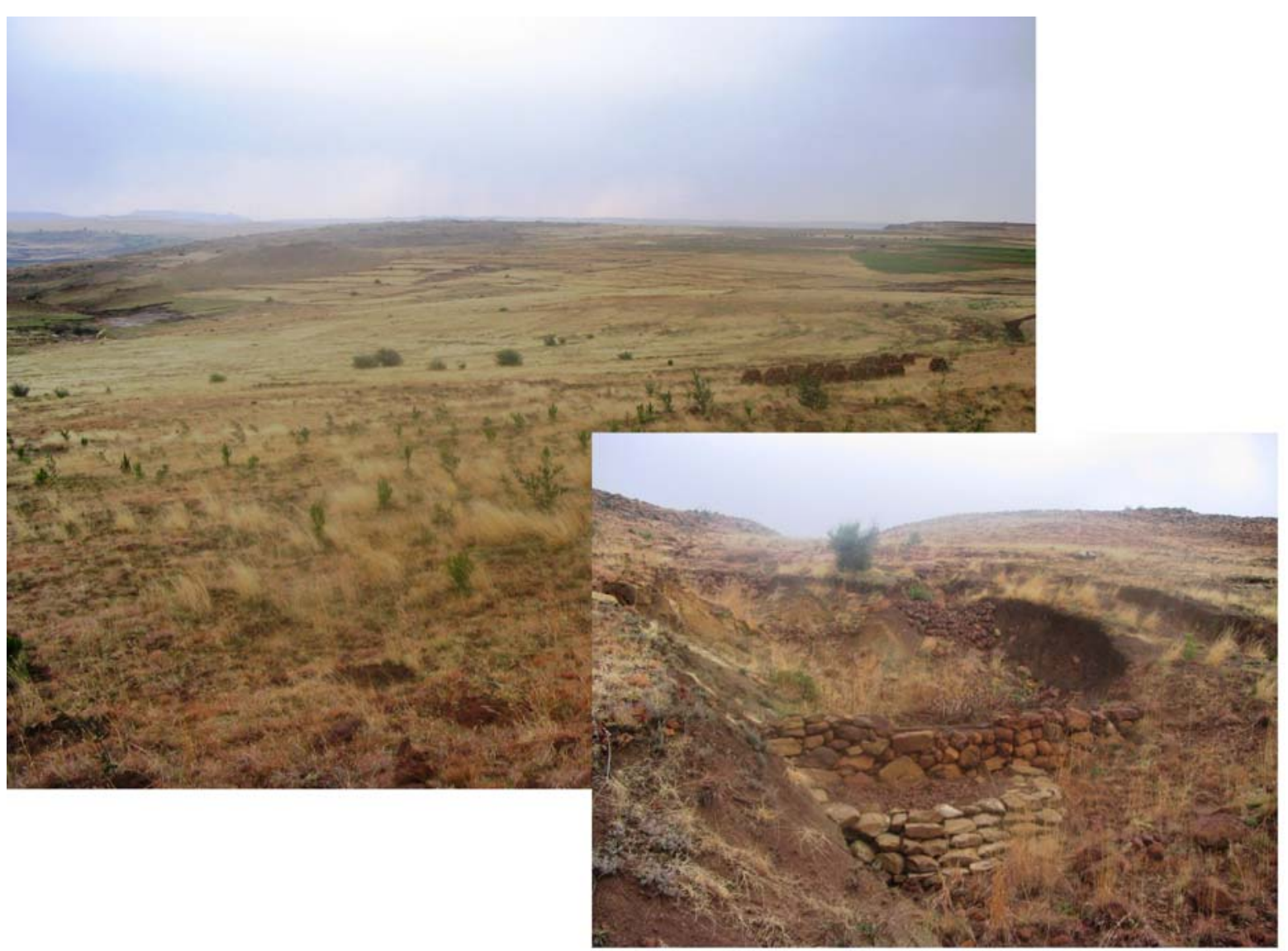

Figure 14: Afforestation and donga reclamation.

The trees however were in a good shape, despite the ones that were planted in a waterlogging area. There were no signs of grazing whatsoever, that means that the area works well in terms of animal grazing.

\subsubsection{The Sampling}

The sampling was done on the $14^{\text {th }}$ and 15th September 2006 near Ha-Ramosoeu in the area of Matelile and in the village of Ha-Lepolesa near Mafeteng (comp. Fig. 15). To gain a comprehensive picture of the relations the responsible members of staff in the district offices of the Ministry of Agriculture and of the Ministry of Forestry and Land Reclamation. On a community level besides the participating and the non participating, interviews were conducted with the chief, the community councillor and the agricultural assistant. 


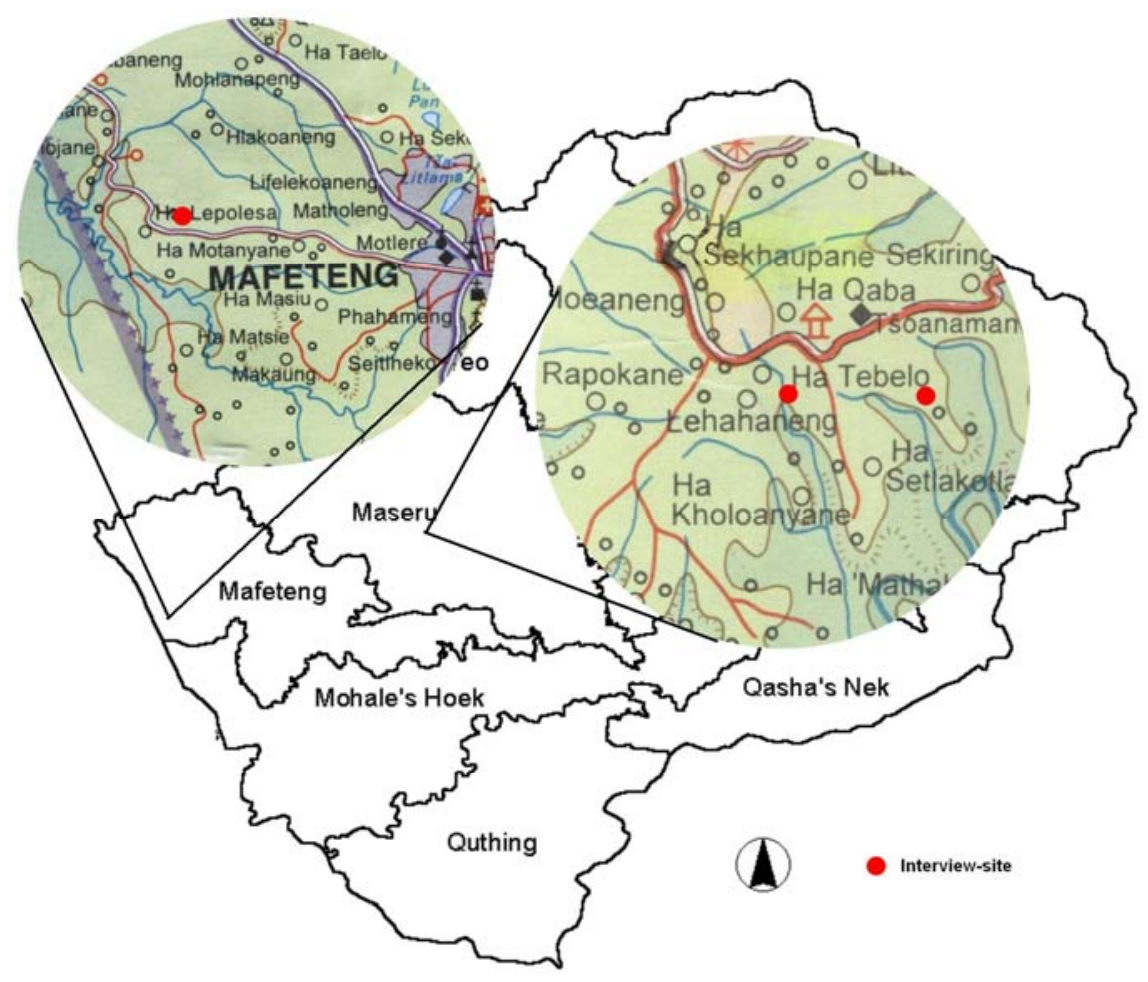

Figure 15: SANReMP interviews.

\subsubsection{Villagers`Statements.}

The people who were involved with the rehabilitation of the pasture areas, mainly got involved because of the provision of money or food for work. The approaching was done by the ministries through the calling of gatherings. However, statements done by the extension workers let one conclude, that they already had decided, what type of action was going to be done, before they actually visited the communities. This is underpinned by the SANReMP officer in Mafeteng, who said, that minimum requirements of how to conduct a Community Action Plan (including tools of rural participatory appraisal) were not met.

- The Ministry of Agriculture and Forestry just came to the community; I think that it was already in their plan to come to this village.

- The chief with the councillor and the supervisor called a public gathering.

- In the beginning we were paid with cash (M733.80) and later we were paid with maize meal.

In the case of the community garden, people in the village started the process. This might be due to the fact, that in the area of Matelile are quite a few successful community gardens under support of different donors. 
- From the very first, we came together as a community and talked about it and made plans so that we can get this garden, and then we went to the chief and she is the one who helped us.

- SANReMP was the organization that helped with a portion of the money and they also paid for the fence.

However, responses from the extension staff let the author suggest, that the decision of constructing a tank and erecting the enormous fence was based upon the decision of the employees of the ministries.

The interesting fact is that in general participators in soil conservation activities could not state advantages. Compared to other projects people were indifferent about this topic (i.e. dam) the activities of SANReMP are completed. The following statements were either done by the chief's son, or an old man not participating in the project.

- Grass will grow and we will use it for roofing and it will stop soil erosion.

- It plays a great role in protecting other people's fields from the erosion.

- We will use the trees for sale and get some money and use the trees for funerals.

As already written, the constructions were built in poor quality. This is no wonder, since people not knowing the advantages could hardly have grasped how the technique works. The agricultural assistant of Ha-Ramosoeu summed up:

- I think that the training they get is not enough for them to learn the importance, so that they can continue by themselves. It is just enough for them to do the job.

The community garden in contrast enables people to state very distinct advantages. People, who were involved with the community garden, showed some general excitement about their project. This exemplifies how different people's feelings of ownership can be. In case of the garden, people have obviously invested a lot of manual labour to achieve the garden, whereas in case of the rehabilitation of rangeland the incentives were the prime reason to start. This directly resulted in how responsible they feel for their projects.

- We are able to eat and support our families. Even though it is in the early stages we see that we are able to feed our families. Even to sell some of the produce. I said earlier it is in the early stages but we are able to sell something. This was the main reason for starting the garden, but only a few people know about it. We want to be able to buy seeds for 
ourselves in the future.

- There were a lot of trees in this place where the garden is now, we worked very hard to get them out so we can have this land.

- We did not get paid for the work but we did pay for the water tank up there. It cost M2500.00, but the people who gave us assistance said they would pay M2000.00, and we would then be expected to come up with M500.00 for the rest of the payment of the water tank. So as a community we pooled ourselves together and came up with the M500.00.

Again, statements regarding possible disadvantages, lead one to the conclusion, that people working on the rangelands do not identify with the project. They either said that they are not benefiting because fields are not next to the donga. This raises the question, why beyond moneymaking then they are participating. Or they responded, that they hope, that their donga will be the next. They refuse to do the job on their own, despite being the prime beneficiary.

- My fields are not next to the reclaimed donga.

- Maybe when the community has finished the work on the other dongas they will go to the site of my fields and start work there.

An old man, not participating due to his age, pointed out quite correctly:

- This is supposed to be done by the community voluntarily.

People always want to be paid and even though the developments are for themselves.

Similar to other villages, the councillor is postulating the need of food for work

- I think that we need to provide them with something to eat when they are working.

In this case, however, the councillor said, that it would be impolite to ask for work and at the same time not to offer anything to eat. The hospitality to offer food and drinks is deeply rooted in Basotho culture. RAMONOT'SI (2006) said, that traditionally drinks (e.g. beer) had been served during communal working parties. In order to get as many people participating as possible, one needs to make a fire (in order to get attention and people believe, that one is brewing beer) and during the working gathering put a barrel of water into the corner -everybody will assume it is beer and work hard as possible in anticipation of the big barrel. The author does not claim to serve beer (given the obvious misuse of alcohol seen everywhere in daily life in Lesotho the opposite is the case), but a catering during such activities as rangeland rehabilitation is certainly worth a trial. 


\subsubsection{Excursus: Agricultural Extension}

Due to the fact that the condition of the extension services is a essential factor for all governmental activities in the natural resource sector and influences even non governmental projects (comp. the chapter of $\mathrm{CA}$ ) the author decided to conduct a small analysis on these. Therefore, six agricultural assistants were questioned about their work, about problems and constraints they faced as well as their satisfaction.

An essential part of Lesotho Poverty Reduction Strategy Programme were structural reforms in the agriculture sector. These were undertaken under the support of the Agricultural Policy and Capacity Building Project (APCBP), World Bank project, cofunded by DFID and GTZ. As a result the project led to a restructuring of ministries. As an example, the Ministry of Forestry and Land Reclamation evolved during this process. Additionally, the extension services were strengthened.

In spite of the joint effort through the APCBP the personnel of the extension services face several constraints lowering their output.

As already written in the chapter of CA the linkage between headquarters and extension is low.

- Furthermore, we don't have an office and communication with the headquarters is a constraint too.

This might result in adoption of new techniques in a very slow rate. The agricultural officer not equipped with facilities, such as agricultural resource centres complains about the lack of buildings and resources in general.

- I have no office and I have to train them in my hut. They cannot concentrate with all the noises around.

Vehicles or transport in general are a big issue.

- I have to travel a lot. There are no cars, so we have to walk to the villagers. This can be up to 20-25 km on foot to do our job.

- Transport is a very big problem. We got a car through SANReMP, but usually the headquarter occupies it.

- The motorbike is broken.

Cars are almost not available for the extension workers. To equip all of them would be too big a burden for Lesotho. Sometimes there are quads, but the ones seen by the author were all broken. 
Another alternative are motorbikes, but according to DECURTINS (2006) this used to be a big problem, since there were some incidents of alcohol misuse. No transport is not an option, since this would mean that just easily accessible villages are in favour of agricultural consultancy. Another alternative which needs to be explored, particularly for agricultural assistants based in the mountains, might be horses.

Another problem is that staff generally have no roots in the area, where it is based, because they are rotated throughout Lesotho.

- I hate this place, I need more than 2 days to meet my child near Leribe.

- I don't know how I ended up here, because I had not applied for a position in QN. Home is very far and that's an issue for me.

Maybe, a preference in the recruitment assessment of staff from the same region would reduce this problem and thus increase staff morale. However, this is a trade off, since this would increase the danger of favouritism (DECURTINS, 2006).

According to official SANReMP documents, extension staff often considered a field posting as a penalty. They would then immediately apply back to Maseru. Similar answers were stated by AA. in Qacha's Nek. They define their job just as a period in their career. This reflects quite well a general problem of Lesotho. Since wages in RSA are considerably higher (twice as much) Lesotho is facing a serious brain drain of graduated workers.

I am expecting to leave this place next year. I want to go to South Africa or Australia.

Generally, the extension workers approached by the author were very young. This results in reduced continuity of work and together with the above mentioned low moral, it hampers the adoption of farming techniques by Basotho habitants.

- Maybe they don't trust the AAs. Sometimes they say the technique brought by us differs from the opinion specialists had before. The say that our techniques harm them and that they don't listen to us.

- Maybe I am not self confident enough. This is my first job.

- They are not open to new ideas like crop rotation or improved varieties.

- Some of them want to think for themselves.

To sum up: Due to overall constraints governmental extension is, albeit having excellent staff/beneficiary ratio, weak and inadequate. Possible resolution could be a stronger involvement of 
NGOs or a higher supervision by the newly elected local authorities, as proposed in the process of decentralisation.

\subsection{The Maluti Drakensberg Transfrontier Project (MDTF)}

Given Lesotho's natural beauty, besides the vast biodiversity and its inherent value for mankind, the author decided to include a rather uncommon natural resource based project in his study. The establishment of transboundary natural reserves and the harnessing of the enormous tourist potential for the benefit of Lesotho's dwellers is the aim of the following project.

\subsubsection{The Project}

The area of the Maloti-Drakensberg transfrontier project features on the exceptional landscape, high biological diversity and a high rate of endemism. Since the dwellers of the highlands are the most vulnerable in Lesotho it also encompasses some of the poorest people in southern Africa. Fig. 16 shows the scope of the project area.

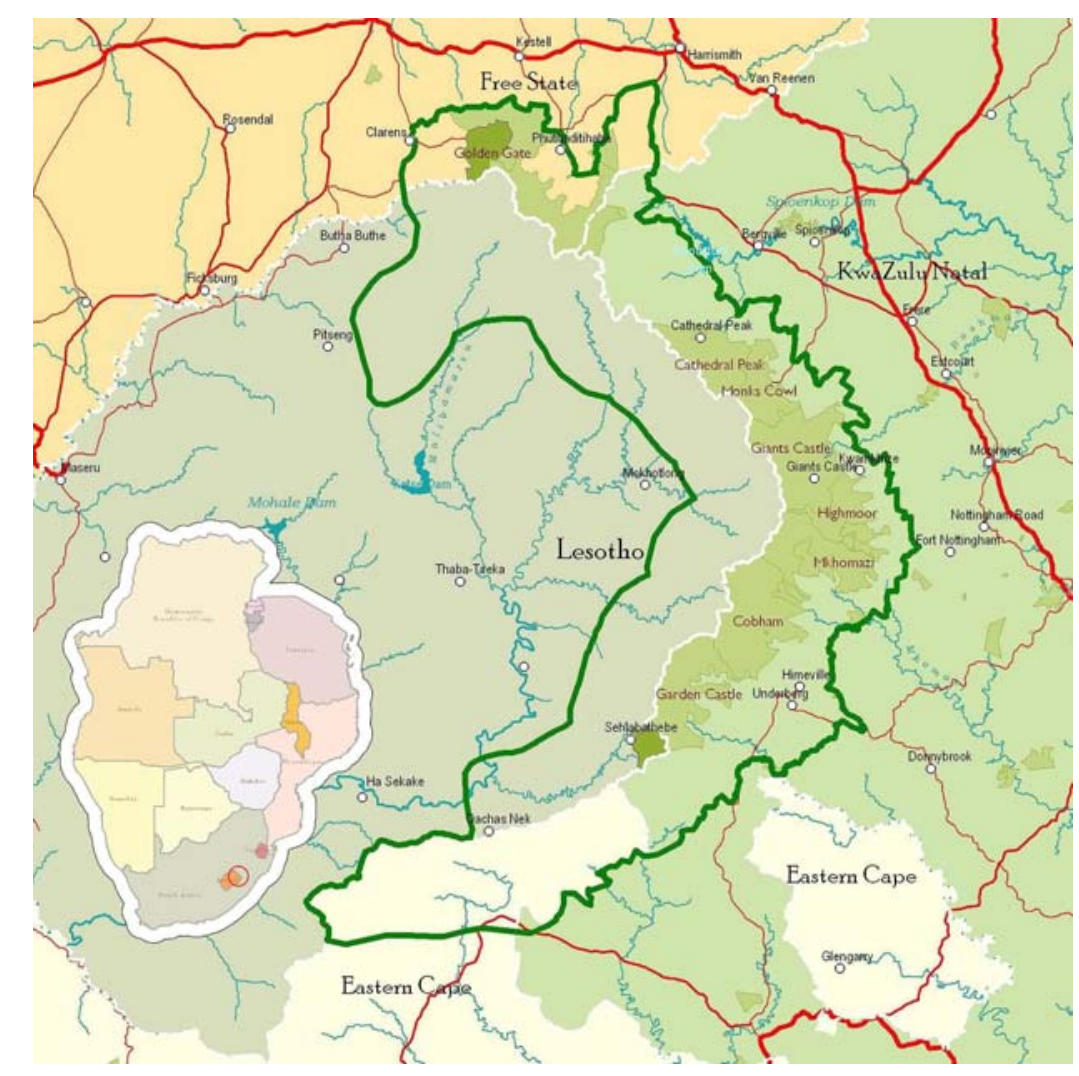

Figure 16: Scope of the project. 
The MDTF is funded by the World Bank and has a financial grounding of 8.42 mill. US\$. It is based on the following components. The implementation period is going to last from 2003 until 2007 (WORLD BANK, 2001).

1. Project management and transfrontier cooperation: this deals with the transboundary collaboration and management issues.

2. Conservation planning: this includes gathering of data and proper zoning to secure species and habitats.

3. Protected area planning: this emphasises the planning regarding zoning, infrastructure and business facilitation of protected and proposed protected areas.

4. Conservation management in existing protection areas.

5. Conservation management outside existing protection areas: both components contain management in terms of alien species regulation, environmental education, staffing with ecologists and the launching of community conservation forums; virtually all aspects required to conserve the area.

6. Community involvement: this component represent a major focus of MDTP. In order to equip people with the abilities challenged by the jobs and opportunities of MDTP, local inhabitants are educated and trained in conservation measures as well as in skills required for cultural and nature based tourism (pony trekking, craft production etc.)

7. Nature based tourism development: albeit the private sector will make most interventions, governmental guidance is needed to steer the private efforts.

8. Institutional development: Lesotho lacks of an effective nature conservation management. This requires the drafting of appropriate legislation.

Concerning this survey activities falling under component six were assessed. Villagers were trained and considered for jobs in the national park of Sehlabathe (e.g. controlled burning of grass, watching for trespassers) as well as income generating activities such as clay pod and handicraft production (weaving of traditional Basotho hat). Fig. 17 gives an idea of the natural beauty of the area. 


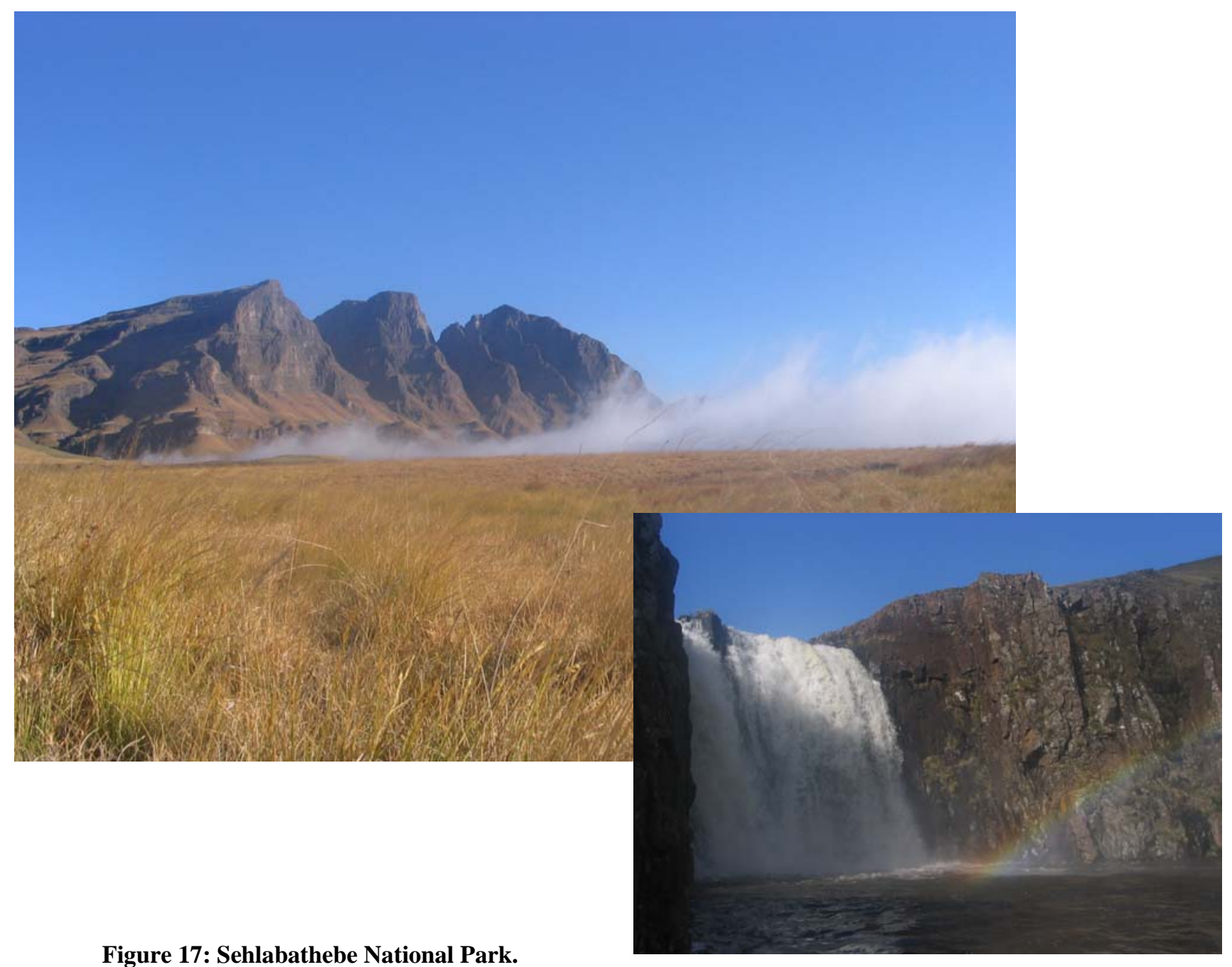

Figure 17: Sehlabathebe National Park.

\subsubsection{The Sampling}

The sampling was done on the $23^{\text {rd }}$ and $24^{\text {th }}$ of September in the area of Sehlabathebe. Like the other projects, participators as well as non-participators were questioned. The author visited the chief and the community councillor of the area, besides two agricultural assistant from the nearby resource centre. Preliminary interviews were held with Mr. Mokuku, the project coordinator in Lesotho and the staff from the MDTP branch in Qacha's Nek. Fig. 18 shows the location where interviews with villagers have been carried out. 


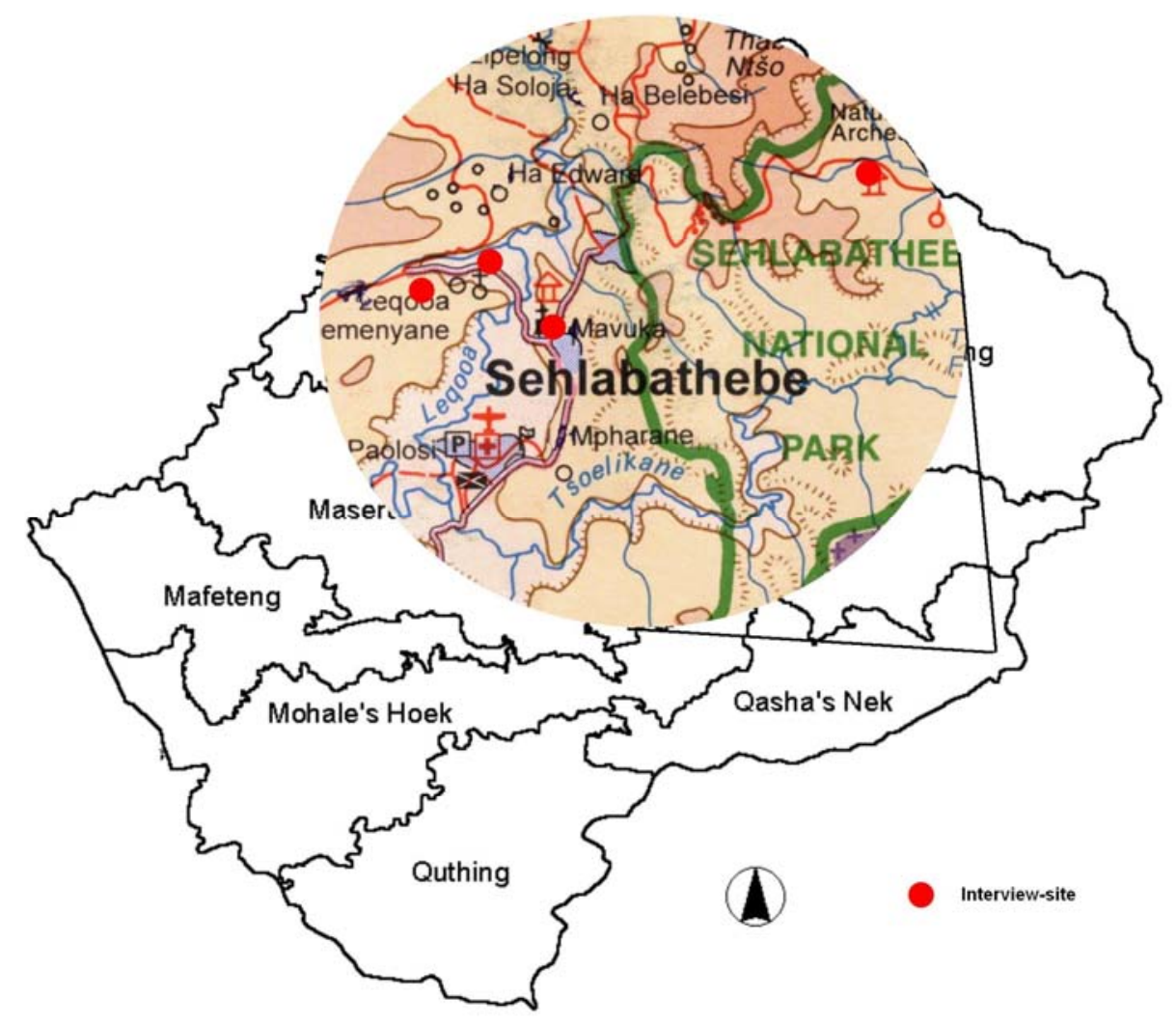

Figure 18: Interview-sites near Sehlabathebe

\subsubsection{Prospects on the Project}

Generally, the perception by local dwellers on the park is very good. People see the park, albeit it restricts them in their life, as a big opportunity. The establishing of the park resulted in less grazing areas for the herders of Sehlebathebe, which was followed by big disputes after revealing the park. The disputes arose basically around the top down decision of taking people their pasture land away (IVY AND TURNER, 1996). However, people's perception has changed. All interviewees stated to be happy because of the presence of the park. This is mainly due to the fact that people are either provided with jobs, or due to the fact that they gained more opportunities to get incomes, such as handicraft production.

- I am very happy that we have the park. Our children will have job opportunities, our horses are going to be hired and the money for renting the huts will go directly to us. -

Furthermore, we are involved in construction work in the park.

- Now we are able to sell some handicrafts like grass hats or clay pots.

- I love to form clay pots, I cannot deal with grass, because I get a rash

- I got a lot of orders for my clay pots 
This even let people think of extending the Park to attract more tourists.

- They should increase its size. They should move the boundaries closer to the mountains, because the caves there provide a great habitat for birds.

- The benefit would be more tourists. I want them to find something unique for Lesotho only.

People were employed in road construction, in controlled burning of rangelands as well as activities such as stone cutting. However since just one person per village per time is allowed to get a job in order to distribute them equally among the villages, some stated that this would not be enough.

- It is a good thing. It provides job opportunities, but 1 person per village is not enough.

Many people in the villages need jobs and that is just not right. We need money.

Another problem villagers frequently stated, was that the park has no clear boundaries and if one is trespassing on them with their cattle, they have to pay a fine. This punishment is done by the chief.

- I ensure that the rangelands are protected and I bring criminals to justice. For instance, cows on rangelands will be charged with $\mathrm{R} 4$, the payment includes the capture costs. The payment differs for different animals. There is also a higher rate if one is coming from another village.

One villager said, that while he had had a job in the rangelands, he caught a trespassing herder with his cattle. However, after approaching the house of the culprit, the author noticed that the man belonged to the Xhosa minority of Lesotho. Communication for them is very hard and they are often marginalised in the village communities. Maybe, that is the reason why he was sued. Unfortunately, the man was not at home and the woman was indifferent in her opinion of the park.

- I do not know anything; just the father and children knows something about the park.

It gives a good example that community based projects might at some stages not be beneficial for all people, - for example for outsiders within the villages.

The grazing schemes are established with the help of grazing associations. Such organisations, like other community conservation committees, help to enhance the acceptance of the project. In the park itself therefore are no problems with for example the burning of grazing areas. But outside the park, where the extensions workers are mainly involved, it is still a problem. However, through the affect of MDTP the extension workers admit, that it is the first year, where herders have 
interrupted the circle of burning.

There are also some problems between the MDTP and the extension services of the ministries. Since MDTP people use more incentives, more farmers are attending their meetings. The AA were complaining, that the staff of MDTP do not inform about their appointments and sometimes the AA thus end up with no attendees.

\subsection{Food for Work promoted by World Food Programme and C-Safe}

\subsubsection{The Organisations involved: WFP and C-Safe}

The World Food Programme of the UN began its interventions in Lesotho in 1964. In a response to the drought of the years 2001-2003 and its implicated famine, WFP increased its effort on serving food to the poor in Lesotho (VAILLANT, 2003). At present the activities of WFP builds upon (WORLD FoOd PROGRAMME, 2007):

Food relief for the most vulnerable: Benefiting are household with a member living with HIVIAIDS, orphans and other vulnerable children, pregnant and nursing mothers, underweight children under the age of five and the elderly (KREFT, 2006).

School Feeding: WFP supports schools to provide free meals a day in order to encourage children to stay in school.

Food for Work : To build up productive assets, people are distributed food for working on community projects. WFP's Conservation Agriculture FFW programme gives subsistence farmers training and experience in CA farming methods.

Health Clinic Food Distribution: WFP delivers food relief to patients at health centres, as well as to pregnant and nursing women and malnourished children.

Lesotho's cereal gap is estimated to be 230,000 tonnes. According to their figures, WFP is about to provide 115000 people with food rations (WORLD FOOD PROGRAMME, 2007).

C-Safe is a consortium of four big international NGOs, namely WorldVision, CARE International, Catholic Relief Services and USAID to combine efforts in food relief in southern Africa.

The concept is as followed: Immediate food needs of vulnerable communities are served within a 
relief programme, whereas regular donations enable vulnerable communities in building productive livelihood assets. This includes the provision of Likoti (Conservation Agriculture), building of compost heaps and generally a provision of inputs such as seeds (FAO, unpubl.).

Due to shortages in milly meal, food distribution, apart from the one allocated to the neediest, was disrupted during the time of this research.

\subsubsection{The promoted Technologies}

WFP promoted in collaboration with either the Ministry of Agriculture or the Ministry of Forestry and Land reclamation various techniques in the natural resource sector. In the case of the examined community, WFP supported the construction of two dams. Water, being scarce in all countries surrounding, is one of Lesotho's major advantages (HORTA, 1995). Albeit having a sufficient amount of water in terms of quantity, the uneven distribution of rainfall makes it highly desirable to store the water for the dry season. This water then, can be used for irrigation or for watering the cattle. VAILLANT (2003) showed, that roof water harvesting is a promising low cost technology for Lesotho. Summing up, it needs to be concluded, that at present the water resources are not harnessed according to its potential.

The technique usually is simple. It includes an earthen dam, with a sealing of clay. Alternatively concrete or plastic can be used. The construction then is enforced with grass-sods. Because, construction material needs to be available, construction-sites are limited to sources of clay soils. 


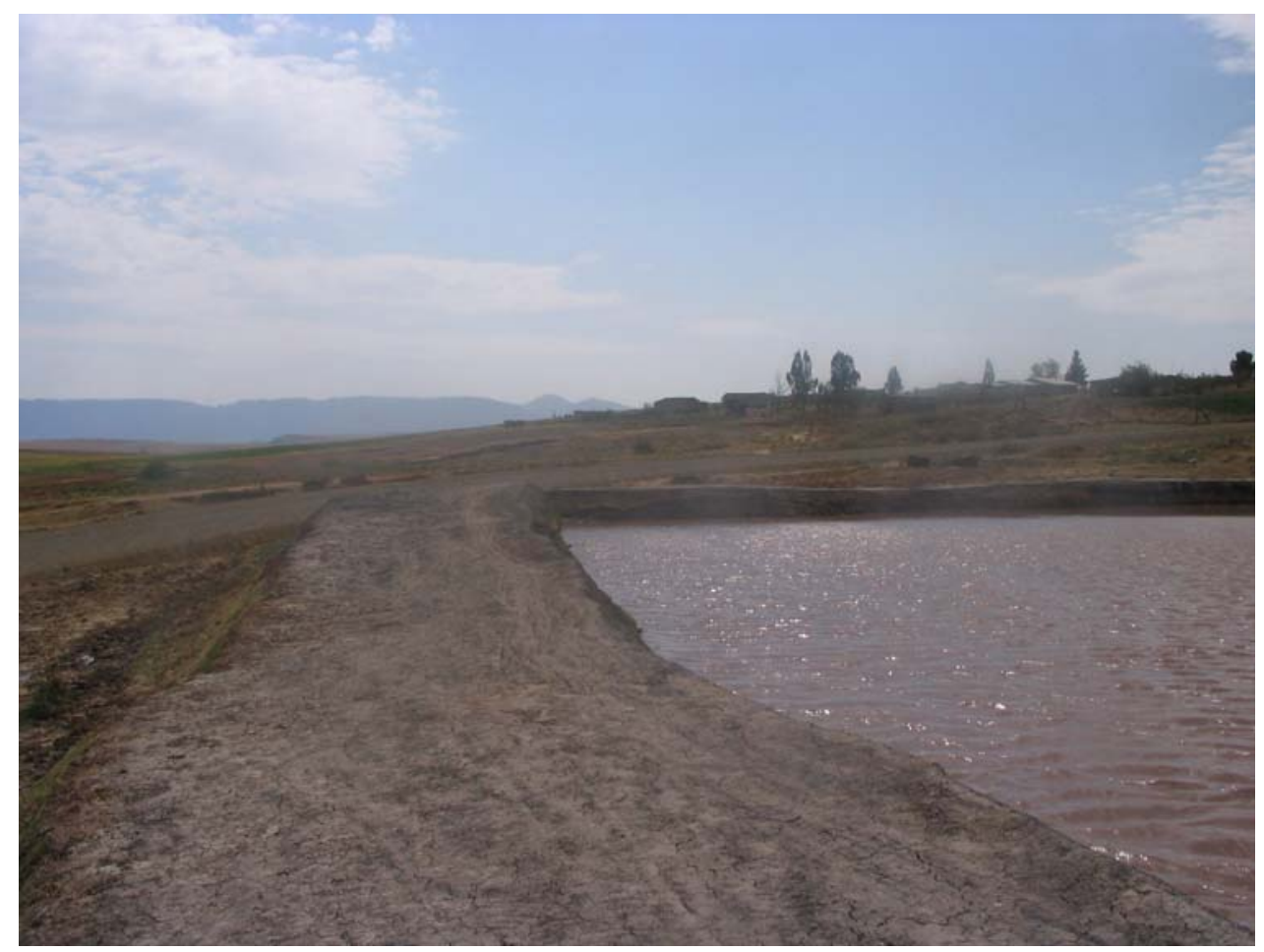

Figure 19: Recently constucted dam

The other technique in the case of C-Safe is the promotion of so called compost heaps and keyhole gardening. Keyhole gardens are based on a technique invented and designed by CARE Lesotho. The technique comprises a dry-stone wall holding different layers of cow-dung, ash, plant residues such as straw and earth. Watering is done with waste washing water, supplying the plants with phosphorous. Major advantage besides the relatively simple design, is that keyhole garden allows to work on waist-height, hence it is manageable for sick and disabled people to produce vegetables. Compost pits also allow the recycling of plant residues and biodegradable waste in general to produce plants for own consumption (C-SAFE, 2005). 


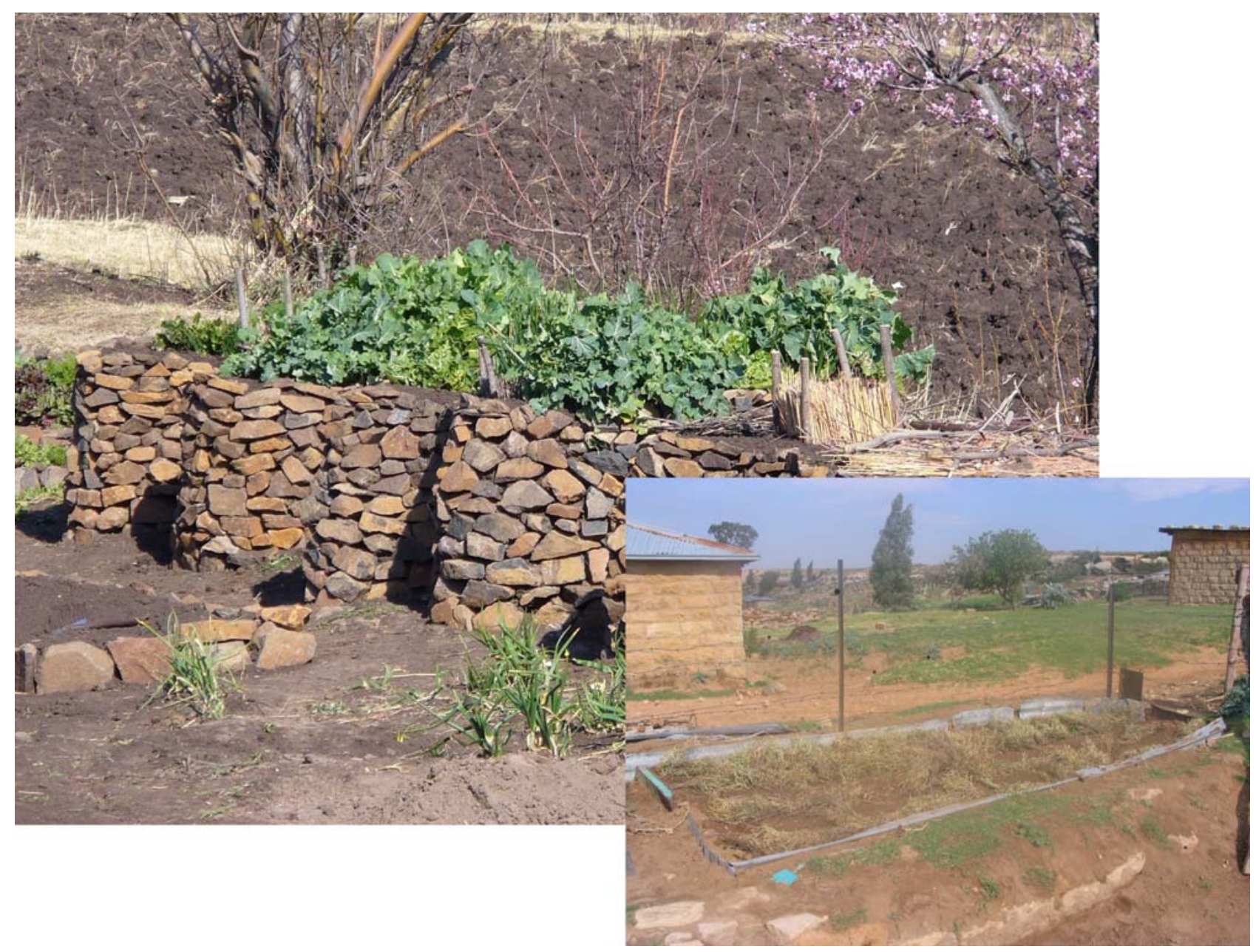

Figure 20: Keyhole Gardens and Compost pits

\subsubsection{The Sampling}

The samplings of the WFP activity were done on the $13^{\text {th }}$ of September, 2006. Six participants or non-participants of a food for work project in the area of Mokoabating were approached and questioned, as well as the chief and the councillor. Together with interviews of the WFP, Head of Unit in Lesotho, this allows us to draw a picture of implications of this food activity.

In case of C-Safe, the author visited the village of Ha-Popolosi on $16^{\text {th }}$ of September. Due to the fact that the villagers were undertaking a joint feast for celebrating the harvest, it was not possible to conduct individual interviews. The author decided to do a group interview with 6 villagers and individual interviews with the chief and his deputy. Since a vast crowd of project participants were surrounding the author at all times, the author abstained from conducting interviews with nonparticipants to avoid a dispute amongst them.

Despite being not far away from the big road between Mafeteng and Mohale's Hoek in absolute measures, the village was entirely isolated by two rivers and big dongas and showed the most 
drastic indices for poverty the author has encountered on his survey. Beginning with the chief, usually the wealthiest man in the community, all villagers were showing signs of destitution. Apart from the relief work, undertaken from C-Safe, there are no other NGO activities or action in general. This exemplifies quite magnificently, how activities are minimised, if the transport infrastructure becomes bad.

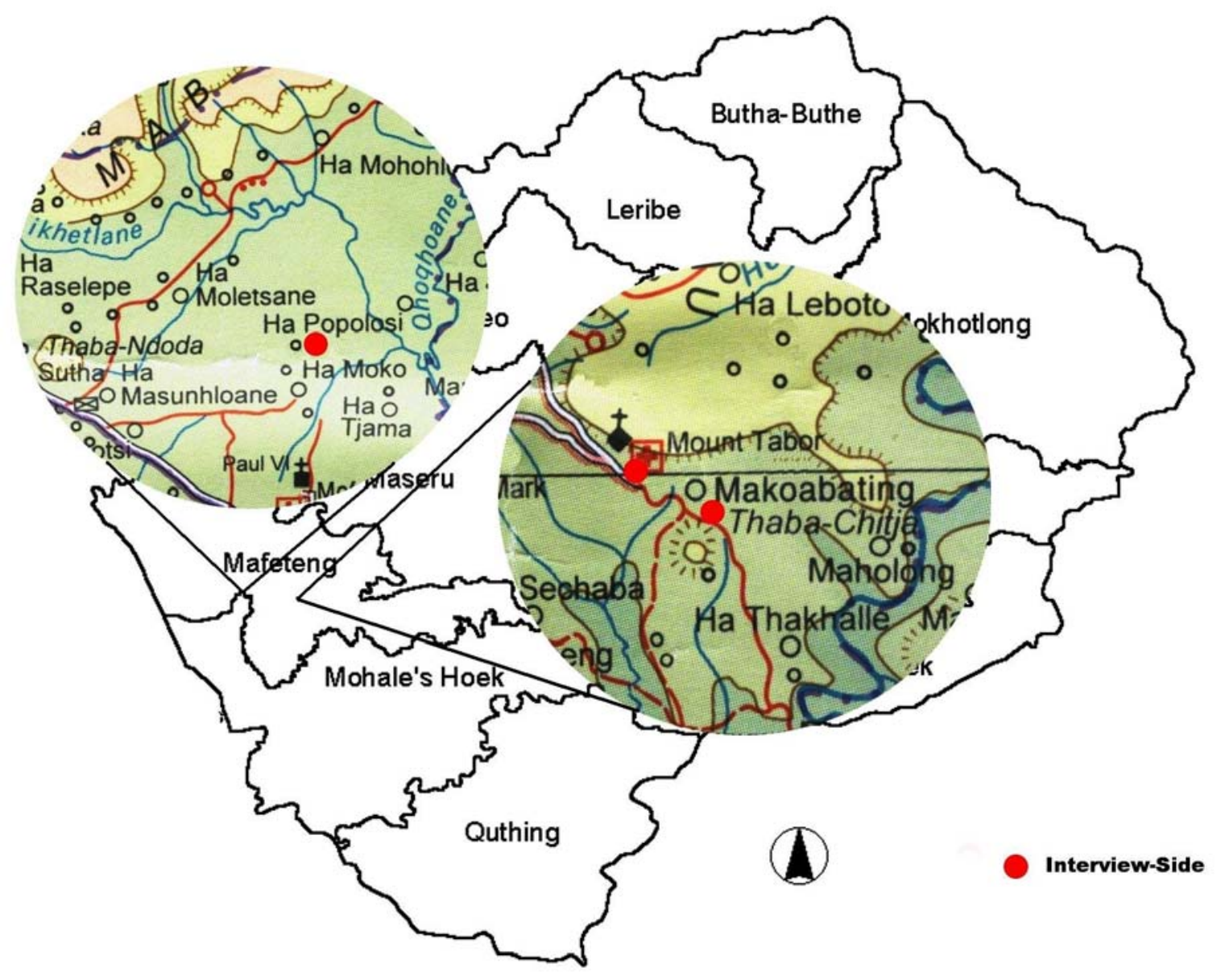

Figure 21: Interviews SANReMP

\subsubsection{The Construction of the Dam}

According to ABDI (2006) the Food for Work schemes are implemented with the help of the local authorities. This is reflected in the quotations by the interviewees:

- The councillor, 'Mahlompho Manyatsa, came up with the idea of building a dam.

- I saw that it could bring development in the community through the creation of jobs.

- Working on the dam gave us something to do and it created jobs for the community. 
The help of WFP apparently changed the people's perception on the councillor. Every participant was stating, that they are satisfied by the work done by the councillor.

- They can bring other services like banks closer to the community.

- They provide us with jobs. For example the dam, filling of the dongas and the fixing of the roads.

This might be of interest for GTZ. To enhance the acceptance of local authorities direct incentives need to be channelled through them. However, this needs to be viewed sceptically as well. If aid or resources are allocated via the chiefs, they might favour people next to them. If resources on the other hand are allocated via community councils, they can be used to buy the villagers`votes. One needs to recall the statement of the $\mathrm{CC}$ in Tebellong, who made a second term in office depending on whether there would be further going WFP activities or not. The author therefore strongly suggests further assessing of the impact of food aid in recently democratised systems.

Since the dam is not operating yet, there were few statements about the advantages of the dam:

- It will make it easier to water the livestock and to irrigate the fields.

Surprisingly, a recent withdrawal of WFP support has not resulted in an abandoning of the project. People are working to a lesser extent, but are still meeting. This might be an achievement by the community councillor and the chief. According to their statements, they each reported independently working very well together in mobilising the community. As already mentioned in the chapter of general condition, this is not necessarily the average situation in Lesotho.

- Despite, WFP stopped coming, we go to work, even though only 2 days every week, initially it was 5 days a week.

People not participating were also questioned about their opinion and faced problems:

- I could not contribute, I am sick and my daughter is not in good health, so I take care of her and her child.

- My fields are not anywhere near the dam.

Remarkably, personal contribution seems not entirely dependent on food as an incentive, but on own prospects linked to the dam.

On a second day the villagers of Ha Popolusi were questioned, why they have started to build keyhole gardens or compost pits. 
- We saw this at Ha-Pikoane.

- We saw that it was very successful.

- In the future it will give us healthy food.

- They [World Vision] told us that there was no more food; they advised us to use the pits in the mean time. They said they would give us food when the food was available.

- They told us that we should not just sit and wait for the food.

Keyhole gardening seems to be a successful technique with a promising diffusion of the technique on its own. The statements above were spoken out so enthusiastically, that one can easily conceive the people's honesty about their opinion. Interestingly, this was related to the keyhole garden not compost pits. Since keyhole gardens look very appealing, one can grasp the villagers' appreciation.

Encountered problems were all related to the seeds. Apparently, WorldVision (which is a part of the C-safe consortium, of course they have to introduce themselves to the villagers as their home organisation) told the villagers, that food aid would stop and to get seeds, each of them would have to construct the gardens. Then, they would get seeds for free to start the growing. However, since some deny to start, or are delayed, people are worried, that they would not get any seeds.

- We have not been given any seeds.

- We don't have any money to buy the seeds.

- Only people who have the means to get the seeds will get food, the rest will suffer

- We don't work together, it would be desired that we work together in order to be equipped with seeds.

In both cases the impact by food aid on villagers behaviour was positive. Especially, in the case of the dam, the food aid inducted the engagement of the people. How long it will sustain in the long run cannot be predicted, but it has clearly increased the work together as a community. However, it cannot be excluded, that this positive example was just the achievement of the concerted effort by local authorities. In the case of the village Ha Populosi the positive impression the author gained about potential long term sustainability of keyhole gardens might be due to the complementary of food aid and technique. Since food aid usually consists of milly meal, plant oil and possibly vitamin enrichment, there might still be the desire to get additional vegetables to vary the diet.

\subsubsection{Discussion: the Impact of Food Aid on Projects}

The current annual FAO report works out the ambivalence of food aid. Despite being negligible in 
terms of absolute percentage of overall cereal production, food aid is a major part of international assistance. In Lesotho it helps to close the cereal gap, estimated to be over two third of overall consumption. MAKENETE (1998) sums up that, due to poor agricultural yields, even in the long run Lesotho will be food dependent.

Nobody denies the fact, that food aid is often the only thing standing between a starving child and death. It might be the only way to force school attendance and therefore break the vicious circle of inheriting poverty from generation to generation. And as it seems to be in the two villages, food aid can improve people's participation and action.

However, critical voices claim that food aid to increases dependency, fosters laziness, undermines local agriculture and to disturb local markets and prices. Regarding Lesotho, nearly all projects stated problems originating from food aid:

Serumula: Farmers insist to get incentives for there work. Serumula complains lack of voluntarism.

Conservation Agriculture: $\quad$ Farmers stated that "food aid is like cutting our hands".

SANReMP: Extensions workers criticise "money and incentive expectations" by the users. Again, they miss the will to do the work voluntarily. Another agricultural assistant opined:

Another problem is food aid. People don't do anything for themselves if there is food aid. They don't wake up early and work because of the food aid. They even abandon their agriculture. They say they will have food aid. They even know the exact dates. They will tell you that by march next year they will have it.

NTSOAKI, Agnes Lekoa, AA

Again, a farmer interviewed in a trial set-up for this assessment believed, that people are not reclaiming there donga, because if one did so, he would be omitted from future Food for Work activities.

Recent literature argues, that there is no dependency on household levels, since food aid is irregular hence not a reliable source of income. This is underpinned by the case of the second village, where villagers' initial motivation was inducted by the absence of WorldVision. That means 
the irregularity facilitates the engagement. Empirical studies suggest, that households neither understand how people are targeted nor how the amount of food aid is determined (comp. HARVEY \& LIND, 2005). However, statements by the agricultural assistants, saying that people know exactly where and when to get food aid combined with responses, that people were saying that one needed to have an HIVIAIDS-patient in the family, only for being enrolled in a food relief programme (DECURTINS, 2006) let one suggest, that people had figured out the pattern of food aid very well.

Since even the comprehensive compilation by FAO (2006) concluded that the answer to the questions, whether food aid has predominantly bad site effects, such as dependency issues or eroding of traditional safety nets, are no, maybe and yes, the author prioritises the need for specified research on this topic. However, this study has also shown, that food aid not necessarily means, that people abandon their work and projects and die soon after the withdrawal of resources. Furthermore, it could be proven, that people are generally open for recommendation, of how to sustain on their own. It should be summed up, that food aid does not need to be demonised. However, since not all side-effects are clear it should be the last instrument of choice. Luckily, this seems to be noted by the official site: The Poverty Reduction Strategy recommends "interventions will be necessary. However, interventions clearly need to go beyond food aid" (KINGDOM OF LESOTHO, 2005). 


\section{Outcomes of the Case Studies}

Achievements and factors determining the success of projects as well as failures are gathered in the following chapter according to the dimensions where they belong to. As far as it could be concluded from the case studies, the diffusion-process enriching the socio-cultural dimension is assessed in Tab.1. The mountain perspective contributing to most of the dimensions has been analysed in Tab.2.

\subsection{The Economic Dimension}

A common feature of the projects is the way people are attracted to them. Usually they are attracted by financial improvement rather than any other beneficial change inducted by the technique. Machobane Farming users started predominantly because of the prospect to reduce one's fertiliser costs. CA-farmers started due to the fact, that they could not afford the high costs of ploughing anymore. Therefore, a successful project must always aim for immediate paybacks to the users.

According to the RRD approach a prime goal to be targeted is the capacity of the users to cope with risks. Many of the examined projects resulted in a better income situation of beneficiaries, either through higher productivity or higher diversity, for strong followers MFS and CA show overwhelming results: Formally subsistence farmers are enabled to sell surpluses to village markets. These then help farmers to hedge against risks (natural, physical, human etc.) to which they are exposed. Food might be considered for initial phases of projects as well, as happened in the case of CA. Since advantages occur often in the medium or long run, in the beginning such incentives can be used, as long as they are not used on a regular basis. However, because not all side-effects of food aid or a very incentive based approach in general can be estimated, this should be the last choice to encourage people. The author adds, that projects providing people with increased capacities should also mention this along with their stated outcomes.

Besides equipping farmers with a higher ability to cope with stress, projects can also help to reduce the probability of crisis by spreading the risks. This is achieved by an diversification of livelihood strategies. Again projects aiming for natural amelioration should announce this positive side effects. Additionally, some projects reduce specific risks for Lesotho. One big problem is the prevalent stock theft, which represents a big uncertainty for farmers. Zero- or reduced tillage systems make the farmers less dependent on cattle and thus more resistant to the devastating 
consequences of such assaults.

A further problem which has to be taken into account is a fair access to projects and to markets. Since mountain dwellers are handicapped by the remoteness and the inaccessibility of the area, their products are imposed with the high transport costs. Local markets, this has been proved by the study, are usually small. Logically, they can just be fed by remittances of either miners or workers from urban areas or RSA. Often Chinese owning local supermarkets are the only purchaser and have the power to put pressure on the prices. Therefore, a component of creating market opportunities should be part of the projects, as MFS has shown successfully. However, the author got the impression that this part is widely disregarded.

Certainly, the project designers have to consider targeting people primarily, who are in need. Albeit VAILLANT (2004) shows in his work, that a narrowing onto poor people results in lower success of project in Lesotho's back-country, an emphasis on people, who are poor, should be used, -not just because of humanitarian reasons. The examined projects are more or less tailored to the needs of the poor. Many statements by villagers lead to the assumption that land allocation is a big problem and that the increased population pressure results in more landless households. Besides cases where land permissions are inherited young people are predominantly affected. Projects focusing on agriculture, albeit concentrating their efforts on poor farmers, miss these people out, whereas food for work, or generally paid approaches like the erecting of stone contours, are more concentrated on the poor. Keyhole garden and community garden are maybe the most suitable technology for the poorest of the poor, since one does not need any land but benefits personally from their produce and not just from the incentives provided by the project.

The MDTP possibly represents the most elegant way to strengthen the financial capacities of its beneficiaries by enabling them to share one of Lesotho's gems, - the natural beauty. JoDHA (1992) defines this as niche; - goods where mountains have comparative advantages over plains. Unless subsistence is the only thing to aim for, projects visited during this study have proved that the harnessing of niche is not exploited for its full potential (comp. Tab.2). MFS for instance, being a permaculture approach, produces high quality fruits and vegetables in organic quality, but it is not sold as such, despite of relatively close markets.

\subsection{The Socio-cultural Dimension}

As defined by ROGERS (1995) diffusion is fundamentally a social process. Tab.1 shows an overview of specificities of the different technologies from a user perspective. This clearly 
highlights why for example keyhole garden as a technology spread by itself. Relative advantage is given by more or less each technique. There are differences, for instance the stone contours will affect people in the long term and the advantage of the technology is blurry, since it is of an indirect nature. The conclusion to be drawn is that projects need to promote their advantages offensively. Compatibility again is a big issue. The author has not encountered cultural and traditional resentment for most of the techniques. However, for the ones which he did so, the author recommends to include it in the projects approach. For example: CA raises problems, since it creates no fallow land, which then would fall under communal access, livestock owners cannot graze their animals on it. Here additional components need to be added, such as growing foddercrops etc. Another example is the mindset of the necessity to use ploughs, which might originate from religious beliefs. This then has to be corrected by the relevant people (i.e. priests). Stone contours and the associated afforestation are often grazed, since formerly people used all areas as pasture lands. The conclusion then would be to first create proper grazing management before rehabilitating the landsites. Complexity of project hampers the spreading as well. Therefore, easily conceivable measures are required. The structure of contours for example were not grasped by the villagers, because interrelations were either too difficult to understand or inadequately explained. The obvious step towards less complexity is a consideration of illustrating with easy measures how the technologies work.

The performance regarding trialability is strongly dependent on the scope of the projects and how expandable they are. Small, individual projects can be tried out better than big ones. Keyhole gardens for example can be constructed one by one. The construction of a whole dam on the other hand does not allow a preliminary test. Trialability is also less if a strong commitment in initial phases is need to get encouraging results. CA scepticals for instance were conducting tests on their plot. Since CA requires a good weeding during the first time, people, who were not persuaded, did not invest all their efforts and got poor results. However, CA usually stands for a high grade of trialability, because one does not need to change the agronomical system at once.

Observability represents another specificity of technology. Projects that are easy to see and recognize, with obvious effects will spread on a faster rate than the ones with less visual impact. Keyhole gardens were more frequently stated to be promising, than compost pits, which were mainly constructed through the pressure of the project. The difference is obvious. Keyhole gardens are more appealing, they stand in the villages like little strongholds, whereas compost pits are on ground level and less appealing. The latter results in less observability and thus in slower adoption.

A second feature affecting the rate of diffusion are communication channels, -the way of how 
technologies are transmitted to the adopters. The most efficient way is face-to-face communication among the members of the community. For Lesotho it seems to be the case, that communication channels consisting of white or even urban Basothos are less effective. People, in particular from remote areas do not trust strangers easily, as exemplified in the case of MFS. BASSON (2006) has recognized this effect and now implements the technique with local trainers. These help to reduce communication barriers between project staff and the beneficiaries. Since old people are often biased in their views, the author recommends to focus more on the youth. A good idea would be to embrace schools. Pupils then would support the projects ideas at home and in this way accelerate the diffusion.

Time being the third feature determining the rate of adoption needs also to be considered. Since projects are bound to a strict time schedule, they often fail due to a lack of patience. According to DECURTINS (2006) the short-term of projects is a general problem of development work.

The last factor which steers the spreading are social systems. Projects, where cosmopolitan village leader, the so called opinion leaders, could be acquired often have a better adoption. MFS again, was spread through the commitment of Mr Ramoat'si. He then applied the techniques and made them visible to the other villagers. He also promoted it offensively. The needed recommendation would be to identify such people in preliminary studies. The persons then should be approached individually. It is also possible to budget for para-professionals on village level, who fall ideally in the above described category of innovators.

It needs to be added, that for a successful spreading of technologies essential inputs must be available. Maybe it is thus better to take traditional crop varieties rather than high yield ones, since the latter cannot be used for the following season, -farmers must therefore get new seeds every year. Other ways to sustain the input supply would be the usage of local resources or the launching of associations, which serve their members with seeds and fertiliser.

\begin{tabular}{|l|l|l|l|l|l|l|l|}
\hline & MFS & CA & Dam & $\begin{array}{l}\text { Keyhole } \\
\text { Garden }\end{array}$ & $\begin{array}{l}\text { Compost } \\
\text { Pits }\end{array}$ & $\begin{array}{l}\text { Community } \\
\text { Garden }\end{array}$ & $\begin{array}{l}\text { Stone } \\
\text { contours }\end{array}$ \\
\hline $\begin{array}{l}\text { Relative } \\
\text { advantage }\end{array}$ & +++ & +++ & + & +++ & ++ & ++ & - \\
\hline Combatibility & +++ & -- & +++ & +++ & +++ & +++ & - \\
\hline Complexity & + & +++ & +++ & +++ & ++ & +++ & -- \\
\hline Trialability & + & ++ & - & ++ & + & - & - \\
\hline Observability & ++ & ++ & ++ & +++ & ++ & ++ & - \\
\hline
\end{tabular}

Table 1: Performance in terms of diffusion (+++very good; ---very poor) 
The mountain perspective also contains socio-cultural components (see. Tab. 2). A multidimensionality of activities should be achieved. CA. shows how natural resource activities can be a part of a more general involvement. Basson conducts socio-cultural events, namely the launching of a football league. This later on helps to increase the general acceptance of adopters. Also the tremendous suffering through HIVIAIDS needs to be considered. The RRD calls for a mainstreaming of HIVIAIDS. MFS has evidently proven to enhance peoples abilities in coping with HIVIAIDS. Other techniques like Keyhole gardens also bring not just natural improvements but advantages for people to handle stresses of socio-cultural nature as HIVIAIDS is. Food for work, or the construction of stone contours by SANReMP again attempt to include not just the enriching of Basotho's diet, but on the same time build up assets, which have ameliorating effects on the natural resources. To sum up, nearly all examined projects have considered the importance of integrating socio-cultural actions in the design and scope of a project.

Secondly, JODHA (1992) requests a planning from below. As a comparison of the case studies shows, projects where people could participate more, were better constructed, more frequently accepted or showed in the authors view a greater success. Projects, where decision were brought by outsiders, like in the case of stone contours, were not understood by the participators. Albeit many projects (including SANReMP) are using CAPs, which are based on Participatory Rural Appraisal tools, the implementation on the ground is done in a very top-down manner. This also contributes to the poor understanding.

Analogously, RRD calls for partnership building. MFS successfully showed how it is possible to build up structures, which then increase the feeling of ownership towards the project's idea. Serumula launched a farmer association which equips the people with the responsibility for their projects. Also the MDTP recognized the importance of building such partnerships to achieve the overall goal of protecting Lesotho's fragile mountain habitats.

Furthermore, similar to the mainstreaming of HIVIAIDS a general consideration of gender issues is needed. Usually, projects did not make difference of any kind regarding women or men. This however requests a gender-neutral approach, at least in terms of the applied technology (required workload etc.). MFS was originally developed to suit the needs of woman-headed households. Even today Serumula still predominantly works with women. The other projects, despite comprising heavy manual labour, were equally welcoming men and women.

To sum up, since the implementation of projects is mainly a social process, the socio-cultural dimension is presumably the most important factor determining the success or failure of the 
projects, or determining whether they are spreading or not.

\subsection{The Political Dimension}

Being a comprehensive approach for the whole rural interface, the political dimension of the RRD is more relevant to national policies than to local or regional ones. However, the projects are affected by the overall political and institutional environment. It has been shown, that for example the extension service of the ministries represents an influential actor on village level, - for or against the sake of a project. In some cases agricultural assistants fostered the technologies, in other cases they hampered them. For instance, CA farmers were encouraged by some AA to start with it and at the same time discouraged by others. It needs to be added, that Roger's theory of diffusion is also applicable on the extension service. Thus, agricultural assistants need to be approached separately to get convinced about the merits of the project's idea.

It could also be shown that local authorities, being chief or councillor, have a strong impact on project outcomes. Chiefs and councillors promoting techniques intensively help to encourage people. MFS spread successfully not just because of the presence of innovators but because the chief was supporting the same idea. On the other hand the chief in another area was not paying his loan back, giving a bad example for the community. Chiefs need to be included, since they are the ones who gather the people. In the interest of the project, councillors need to have a vital role in the project as well, not just for promoting the techniques among the villagers, but also because other development activities will in future be channelled through them.

In the case of food or incentives in general it needs to be noticed by whom the targeting is done. As stated a precise targeting of people who are needy is essential to reduce side effects of food aid. However, both institutions, the chiefs and community council, may misuse them in their own interest. Chiefs may behave intransparently, which triggers nepotism, whereas the councillors want to be elected again and therefore use the food for gaining votes.

The pasture land rehabilitation by SANReMP showed how political institutional factors determine the failure. Since the afforestation requires strictly maintained grazing regimes, the plantations collapsed due to the absence of grazing regimes. Therefore, the establishing of a Grazing Association needs to be prioritised.

How successful such grazing association can be shows the case of MDTP. Albeit conducted under the umbrella of the ministry of forestry it proved, that the founding of such associations have 
apparent effects on the conserving of Sehlabathebe National-park. The challenge for the Sehlabathebe area now is to extend it beyond the boundaries of the park.

\subsection{The Ecological Dimension}

According to RRD the biggest challenge is to find appropriate technologies to fight natural resource based problems.

JODHA (1992) asks for an integrated approach. Since problems do not necessarily have one common origin, projects should cover a range of activities, rather than separate actions.

MFS and in particular CA exemplify very well, how the improvement of productivity can also help to stop deterioration of natural resources. In both cases the technique itself consist of such an integrated nature. In other cases where projects need to include different components to tackle the complexity of problems, like the SANReMP programme for instance, this is much more fragile in its outcomes. To sum up: The challenge is to find highly integrated but simple technologies. In the case of this study this was CA and to a lesser extend MFS.

MDTF on the other hand also results in measurable improvement of natural resources, not through adapting the way of managing the resources, but with supplying the communities with alternative forms of income, which then replaces nature exploitive practices of money earning.

The same applies to food for work schemes. By providing them with food, villagers do not have to abuse natural resources to such an extent anymore.

All of the examined projects were using technologies adapted to the fragility of mountains. However, none of them seemed to have a comprehensive effect on the whole of the area. Since erosion is the most urgent problem natural-resource-wise, the origin of the deterioration lies in the upper slopes of the rangeland. The results are then massive consequences in the lower parts. Therefore, the rehabilitation of pasture land is highly desired and has huge benefits for all of Lesotho. However, it could be shown that such activities are difficult to implement with a community based project. RRD explains this phenomenon with the fact, that individual outcomes are small but the social benefit is big. Thus, a big scale governmental involvement should be considered, but being aware of the above mentioned requirements should not clash with the communities or collapse through their pressure. 


\begin{tabular}{|l|l|l|l|l|l|l|l|}
\hline & MFS & CA & $\begin{array}{l}\text { Keyhole } \\
\text { Garden }\end{array}$ & Dam & $\begin{array}{l}\text { Compost } \\
\text { Pits }\end{array}$ & $\begin{array}{l}\text { Community } \\
\text { Garden }\end{array}$ & $\begin{array}{l}\text { Stone } \\
\text { contours }\end{array}$ \\
\hline Niche & + & - & - & n/a. & - & - & n/a. \\
\hline $\begin{array}{l}\text { Planning } \\
\text { from below }\end{array}$ & +++ & ++ & + & ++ & + & ++ & -- \\
\hline Integration & ++ & +++ & - & + & + & + & - \\
\hline $\begin{array}{l}\text { Multidimensi } \\
\text { onality }\end{array}$ & ++ & ++ & - & ++ & - & - & + \\
\hline
\end{tabular}

Table 2: Performance of projects regarding the mountain perspective. (+++very good; ---very poor)

\subsection{Conclusion}

The case studies show that factors determining the success or failure of the project embrace all dimensions of the RRD. Therefore, projects needs to be based on all four elements of RRD in order to ensure sufficient project outcomes.

Secondly, the factors fostering or hampering the spreading of the project's ideas can be explained with the theory of Rogers. Hence, in order to sustain technologies beyond the end of a project, future projects should consider the basics of diffusion in the approach. The researcher also recommends to design channels for essential inputs during the span of a project.

Thirdly, technologies which would be worth for a countrywide scaling-up have to feature multidimensional advantages. They also have to be of an integrated nature. The technology with the most promising outcome was CA, since it applicable for different kinds of beneficiaries, including very poor farmer. As a major advantage it shows the most promising integrated results, since it enables a higher productivity and reduces soil losses at the same time. However, the disadvantages regarding complementary towards Basotho culture, which have been encountered in this study, cannot be ignored and have to be included in the scaling-up process. 


\section{Lessons learnt}

1. While being in Lesotho one gets the impression that the country is flooded with researchers, students and consultants. Scirius.com produces somewhat of 2500 results on Lesotho topics, -only for journals. However, the actual impact on ground is fairy low. Research support towards service providers seems to be inadequate, since poor farming practices, constructing or managing measures are visible throughout Lesotho.

Lesson learnt: Link up the research with the service providers on grassroots-level.

2. Most beneficiaries get attracted in projects by financial benefits, other advantages matter only rarely.

Lesson learnt: Ensure immediate financial improvements to be as much attractive for beneficiaries as possible.

3. Marketing for peasant production is often a problem, since village markets are small and retailers are far. However, the mountains also offer opportunities for better livelihoods.

Lesson learnt: Establish access to markets. Also ensure that niche-opportunities are harnessed according their potentials.

4. Food aid impacts projects throughout Lesotho. However in some cases incentives for initial stages of projects are needed.

Lesson learnt: Food aid should be the last choice. Development must go beyond food aid. 
5. Due to constraints of their living situation farmers are always reluctant on adopting measures, which harm the resources less.

Lesson learnt: If possible, rural dwellers should be enabled to get their income from alternative sources.

6. The characteristics of the technologies influence the rate of adoption.

Lesson learnt: Consider how technologies are perceived by the potential users. For an optimise take-off maximise the degree of Relative Advantage, Compatibility, Trialability and Observability:

7. Opinion leaders have a vital role in promoting the technologies. They often have a higher education and experiences from other areas.

Lesson learnt: Identify opinion leader on village level and support them separately.

8. Youth are regarded as more open minded. Their opinion can be a gateway to the households to arise the acceptance of projects.

Lesson learnt: Work together with youth and schools.

9. The feeling of ownership is very important to ensure the sustainability of projects. Projects where decision are brought by outsiders are understood to a lesser extent. The research and development process together rather than for the beneficiaries only also trigger ownership. Projects where people contribute more also show a higher degree of ownership. 
Lesson learnt: Always apply a bottom-up way of implementing rather than top-down. Input provision should always be based on loans, - whether on base of money or on base of the farmer's own harvest.

10. Despite having poor staff morale and other constraints, extension services can influence the project, - for or against the sake of it.

Lesson learnt: Include extension service in the project design. Alternatively, convince governmental executives about the techniques.

11. Local authorities also act as opinion leaders. They are needed to gather people and they provide the linkage between project personnel and villagers.

Lesson learnt: Always approach chiefs and CCs. Since their role is essential, this needs to have a high priority.

12. The origins for natural deterioration lay in the upper parts of the rangelands. Here action needs to be taken, for instance the launching of Grazing Associations.

Lesson learnt: The rehabilitation of rangeland has a high social benefit. The establishing of Grazing Associations needs to be prioritised. Since rangelands fall under communal land and villagers show few will to start on their own, direct governmental intervention can be considered.

13. Due to the diversity of the mountains, projects should also embrace a diversity on their own. The more integrated the technique is the less prone it is against failure. 
Lesson learnt: Find integrated techniques, which provide users with income and maintain the natural resource at the same time. Particularly, Conservation Agriculture and to a less extend MFS show promising results.

14. Sustainable projects include advantages of all dimension. Successful natural resource based interventions combine not just an technical approach to tackle the symptoms of natural deterioration but also include the economic, socio-cultural and politic-institutional approach.

Lesson learnt: Apply a multidimensional approach on all stages of project implementation.

I can only bring the horse to the water I cannot make it drink

Rev. Basson (2006) 


\section{References}

ABDI, H. (2006): Personal communication, Programme Officer, Food For Work Head of Unit, WFP Lesotho, United Nations Building, Maseru.

AHAL, R. (2006):Personal communication, Adviser Decentralisation in Ministry of Local Government, Mposo House, Kingsway Road, Maseru.

BAsson, A. (2006): Personal communication, Africa Inland Mission in Lesotho, PO Box 252, Matatiele, 4730, RSA.

BERNARD, H., (2000): Social research methods: Qualitative and quantitative approaches, Thousand Oaks, USA: Sage Publication.

Chisholm, A. and Dumsday, R. (1987): Land Degradation: Problems and Policies, Cambridge: Cambridge University Press.

C-SAFE (2005): Case study Key hole gardening technique, C-SAFE Newsletter, (01).

DECURTIN, S. (2006): Personal communication, Programme Coordinator, GTZ Lesotho, P.O. Box 988, Maseru 100.

FAO (unpubl.): Lesotho Conservation Agriculture Map. FAO Representation Lesotho, Maseru, Lesotho.

FAO (2006): The State of Food and Agriculture, FAO Agriculture Series, 37.

FAO (2007): Economic aspects of Conservation Agriculture, http://www.fao.org/ag/ca/5.html accessed 21/03/07.

FAOSTATS (2005): Demography Lesotho, http://faostat.fao.org/ accessed 18.03.07.

FlyVBJERg, B. (2006): "Five Misunderstandings About Case Study Research." Qualitative Inquiry, 12(2), 219-245.

Fischer, A., Petersen, L. and Huppert, W. (2004): Natürliche Ressourcen und „Governance“: 
Anreize nachhaltiger Nutzung, Eschborn: Gesellschaft für Technische Zusammenarbeit.

García-Torres, l., Martínez-Vilela, A., Holgado-Cabrera, A. and GónZalez-Sánchez, E (2002): Conservation agriculture, environmental and economic benefits, http://www.ecaf.org/ accessed 21/03/07.

GraVes, A., MATHEWS, R. and WALDIE, K. (2004): Low external input technologies for livelihood improvement in subsistence agriculture. Advances in Agronomy, 82, 473 - 556.

GIRTLER, R., (2001): Methoden der Feldforschung, Wien; Köln; Weimar; Böhlau: UTB.

GTZ (2005): Programme Offer, GTZ Lesotho, P.O. Box 988, Maseru 100.

HARDIN, T. (1968): The Tragedy of the Commons. Science 162, 1243-1248.

HASSAN, F. and OJO, O. (2002): Lesotho: Development in a Challenging Environment: A Joint, African Development Bank Evaluation, Washington, D. C.: The World Bank.

HELVETAS (2004): Nachhaltige Bewirtschaftung der natürlichen Ressourcen in Lesotho, www.helvetas.ch/global/pdf/projects/africa/04_10_Lesotho_Innovative_Verfahren_d.pdf accessed 15/03/07.

HELVETAS Lesotho (2003): The NRM Program in Lesotho, Intermediary report, Maseru: Swiss Association for International Cooperation Lesotho Programme Office.

HARVEY, P. and LIND J.(2005): Dependency and humanitarian relief: a critical analysis, London: Overseas Development Institute.

HORTA, K. (1995): The Mountain Kingdom's White Oil. The Lesotho Highlands Water Project, The Ecologist, 25(6): 227-231.

IFAD (undated): IFAD in Lesotho, http://www.ifad.org/english/operations/pf/lso/index.htm accessed 27/03/07.

IVY, D. and TURNER, S. (1996): Range management areas and grazing associations - experience at Sehlabathebe, Lesotho, in, Critchley, W. \& Turner, S. (eds.): Successful natural resource management in southern Africa, : Windhoek: Gansberg Macmillan, 117-146. 
IIRR \& ACT (2005): Conservation Agriculture: A manual for farmers and extension workers in Africa, Nairobi; Harare: African Conservation Tillage Network.

JODHA, N. (1992): Mountain perspective and sustainability: A framework for development strategies, in Jodha, N., Banskota, M. and Partap, T. (eds): Sustainable mountain agriculture, New Delhi: Oxford \& IBH. 41-82.

JoDHA, N. (1997): Mountain agriculture, in Messerli, B. and Ives, J. (eds.): Mountains of the world. A global priority. New York, London, 313-335.

KATONGE, J., (2001): Application of chaos theory to solving the problems of social and environmental decline in Lesotho. Journal of Environmental Management, 65, 63-78.

KINGDOM OF LeSOTHO (2000): Report of Land Policy Commission, Maseru: Kingdom of Lesotho.

KINGDOM OF LESOTHO (2005): Poverty Reduction Strategy, Maseru: Kingdom of Lesotho.

KREFT, S. (2006): Where to find support? Qacha's Nek District, Maseru: GTZ Lesotho.

LEKHOlOANE, B. (2006): Personal communication, Serumula Managing Director, Serumula House 88 Qoqolosing Road, Maseru, Lesotho, Tel.: 22317875.

LeVy, R. and Hollan, D. (1998): Person centered interviewing and observation, in, Bernard, H. (eds.): Handbook of methods in cultural anthropology, Walnut Creek, California.: AltaMira 333364.

MAKENETE, A., Ortmann, G. \& Darroch, M. (1998): Food-aid dependency in Lesotho: issues and policy implications, Development Southern Africa, 15(2).

Marake, M., Basson, Camarada, A., Abdi, H, Zergaber, T and Phororo, D. (2005): Case Study - CA In Lesotho, Beyond the III World: Congress on Conservation Agriculture, Nairobi, Kenya.

MATLALeng, S. (2006): Personal communication, Serumula Coordinator for Phamong Area, Phamong.

MATABO, T., KHOELI, M. and MPEMI, R. (2006): The Impact of HIV and AIDS on Agriculture and Food Security in Lesotho, Maseru: FANRPAN, (No: Nat LES006). 
MinistRy FOR Agriculture, FoOd AND RURAL AfFAiRs (2000): Universal Soil Loss Equation (USLE), http://www.omafra.gov.on.ca/english/engineer/facts/00-001.htm\#tab4a accessed 19/03/07.

MOKITIMI, N. (1998): Impact of Land Administration Institutions in Lesotho, Review of Southern African Studies, 2, 01-20.

MokITIMI, N (2006): Analysis of Security of Tenure under the Customary Land Tenure System of Lesotho, Research Report No.36, Roma, Lesotho: Institute of Southern African Studies.

Мококо, M (2006): Personal communication, Community Council: Nyakoane.

MosivoA, B. (2006): Personal communication, Serumula Business Development Facilitator, Serumula House 88 Qoqolosing Road, Maseru, Lesotho, Tel.: 22317875.

NATIONAL ENVIRONMENT SECRETARY. (1999): State of the environment in Lesotho Maseru: National Environment Secretary.

Nill, D., Schwertmann, U., Sabel-Koschella, U., Berhard, M. and Breuer, J. (1996): Soil erosion by water in africa, Rosdorf: Gesellschaft für technische Zusammenarbeit.

ODHIAMBO, E. (2001): The role of rural youth in promoting conservation agriculture in Kenya, Nairobi: Kenya Youth Foundation.

PANTANALI, R. (1996): Lesotho: a note on the Machobane System. TCI Occasional Paper Series, 7.

PRETTY, J. (2004): Can sustainable agriculture feed Africa? New evidence on progress, processes and impacts. Environment, Development and Sustainability, 1: 253-274.

RAMONIT'SI, B. (2006): Personal Communication. Mamohase Guest House, POBox 57,Khukhune 452, Butha Buthe.

RAlitsoele, S. (2006): Personal communication. Machobane Agricultural Development Foundation, P./Bag A139, Maseru 100, Tel.: 22321315. 
RAUCH, T., BARTELS, M. and ENGEL, M. (2001): Regional Rural Development: A regional response to rural poverty, Schriftenreihe der GTZ, 274.

Rogers, E. (1995): Diffusion of Innovations, New York: Free Press.

SANREMP (2004): Post appraisal report, Maseru: Sustainable Agriculture and Natural Resource Management Programme (1595-LS).

SANREMP (2006): Annual Report 2005/06, Maseru: Sustainable Agriculture and Natural Resource Management Programme.

SERUMULA (2006a): About Serumula, http://www.serumula.org.ls/. Accessed 07/03/2007.

SERUMULA (2006b): Beneficaries, http://www.serumula.org.Is/beneficiaries.php. Accessed 07/03/2007.

SILICI, L and PEDERSEN, S. (2006): Presentation on Baseline-study comparing conservation and conventional practices, Conservation Agriculture Meeting 15.09.2006, FAO Representation Lesotho, Lesotho, Maseru.

SIMANDA, H. (2003): The Conflict Dimension of Environmental Degradation and the Case of Lesotho, African Journal on Conflict Resolution, 3(1), 29-52.

TURNER, S. D. (2001): Livelihoods in Lesotho, Maseru: CARE Lesotho.

United NATIONS (2006): Human Development Report 2006. NY: United Nations.

VAILLANT, J. (2003): Some Lessons Learned from Rural Development Projects in Lesotho, Maseru: GTZ Lesotho.

VAILLANT, J. (2004): Ex post Bewertung von Entwicklungsmaßnahmen im ländlichen Raum Lesothos, Thesis (Msc), Humboldt-Universität Berlin.

WORLD BANK (2001): Project Appraisal Document, Maseru: Environment and Social Development Unit Africa Region.

WORLD BANK (2005): Country Brief, http://go.World Bank.org/3D2PCW5DC0 accessed 20/03/07. 
WORLD BANK (2006): Lesotho at a glance, http://devdata.World Bank.org/AAG/lso_aag.pdf accessed 20/03/07.

WorLd FoOd PROGRAMme (2007): Where we work - Lesotho, http://www.wfp.org/country_brief/indexcountry.asp?country=426 accessed 24/03/07.

WUest, S.; McCool, D.; MiLler, B. and Veseth, R. (1999): Development of more effective conservation farming systems through participatory on-farm research, American Journal of Alternative Agriculture,14(3), 98-102.

ZICHE, J. (1992): Some Critical Aspects in Gathering Socio-economic Data in Rural Areas of NonWestern Societies, in, Reichert, C. Scheuch, E. and Seibel, H. (eds): Empirische Sozialforschung über Entwicklungsländer: Methodenprobleme und Praxisbezug, Saarbrücken; Fort Lauderdale: Breitenbach Publishers Verlag, 306-316. 


\section{Appendix}

\section{Questions-guide:}

Since when have you been involved with the project?

From whom have you heard about the technique?

Why have you started?

What are the advantages of the technique?

Which problems should be improved?

How has your situation changed since the implementation?

Have you got any training, if so where?

Which problems would you face, if the project stops?

What is your perception on the local authorities?

Where should one focus on to develop the community? 


\section{Analyses of interviews:}

In Sesotho the ' in front of a name refers to a woman, the absence to a man respectively

Serumula: user

\begin{tabular}{|c|c|}
\hline Motivation to start: & $\begin{array}{l}\text { - saw other people how successful they were. } \\
\text { - wanted to improve the quality of the soil } \\
\text { - persuaded by the fact, that it improves the soil } \\
\text { Teboho Makhoabenyane (34) } \\
\text { - have to pay just half of the seed-prices } \\
\text { - better taste and it has more minerals and vitamins } \\
\text { - bad financial situation and no means } \\
\text { - supply with seeds every year, that has to be paid back at the end of } \\
\text { the harvesting season } \\
\text { approached in her garden to physically show what to do } \\
\text { 'Manyakane Lephutsa (41) }\end{array}$ \\
\hline Advantages of the technique & $\begin{array}{l}\text { - continuous harvest throughout the year } \\
\text { - stop the soil erosion and keep the moisture } \\
\text { - have enough to eat } \\
\text { - continuous harvesting of the crops and vegetables, plots doesn't } \\
\text { need to be big to gain a good harvest } \\
\text { - because people plant the same crop, I am able to sell my produce } \\
\text { as alternatives } \\
\text { - use of manure not fertilizer is cheaper. } \\
\text { - reduced impact of pests } \\
\text { - don't have to buy any vegetables } \\
\text { - now able to sell surpluses to the community (34) } \\
\text { - even times of hunger (spring, when last years harvest is depleted) }\end{array}$ \\
\hline
\end{tabular}




\begin{tabular}{|c|c|}
\hline & \begin{tabular}{|l} 
there is still something in my garden. \\
'Maseeng Poulo (23) \\
- have been able to take some of his produce (potatoes) to the \\
'Market and sell it \\
pest affecting one crop does not result in loss of whole harvest \\
Mohlolo Putsoane (29) \\
continuous harvesting \\
the work load is not big. \\
We are also able to take some of the produce to the market and we \\
have some money. We sell to GENDRAL SUPERMARKET, \\
through the help of Serumula. \\
Life is easier; I don't have to go around looking for food. All I have \\
to do is to take care of my garden. \\
'Manyakane Lephutsa (41)
\end{tabular} \\
\hline Encountered problems & $\begin{array}{l}\text { - trainers do not come as often as in the beginning of the project } \\
\text { 'Mamolibeli Mashaile (55) } \\
\text { system mainly focuses on grains and I focus on vegetables. And } \\
\text { because of this might not follow the technique strictly } \\
\text { Teboho Makhoabenyane (34) } \\
\text { - use of not decomposed manure resulted in small harvest } \\
\text { - we have problems with small black beetles, it is difficult to store } \\
\text { the maize } \\
\text { 'Matumelo Nthahane (45) } \\
\text { - just lazy to implement the knowledge that is given to us } \\
\text { they don't give us food for the work or money } \\
\text { the demand for produce is generally not good. There are times when } \\
\text { we do sell but most of the time people don't buy the vegetables. } \\
\text { 'Maseeng Poulo (23) } \\
\text { don't have cattle so we ask for it from the community } \\
\text { Mohlolo Putsoane (29) } \\
\text { shortage of water causes our plants not to be as successful as they } \\
\text { could have been } \\
\text { some people don't have manure. That is why they have stopped } \\
\text { using this farming system. }\end{array}$ \\
\hline
\end{tabular}




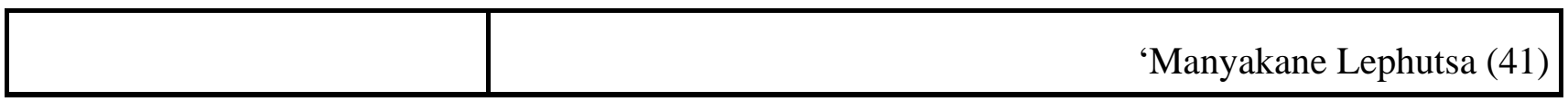

Serumula: non-user

\begin{tabular}{|c|c|}
\hline Advantages of MFS & $\begin{array}{l}\text { you don't have to buy fertilizer } \\
\text { Tlali Thakabanna (50) } \\
\text { they are quite happy with planting potatoes and vegetables } \\
\text { 'Mathant'si Makakole (66) }\end{array}$ \\
\hline Disadvantages & $\begin{array}{l}\text { don't have the energy to do the hard work that is involved } \\
\qquad \begin{array}{l}\text { 'Mathant'si Makakole (66) } \\
\text { 'Maphuthing Khaile (59) }\end{array} \\
\text { stopped because it was a lot of work } \\
\text { 'Mamot'selisi Rasoja (45) }\end{array}$ \\
\hline $\begin{array}{l}\text { Reasons not starting } \\
\text { it/abandoning it }\end{array}$ & $\begin{array}{l}\text { We are planning to join the group this year } \\
\text { think it is too hard work } \\
\text { 'Mathant'si Makakole (66) } \\
\text { don't know enough about it. } \\
\text { I don't know what my fields should give me, I cannot afford to } \\
\text { plough them } \\
\text { work was to laborious } \\
\text { somebody stole my cows } \\
\text { harvest was not good. } \\
\text { Mamot'selisi Rasoja (45) }\end{array}$ \\
\hline
\end{tabular}

Why have you started Conservation Agriculture
- Rev. Basson spoke about Conservation Agriculture. I saw the importance: the ploughing resulted in development of dongas 


\begin{tabular}{|c|c|}
\hline & 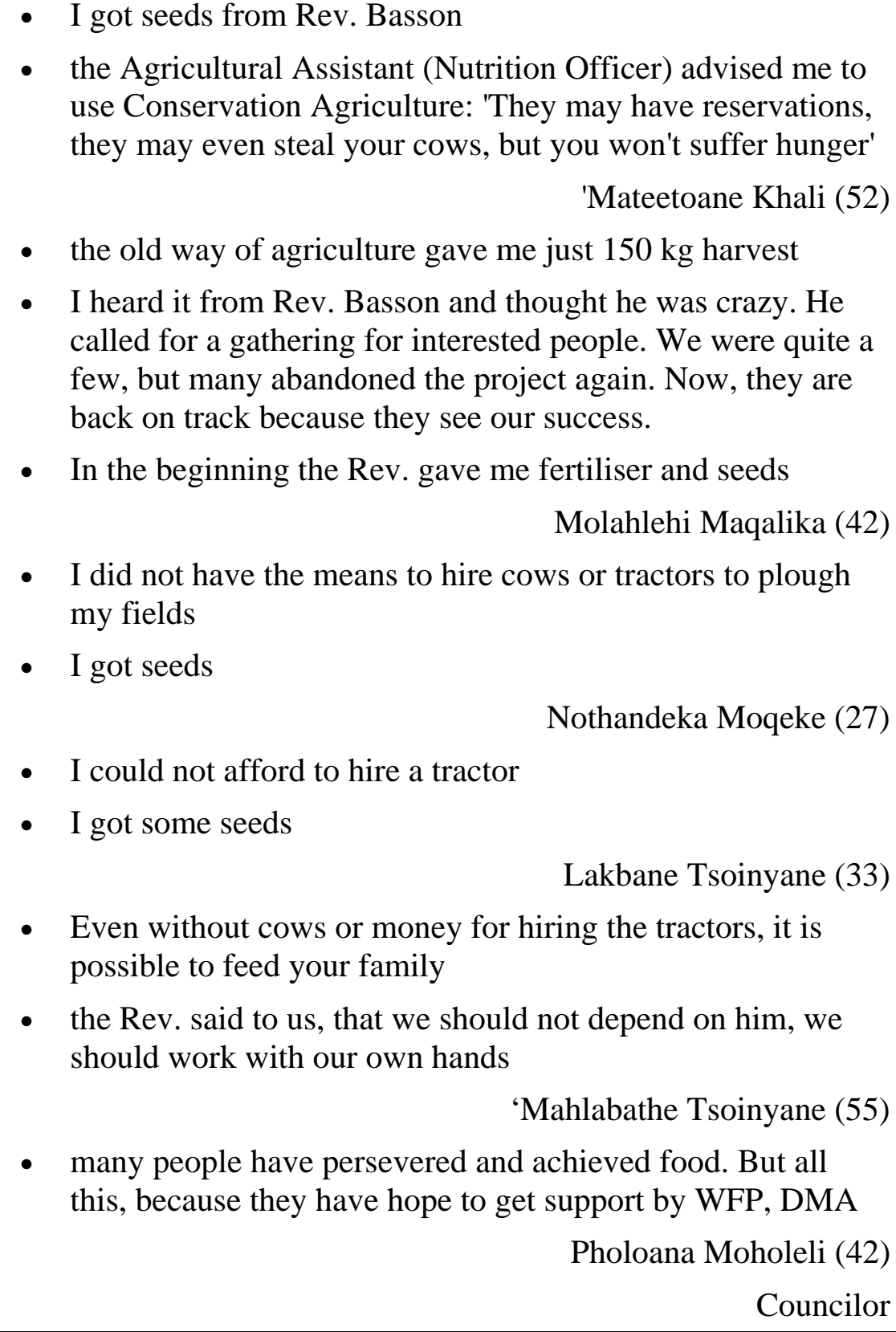 \\
\hline $\begin{array}{l}\text { Advantages of Conservation } \\
\text { Agriculture }\end{array}$ & 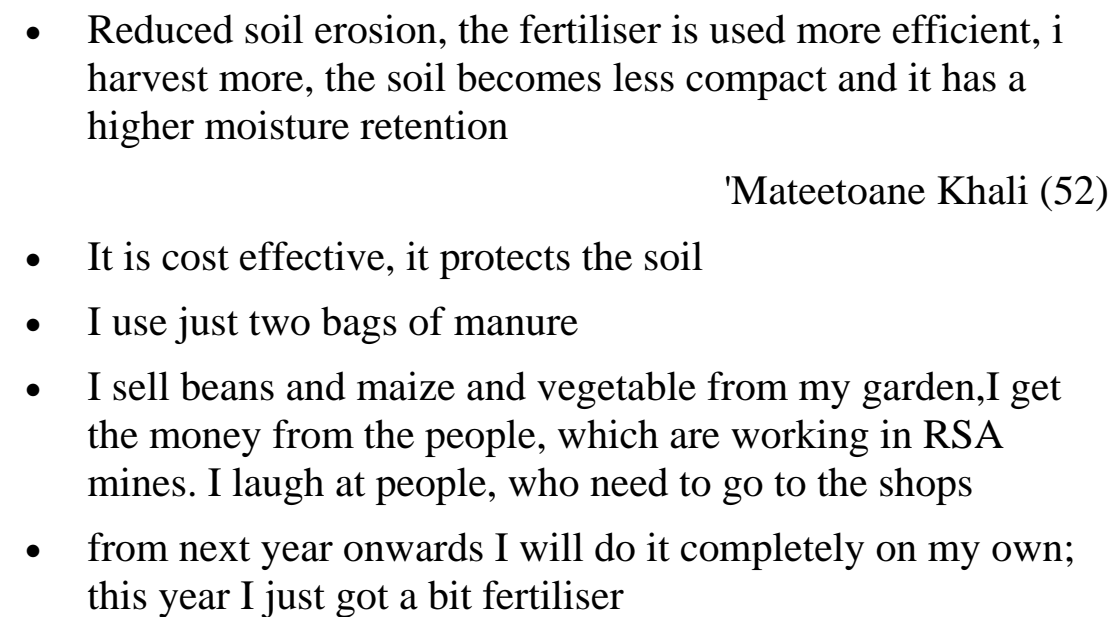 \\
\hline
\end{tabular}




\begin{tabular}{|c|c|}
\hline & $\begin{array}{l}\text { Molahlehi Maqalika (42) } \\
\text { - we are able to eat and support our families. Even though it is } \\
\text { in the early stages we see that we are able to feed our } \\
\text { families. } \\
\text { - It is proven, that you have less soil erosion. Beforehand, I } \\
\text { used my produce just for own consumption. Now, I can sell } \\
\text { some of the harvest } \\
\text { - } \quad \text { it protects the soil; the wheat from my ploughing neighbours } \\
\text { were growing everywhere in the donga } \\
\text { when it rains, it becomes very successful } \\
\text { 'Mamatabane Matabane (78) }\end{array}$ \\
\hline $\begin{array}{l}\text { Encountered problems } \\
\text { (erosion management) }\end{array}$ & $\begin{array}{l}\text { - } \quad \text { there is a big problem with cow thieves } \\
\text { - } \text { if you do not have cows, people let you pay for the cow dung } \\
\text { (5 M/50kg). This might be a problem for some people } \\
\text { - the AA and me are like oil and water. He wants to use } \\
\text { ploughing. At vegetables fairs, he uses to stand close to me, } \\
\text { because my harvest is the best and better than his } \\
\text { - a lot of people are discouraged to start with CA. You need to } \\
\text { know the importance of your work and the success to resist } \\
\text { such. } \\
\text { - I caught some herders grazing in my fields during the night. } \\
\text { They did it last year and the year before. I am on alert. They } \\
\text { do it on purpose! They should send the cattle to the } \\
\text { mountains, where the grass is green. They should buy some } \\
\text { fodder in the winter. } \\
\text { - They (Community Councils) should stop with food aid. It is } \\
\text { like cutting our hands, because we just wait for the aid and } \\
\text { don not do anything. How long will food aid last? } \\
\text { The cattle grazing is a big problem. We talk to the owners, } \\
\text { but they do not listen to us. }\end{array}$ \\
\hline
\end{tabular}


- some people come in the night to graze my fields. I can just observe the damage the next day. I suspect some people from my very own village, who do not like CA.

Lakbane Tsoinyane (33)

- the AA told me to abandon CA. I did not listen to him, because I could not afford the plough

- last year some cattle grazed on my fields during the night. It was a disaster. I could not identify the culprit

'Mahlabathe Tsoinyane

- it is difficult; in order to gain a good harvest it requires a lot of weeding

- it requires, that people come together to work on our fields

- regarding grazing in other people's fields. It depends on the action, that we want to take. We want them to forgive each other, rather than push charges

- $\quad$ poverty hinders the spread of CA. But with the help of WFP we might overcome it.

Pholoana Moholeli (42)

Councilor

- there was just little rain

- it requires a lot of work. We are lazy. The soil is very hard, I cannot do the work; I am old.

'Masera Phatela (84)

Non-user

- using ploughing I yielded about 17 bags of $8 \mathrm{~kg}$ each. From CA I only got three bags

- it requires a lot of work. It is very hard for people, who are not in good health. The weeding is very difficult without ploughing.

- Without the cooperation of the Rev. it would be impossible to do it on one's own. He does this, because he is white and gets the help from donors

- we do not need the food aid. How long will they stay?

Phato Phatela (67)

Chief, Non-user

- CA has brought hunger into the community. Those people practising it, are hired and paid with food aid. How should you do the job without any help?

- I will never practise it as long as I live 


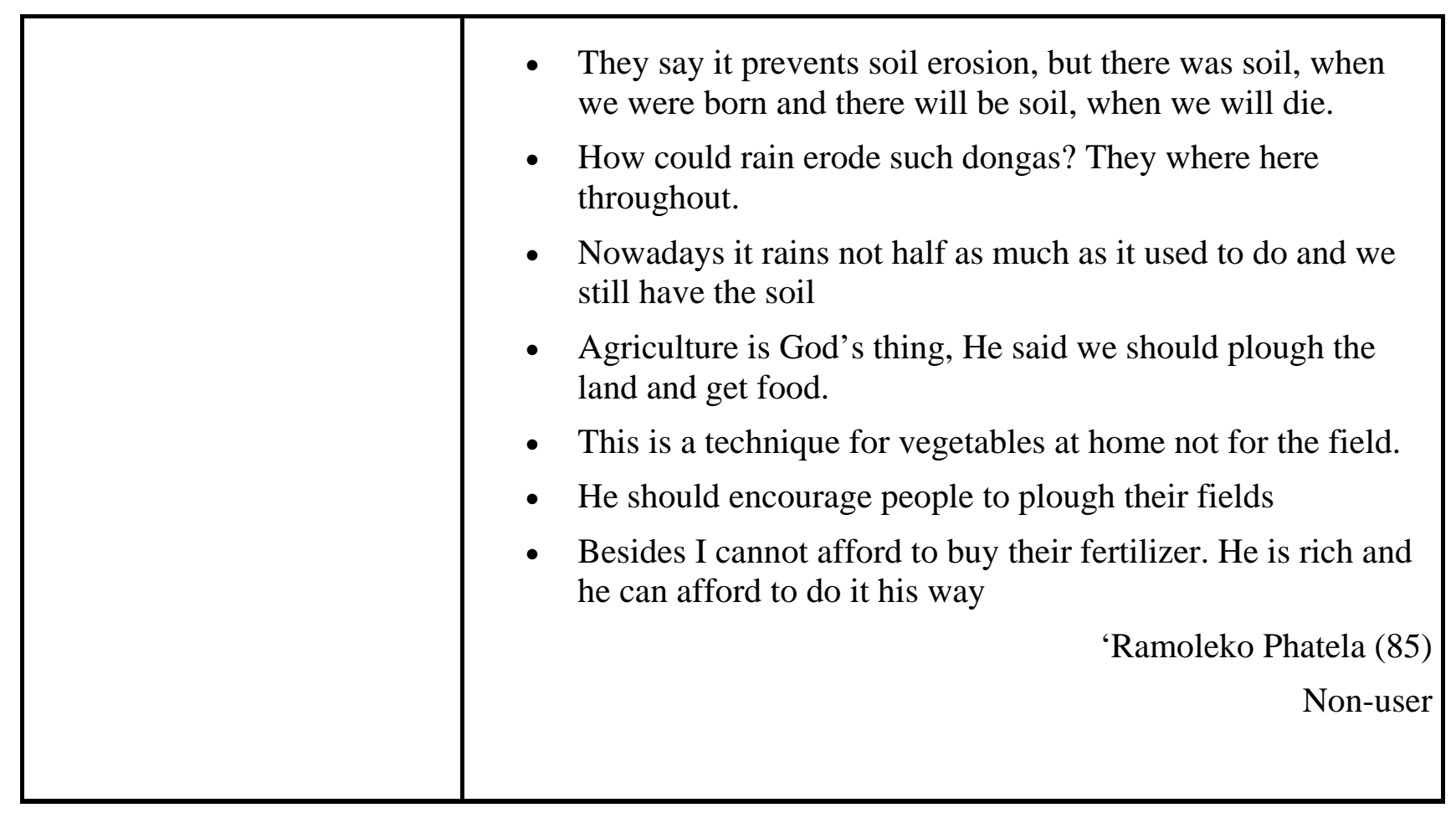

SANReMP

Why are you building the stone contours:

Why are you building the communal gardens?
- The Ministry of Agriculture and Forestry just came to the community; I think that it was already in their plan to come to this village

Sekautu Sekautu (31)

- the chief with the councilor and the supervisor called a public gathering

'Mpotlakop Libocha (66)

- in the beginning we were paid with cash (M733.80) and later we were paid with maize meal

Motlatsi Mabatla (30)

Khampepe Sekautu (55)

- from the very first, we came together as a community and talked about it and made plans so that we can get this garden, and then we went to the chief and she is the one who helped us

- we did not get paid for the work but we did pay for the water tank up there. It cost M2500.00, but the people who gave us assistance said they would pay M2000.00, and we would then be expected to come up with M500.00 for the rest of the payment of the water tank. So as a community we out 


\begin{tabular}{|c|c|}
\hline & $\begin{array}{l}\text { ourselves together and came up with the M500.00. } \\
\text { Ret'selisitsoe Motemana (32) } \\
\text { Thabiso Ralipoli (52) } \\
\text { - SANREMP was the organization that helped with a portion } \\
\text { of the money and they also paid for the fence. } \\
\text { Ret'selisitsoe Motemana (32) }\end{array}$ \\
\hline $\begin{array}{l}\text { Advantages of the technique } \\
\text { (communal garden) }\end{array}$ & $\begin{array}{l}\text { - Grass will grow and we will use it for roofing and it will } \\
\text { stop soil erosion } \\
\text { - } \text { great role in protecting other people's fields from the erosion } \\
\text { - We will use the trees for sale and get some money and use } \\
\text { the trees for funerals } \\
\text { - Khampepe Sekautu (55) } \\
\text { we are able to eat and support our families. Even though it is } \\
\text { in the early stages we see that we are able to feed our } \\
\text { families. Even to sell some of the produce, I sad earlier it is } \\
\text { in the early stages but we are able to sell something. This } \\
\text { was the main reason for starting the garden, but only a few } \\
\text { people know about it. We want to be able to buy seeds for } \\
\text { ourselves in the future }\end{array}$ \\
\hline $\begin{array}{l}\text { Encountered problems } \\
\text { (erosion management) }\end{array}$ & $\begin{array}{l}\text { - My fields are not next to the reclaimed donga } \\
\text { - Maybe when the community has finished the work on the } \\
\text { other dongas they will go to the side of my fields and start } \\
\text { work there } \\
\text { - I have a field but I don't see what it can give me. } \\
\text { - Khampepe Sekautu (55) } \\
\text { - } \text { this is supposed to be done by the community voluntarily } \\
\text { developments are for themselves } \\
\text { - I think that the training they get is not enough for them to } \\
\text { learn the importance, so that they can continue by } \\
\text { themselves. It is just enough for them to do the job }\end{array}$ \\
\hline
\end{tabular}




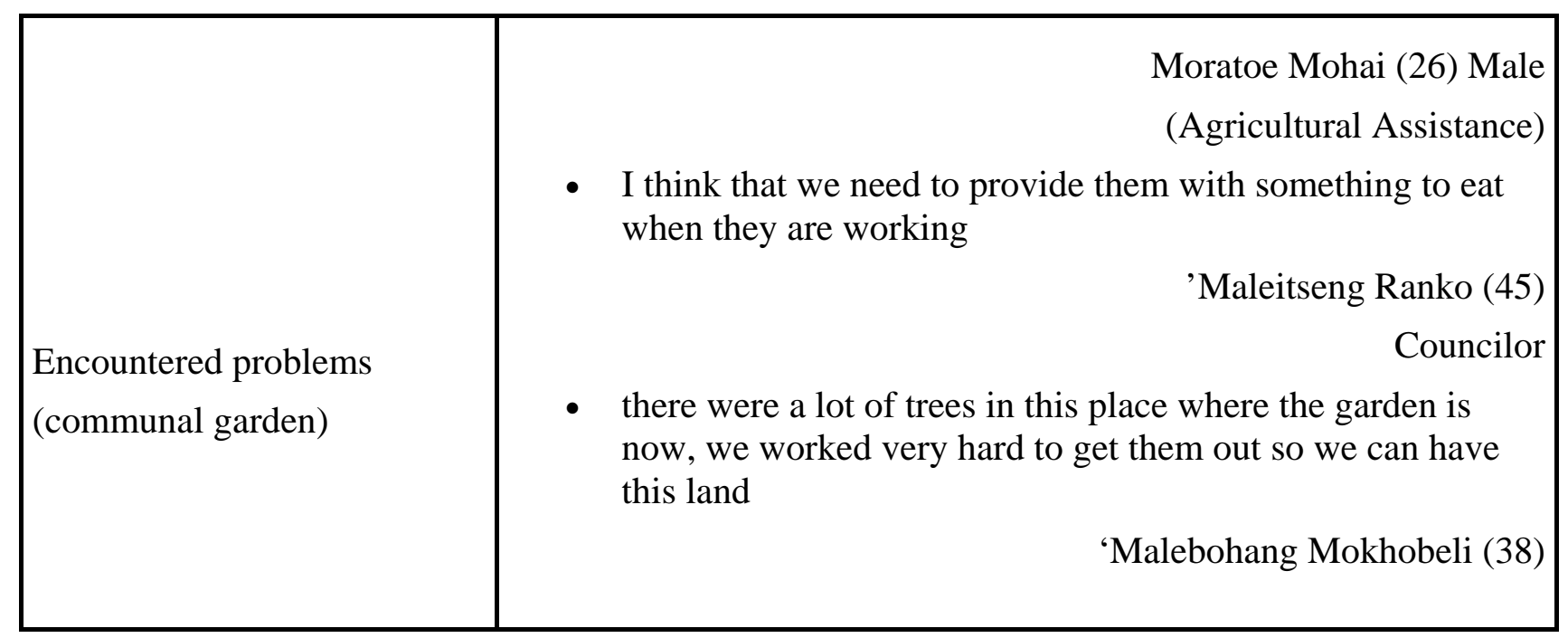

MDTP

How are you involved in the park?

Why did you become involved?

What kind of expectation do you have?
- I am very happy that we have the park. Our children will have job opportunities, our horses are going to be hired and the money for renting the huts will go directly to us. Furthermore, we are involved in construction work in the park.

- Now we are able to sell some handicrafts like grass hats or clay pots.

'Maliopelo Mothibeli (57)

- I ensure that the rangelands are protected and I bring criminals to justice. For instance, cows on rangelands will be charged with R4, the payment includes the capture costs. The payment differs for different animals. There is also a higher rate if one is coming from another village.

'Makabeli Tlali (52)

- I show them how to produce handicrafts

'Ntsoaki Agnes Lekoa (26)

Agricultural Assistant

- we saw this at Ha-Pikoane

'Makaelang Makato (22)

- I do not know anything; just the father and children knows something about the park.

Nowhite Mthwa (55)

- I love to form clay pots, I cannot deal with grass, because I get a rash 


\begin{tabular}{|c|c|}
\hline & $\begin{array}{l}\text { - I got a lot of orders for my clay pots } \\
\text { 'Mahabofanoe Chabeli (58) } \\
\text { - we saw that it was very successful } \\
\text { 'MalikelekoMolehe (58) }\end{array}$ \\
\hline $\begin{array}{l}\text { How could one improve the } \\
\text { park? }\end{array}$ & $\begin{array}{l}\text { - they should increase its size. They should move the } \\
\text { boundaries closer to the mountains, because the caves there } \\
\text { provide a great habitat for birds. } \\
\text { - The benefit would be more tourists. I want them to find } \\
\text { something unique for Lesotho only. } \\
\text { Lahtekile Ngqantsana (41) }\end{array}$ \\
\hline Encountered problems & $\begin{array}{l}\text { - There are no clear boundaries of the park, so when a cattle } \\
\text { graze there they get captured and it cost money to get them } \\
\text { released. } \\
\text { - Tahtekile Ngqantsana (41) } \\
\text { The prime minister promised us, that everybody with } \\
\text { park. We then went to the councilor but she neglected } \\
\text { everything. So she is lying. She wants to give the jobs just } \\
\text { her people. } \\
\text { - The park has no clear boundaries or fences, when our } \\
\text { animals graze in the Park they are taken and we have to pay } \\
\text { in order to get them back from the Park Manager } \\
\text { There are now job opportunities for example fixing the roads } \\
\text { or setting fire boundaries. The problem is that only } 1 \text { person } \\
\text { from each village is selected for the job, afterwards they } \\
\text { cannot be selected again, in case of new job opportunities. } \\
\text { Many people in the villages need jobs and that is just not } \\
\text { right. We need money. } \\
\text { - } \\
\text { my work is often foiled by the fact of food aid. Food aid } \\
\text { spoils the people. They do not wake up each day. They can } \\
\text { even say, } \\
\text { that they will get the next food aid by march } \\
\text { more money and more incentives. Other than this, we work } \\
\text { hand in hand }\end{array}$ \\
\hline
\end{tabular}




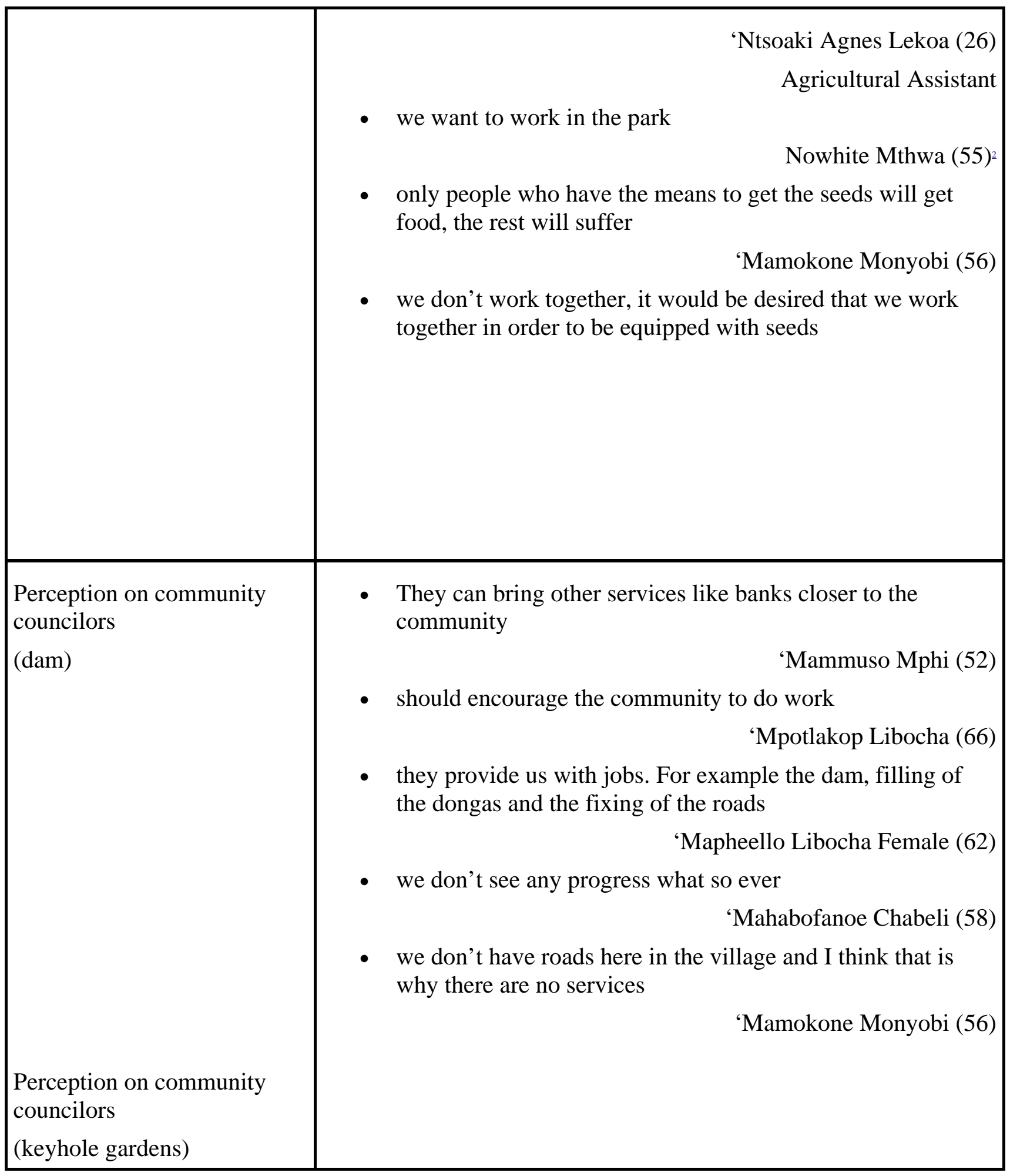

1BBelongs to a Xhosa-speaking minority within in the village. I contacted her, because her husband was denounced of letting their cattle graze in the park by Lahtekile Ngqantsana

\section{WFP and C-SAFE}

Why are you building the

- the councilor, 'Mahlompho Manyatsa, came up with the idea 







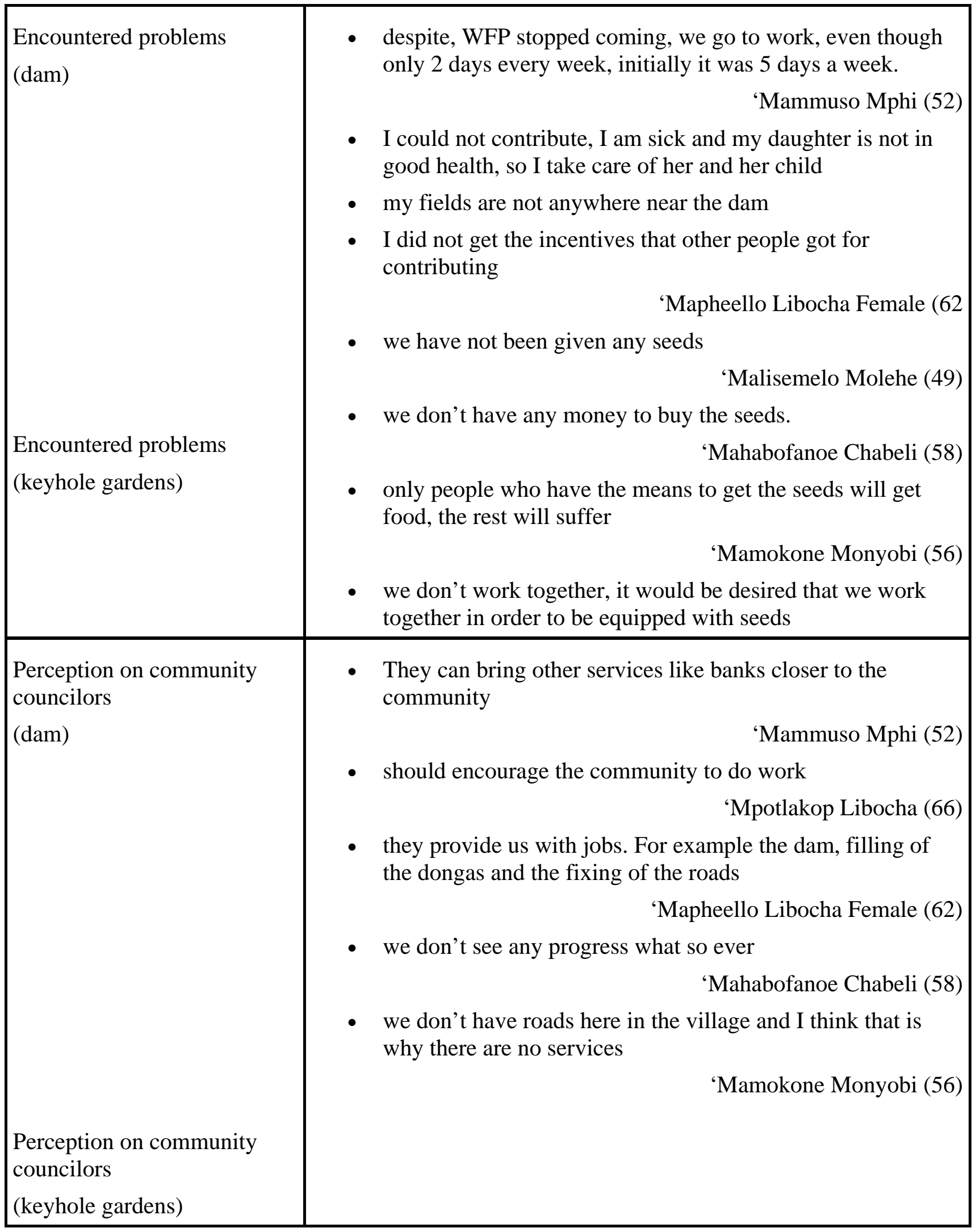


Eidesstaatliche Erklärung

Hiermit versichere ich, die vorliegende Arbeit selbstständig verfasst zu haben und keine anderen als die angegebenen Quellen und Hilfsmittel benutzt zu haben.

Datum:

Unterschrift: 